\title{
Inflación crónica: patrones macroeconómicos y procesos de desinflación
}

\author{
Fernando Morra (UNLP)
}

Tesis

Doctorado en Economía

Facultad de Ciencias Económicas de la Universidad Nacional de La Plata

Director: Daniel Heymann

La Plata, Buenos Aires, Argentina

Marzo de 2021 


\section{Contenido}

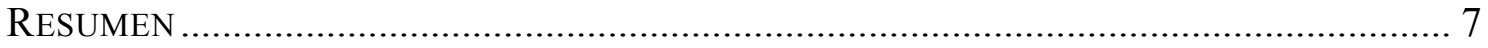

CAPÍTUlo I: INFLACIÓN CRÓNICA Y PATRONES MACROECONÓMICOS........................... 9

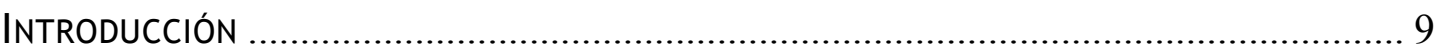

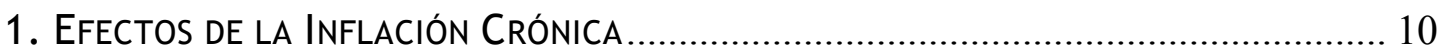

2. IDENTIFICACIÓN Y CARACTERIZACIÓN DE REGÍMENES DE INFLACIÓN CRÓNICA.............. 15

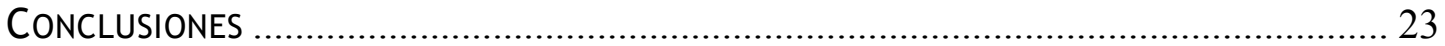

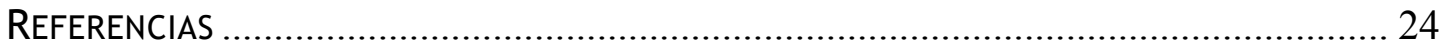

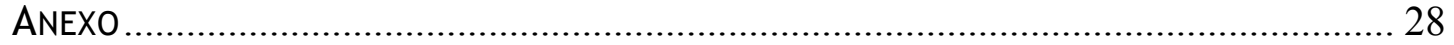

Capítulo II: Inflación CróniCA y Procesos de Desinflación en AmÉRICA

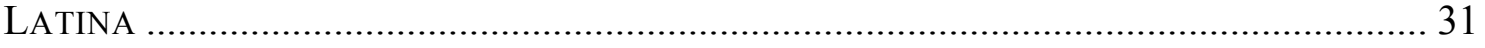

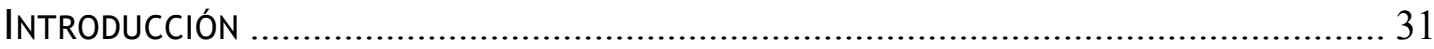

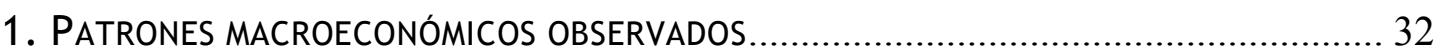

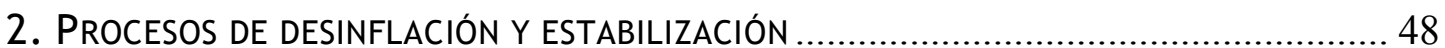

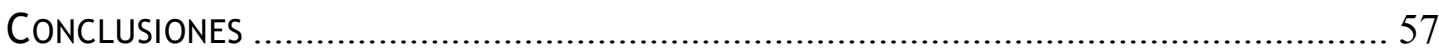

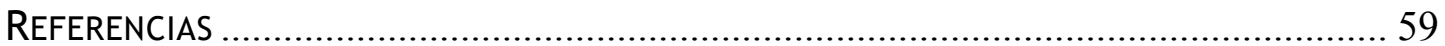

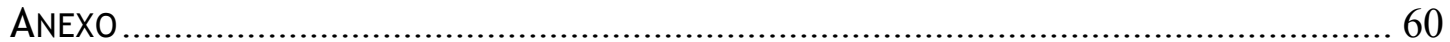

CAPÍtulo III: Ritmos E instrumentos en Desinflaciones GradualeS ............... 63

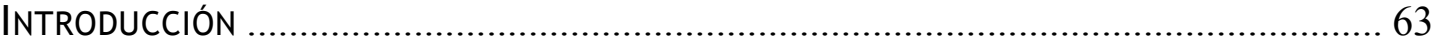

1. DiSEÑO E INSTRUMENTOS DE POLÍTICA MONETARIA ...................................................6 65

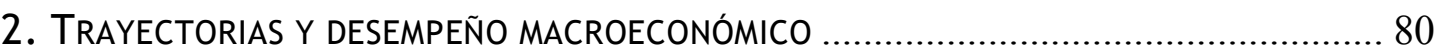

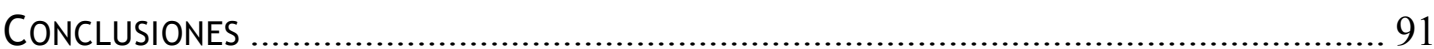

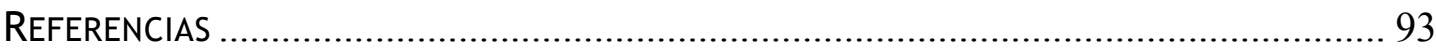

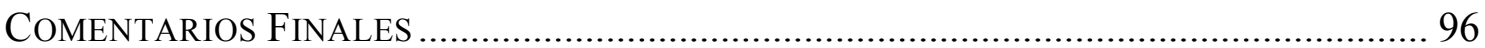




\section{Tabla de gráficos}

Gráfico 1. Cantidad de países según regímenes de inflación (como \% total muestra) 18 Gráfico 2. Años totales en regímenes de inflación persistente. Promedio por región.

20

Gráfico 3. Años totales por país según regímenes.

Gráfico 4. Frecuencia de transición a regímenes de inflación crónica desde baja inflación

Gráfico 5. Frecuencia de transición entre regímenes por régimen de origen ............... 23

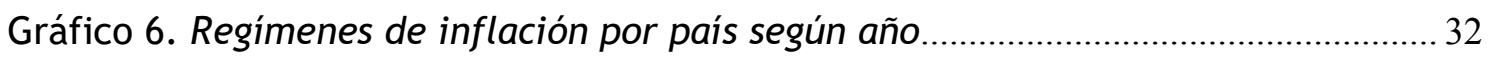

Gráfico 7. Inflación interanual mensualizada y tendencia. .............................................. 35

Gráfico 8. Estimación del coeficiente de persistencia en ventanas móviles (5 años) y

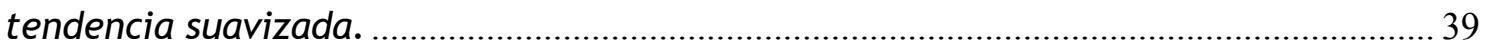

Gráfico 9. Relación entre inflación y señoreaje según régimen. ................................... 42

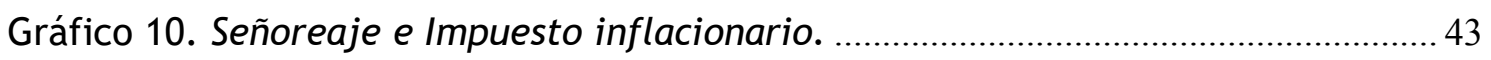

Gráfico 11. Correlación entre tasa de devaluación e inflación (ventanas móviles 15 años).

Gráfico 12. Coeficiente de correlación entre inflación y devaluación por régimen... 48 Gráfico 13. Déficit al inicio de la desinflación (como \% PIB). Desde inflación alta.... 51 Gráfico 14. Déficit al inicio de la desinflación (como \% PIB). Desde inflación moderada-Alta.

Gráfico 15. Déficit al inicio de la desinflación (como \% PIB). Desde inflación moderada.

Gráfico 16. Tipo de Cambio Real Bilateral USD (diferencia porcentual respecto al nivel inicial). Desde inflación alta.

Gráfico 17. Tipo de Cambio Real Bilateral USD (diferencia porcentual respecto al nivel inicial). Desde inflación moderada-alta.

Gráfico 18. Tipo de Cambio Real Bilateral USD (diferencia porcentual respecto al nivel inicial). Desde inflación moderada.

Gráfico 19. Duración de la desinflación. Desde inflación alta............................................ 56

Gráfico 20. Duración de la desinflación. Desde inflación moderada-alta. ..................... 56

Gráfico 21. Duración de la desinflación. Desde inflación moderada. ............................... 57

Gráfico 22. Chile. Tasa de inflación interanual y metas. .................................................. 68

Gráfico 23. Colombia. Tasa de inflación interanual y metas. ..........................................69

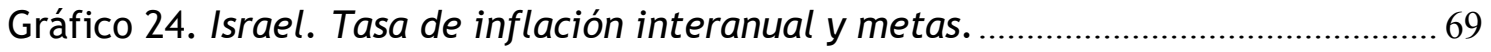

Gráfico 25. Perú. Tasa de inflación interanual y metas..................................................... 70

Gráfico 26. Polonia. Tasa de inflación interanual y metas. ............................................. 70 
Gráfico 27. Chile. Tipo de cambio nominal (Moneda Local por USD) durante la desinflación

Gráfico 28. Colombia. Tipo de cambio nominal (Moneda Local por USD) durante la desinflación.

Gráfico 29. Israel. Tipo de cambio nominal (Canasta por USD) durante la desinflación.

Gráfico 30. Perú. Tipo de cambio nominal (Moneda Local por USD) durante la desinflación.

Gráfico 31. Polonia. Tipo de cambio nominal (Moneda Local por USD) durante la desinflación.

Gráfico 32. Chile. Depósitos del sistema financiero denominados en Unidad de

Fomento.

Gráfico 33. Perú. Dolarización de la liquidez.

Gráfico 34. Resultado Financiero durante la desinflación.

Gráfico 35. Tipo de Cambio Real durante la desinflación.

Gráfico 36. Reservas internacionales del Banco Central. En millones de USD 84

Gráfico 37. Tasa de interés real y en USD (ex-post). .86

Gráfico 38. Tipo de cambio real y balance de cuenta corriente. 88

Gráfico 39. Tasa de crecimiento del PIB (a precios constantes) .89

Gráfico 40. Índice de Salario Real $(2007=100)$ 90 


\section{Tablas}

Tabla 1. Regímenes de inflación crónica. Episodios identificados por tipo. ................... 16

Tabla 2. Regímenes de inflación crónica. Estadísticas descriptivas................................ 17

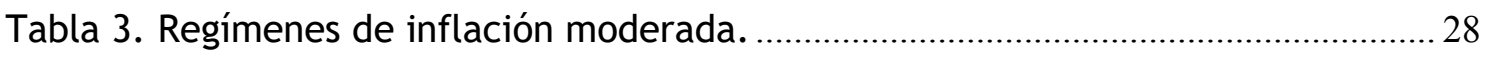

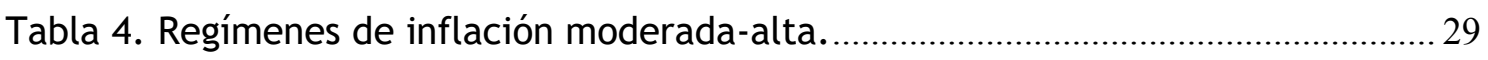

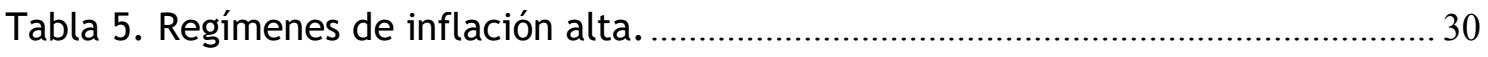

Tabla 6. Desinflaciones identificadas según régimen de origen y tipo de transición.. 49

Tabla 7. Resultados de regresión entre Señoreaje y Déficit Fiscal. ................................ 60

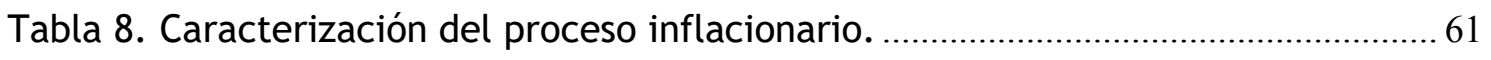

Tabla 9. Caracterización del proceso de desinflación para los casos seleccionados

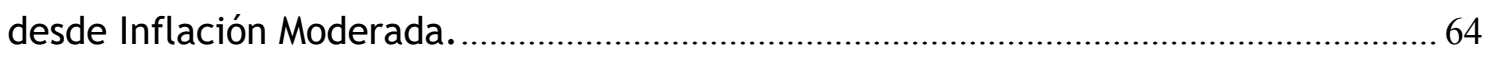

Tabla 10. Caracterización del proceso de desinflación para los casos seleccionados desde Alta Inflación..

Tabla 11. Características principales de la Carta Orgánica de los Bancos Centrales al momento de la desinflación según país y año de reforma. ............................................. 66

Tabla 12. Caracterización de los arreglos cambiarios por país según período. ............. 72

Tabla 13. Principales tasas de referencia de la política monetaria por país y período. 
RESUMEN

El trabajo que se presenta a continuación analiza diferentes patrones que surgen en economías donde la inflación se mantiene en niveles elevados de manera persistente en el tiempo y su asociación con la forma en la que los países han diseñado estrategias para establecer transiciones a baja inflación. El mismo tiene dos objetivos: el primero de ellos, es ofrecer un panorama relativamente completo sobre el conjunto de cuestiones que la economía ha considerado a la hora de abordar el proceso inflacionario desde el punto de vista teórico. Las características propias del mismo, en particular, las complejas relaciones de causalidad que aparecen cuando se intenta establecer una relación entre este proceso y alguna variable que lo afecta plantea un desafío para su análisis. Dado que gran parte de estas relaciones tienen lógicas de causalidad circular acumulativa, se propone aquí que existen ciertos patrones observables relevantes que, a medida que la inflación se torna en un estado crónico, refuerzan las dinámicas del sistema estableciendo regímenes.

La segmentación de las dinámicas de acuerdo al ambiente imperante es un procedimiento que ha sido ampliamente utilizado en el plano de la macroeconomía monetaria. En el primer capítulo se realiza una revisión de la literatura que considera los cambios que operan a nivel agregado a medida que la inflación se transforma en un estado crónico del sistema económico. Este recuento sobre la historia contemporánea del pensamiento sobre los procesos inflacionarios será el prisma a través del cual se observará la forma que han tomado a lo largo de la historia en diferentes países del mundo el objeto de estudio de este trabajo. A través de la magnitud y duración de los procesos inflacionarios, se analiza en la segunda sección del primer capítulo la distribución, magnitud y duración de los estados de inflación crónica desde la segunda mitad del siglo XX hasta la actualidad.

En el segundo capítulo se analizan con mayor precisión los procesos inflacionarios de once países de América Latina, región que fue particularmente afectada por procesos de inflación crónica. Se procede a su vez a analizar algunos patrones que suelen considerarse conceptualmente relevantes para estas situaciones: la naturaleza del proceso inflacionario en cuanto a su dinámica temporal y su convergencia en el tiempo, la asociación de las fluctuaciones cambiarias con los precios internos y las interacciones entre la política monetaria y la política fiscal. A través de estos patrones, se analizan los procesos de desinflación a lo largo de la historia de estos países con el fin de establecer elementos comunes en las transiciones. 
En el tercer capítulo se realiza un estudio de caso sobre cinco procesos de desinflación donde se observan estrategias graduales, con el fin de observar posibles elementos comunes entre las mismas. La selección de estas economías busca establecer un paralelo entre un conjunto diferente de economías, en un lapso de tiempo común que permita observar la respuesta de las mismas a impactos y condiciones internacionales comunes. Se analiza el marco institucional y la elección sobre el manejo de instrumentos durante la transición, así como las trayectorias y el desempeño macroeconómico de cada una de las mismas. El objetivo en este caso es observar cómo estrategias no convencionales sobre las transiciones hacia ambientes de baja inflación en economías con características diferentes guardan elementos comunes que a su vez se asocian con algunos de los patrones macroeconómicos planteados previamente.

El objetivo del trabajo es consolidar un abordaje a los procesos de inflación crónica y las políticas económicas asociadas a ellos que, sostenido en un andamiaje conceptual que sin ser novedoso permite una visión unificada, permita observar cómo el mismo se aplica a procesos históricos específicos y al desarrollo de las políticas de desinflación. En este sentido, la última sección ofrece un conjunto de comentarios de carácter general sobre los resultados del trabajo considerados de manera conjunta. 


\section{Capítulo I: Inflación Crónica y Patrones Macroeconómicos}

\section{INTRODUCCIÓN}

La posibilidad de que el comportamiento de un sistema resulte condicional a la situación o estado en la que el mismo se encuentre es una hipótesis habitual en diferentes ramas del conocimiento $y$, muchas veces de manera implícita, ha sido parte del desarrollo de la literatura económica. En el contexto de la macroeconomía monetaria, desde el trabajo seminal de Cagan (1956) se han desarrollado una serie de estudios abocados al análisis del comportamiento de la economía en situaciones de alta inflación y, en menor medida, a los cambios que ocurren en regímenes de menor magnitud, como la inflación moderada (Dornbusch y Fischer, 1991). Esta estrategia de investigación ha indagado en la evolución de las economías en condiciones extremas, entendiendo de ello que las mismas eran capaces de revelar ciertos aspectos del sistema que no serían observables en condiciones de relativa estabilidad.

La segmentación del estudio de las dinámicas inflacionarias considera que existen cambios relevantes en comportamiento de los agentes y relaciones económicas de tal forma que los mismos afectan ciertos patrones macroeconómicos, desde las características propias de la tendencia y volatilidad del proceso inflacionario o la dispersión de precios relativos, hasta las tasas de inversión y el crecimiento de largo plazo de la economía. El trabajo considera que los procesos inflacionarios recurrentes en el tiempo son capaces de generar efectos sobre la estructura y configuración de la economía a nivel agregado. En este sentido, la inflación no es simplemente un indicador de desempeño, en tanto que su presencia persistente en él es capaz de alterar ciertas condiciones en las que el mismo opera. Un abordaje no lineal del fenómeno inflacionario plantea que las intervenciones o prácticas recomendadas sobre el diseño de la política económica en ciertos contextos carecen de sentido cuando el mismo se ve alterado. La situación hace a la oportunidad.

En la primera sección de este capítulo se realizará un repaso sobre la literatura que vincula el nivel de inflación con la forma de funcionamiento del sistema económico. En la segunda sección se propone una caracterización específica para identificar los procesos de inflación crónica de acuerdo a su intensidad. Utilizando una base de información de larga duración para un número amplio de países, se identifica la frecuencia en la que estos fenómenos se han presentado. Se intentará con ello establecer la magnitud (en cantidad de países y episodios) y duración de los diferentes regímenes de inflación, al tiempo que permitirá identificar los períodos donde estos fenómenos han sido relevantes, tanto a nivel mundial como hacia el interior de cada 
país. Por otra parte, se intentará observar hasta qué punto estos fenómenos se han mantenido como regímenes persistentes, observando para ello la frecuencia de transición entre uno y otro estado. Esta identificación será utilizada en los próximos capítulos tanto para evaluar patrones macroeconómicos considerados en la literatura como para analizar procesos de transición entre estados.

\section{EFECTOS dE LA INFLACIÓN CRÓNICA}

La literatura ha analizado desde diferentes perspectivas los cambios que operan en el sistema económico cuando el mismo se encuentra expuesto a procesos de inflación elevada y persistente. En general, cada uno de estos trabajos ha recogido un aspecto particular de este fenómeno, por lo que obtener un panorama general requiere considerar estas contribuciones de manera conjunta.

Una de las formas más convencionales para definir los efectos de la inflación dentro de los modelos macroeconómicos es a través del dinero. Dado que el mismo es un pasivo con la particular característica de no rendir interés la inflación es equivalente a la pérdida de recursos por parte de sus tenedores, lo que se conoce habitualmente como el "impuesto inflacionario". El deterioro del poder adquisitivo de la moneda es una transferencia desde los demandantes hacia el emisor pero, dado que solamente el sector público es capaz de emitir este pasivo, es natural considerar que la inflación puede ser el resultado del financiamiento recurrente del déficit fiscal a través del señoreaje ${ }^{1}$. Un segundo elemento considerado en la literatura para abordar la determinación de las tasas de inflación ha sido considerar los procesos de formación de precios. En su forma moderna, los mismos suelen considerar a la misma como el resultado no solo de los niveles de liquidez sino también de la secuencia de costos marginales presentes y futuros. La forma en la que los agentes económicos actúan en la definición de los precios y las expectativas respecto de los mismos en el futuro incide también en la tasa de inflación. La relación causal entre los distintos elementos que afectan a la inflación desde ambas perspectivas resulta sin embargo difusa.

En cuanto a las relaciones fiscales, Olivera (1967) y Tanzi (1977) muestran que, si existen rezagos en la recaudación impositiva, la misma se ve afectada por el aumento de precios, por lo que niveles más altos de inflación implicarían, al mismo nivel de gasto, mayores déficit fiscales. Un segundo argumento que es capaz de invertir la

\footnotetext{
${ }^{1}$ En el extremo, algunos autores han interpretado que, dado que los precios reflejan el valor del dinero, los mismos son el resultado del valor presente descontado de los excedentes fiscales, lo que algunos han llamado la "teoría fiscal del nivel de precios" (véase, por ejemplo, Kocherlakota y Phelan, 1999).
} 
relación es el propuesto por Heymann, Navajas y Warnes (1991): un contexto de inflación elevada deteriora las condiciones sobre las cuales se define el presupuesto público y tiende a generar una negociación "bilateral” de diferentes grupos de presión. El conflicto por la distribución del presupuesto tiene, en este contexto, un sesgo propiamente inflacionario al deteriorar el balance fiscal. En este caso el ambiente inflacionario es una condición que hace al sector público más propenso a incurrir en déficit recurrentes, lo que vuelve a invertir la causalidad.

El impuesto inflacionario, como todo impuesto, no se encuentra exento de efectos asignativos. A medida que la inflación aumenta las personas tienden a reducir su demanda por liquidez, lo que provoca una disminución de la base imponible sobre la que se obtienen recursos. A medida que la inflación aumenta, emerge una relación más estrecha entre el crecimiento de los agregados monetarios y la inflación, que no necesariamente ocurriría cuando la misma es baja y la demanda por activos líquidos es flexible. De Grauwe y Polan (2005) encuentran que la relación de largo plazo entre dinero y precios está fuertemente concentrada en episodios de inflación mayor a 10\%, resultado similar al que arriban Teles, Uhlig y Azevedo (2016), quienes corrigen la relación por la elasticidad de demanda de dinero, mientras que en ambientes de inflación baja la demanda de dinero es relativamente flexible, rompiendo la asociación respecto del nivel de precios. En la práctica, existe evidencia de que los individuos tienden a desprenderse de cualquier activo denominado en moneda local. Boyd, Levine y Smith (2001) encuentran evidencia de que a medida que la inflación se incrementa (en un umbral por encima del 15\%) existe una asociación negativa entre el desarrollo financiero (préstamos y depósitos del sistema bancario, así como también de mercados bursátiles) y el nivel de la tasa de inflación. En este contexto, la relación entre déficit fiscal y el señoreaje puede también ser el reflejo de la incapacidad de acceso al financiamiento a través de los mercados de crédito, incluyendo a su vez al dinero como un activo financiero que depende de la solvencia del sector público.

Heymann y Leijonhufvud (1995) consideran que la inflación afecta los acuerdos institucionales y las rutinas habituales que, en otras situaciones, permiten a los individuos operar en un entorno que facilita las decisiones y las transacciones económicas, alterando también el proceso de formación de precios. Un efecto colateral de la disminución en la demanda de dinero es que la posibilidad de que el mismo se posicione como unidad de cuenta suele verse afectada. En un entorno donde los errores de pronóstico generan grandes redistribuciones de ingresos entre acreedores y deudores en el mercado financiero o entre compradores y vendedores en el mercado de bienes, la asignación de riesgos se convierte en un elemento central. 
No es extraño en este sentido que en contextos de inflación crónica se observe la aparición de cláusulas más o menos explicitas de indexación para intentar evitar una redistribución abrupta entre las dos partes de una transacción. Se han observado prácticas indexatorias tanto en el sistema financiero como en los convenios salariales, pero también el sector público ha indexado en ciertos contextos parte del sistema impositivo (en particular, en los impuestos de base fija). A nivel individual la indexación facilita las transacciones al permitir mantener el valor real de los contratos, pero a nivel agregado ha sido relacionada con una mayor persistencia del proceso inflacionario, esto es, con una mayor duración de los impactos que generan desvíos de la inflación respecto de su tendencia (Edwards y Lefort, 2002). El nivel de inflación no solo estaría relacionado con una mayor persistencia sino también con el hecho de que la inflación se torne más inestable y no tienda a una media constante en el tiempo (Noriega y Capistran, 2012). Bruno (1989) considera que una mayor indexación, al compensar las pérdidas ocasionadas por las fluctuaciones en la tasa de inflación, resulta análoga a una mayor respuesta frente a divergencias entre la inflación esperada en el pasado y la efectivamente realizada. Estos cambios en los procesos de formación de precios pueden convalidar en sí mismos la estabilidad de un estado de alta inflación, para un mismo nivel de señoreaje. En este sentido, la indexación no solo es el resultado de la inflación sino que el nivel de inflación está influido por la indexación.

Ciertos activos como la moneda extranjera reflejen un valor nominal que se adapta a la inflación hace que el mismo se utilice como reserva de valor, pero también que sirva como referencia para el establecimiento de los precios internos como sustituto de la indexación. Este fenómeno tiende a generar una mayor relación entre los precios internos y el valor del tipo de cambio en estados de mayor inflación. Taylor (2000) analiza el fenómeno de disminución del traspaso a precios internos de las fluctuaciones del tipo de cambio a partir de la década de los noventa, considerando que el mismo se debe fundamentalmente al cambio en el "ambiente inflacionario". En otras palabras, se considera allí que un contexto de baja inflación es capaz de modificar el proceso de formación precios, en particular a través de una disminución de los traspasos a precios internos de los movimientos cambiarios. Una serie de trabajos han ofrecido evidencia para evaluar la veracidad de la relación entre el contexto inflacionario y el coeficiente de traspaso. Bailliu y Fujii (2004) utilizan datos trimestrales para 11 países entre 1977 y 2001 para determinar si ambientes de inflación reducida son capaces de generar una disminución en el coeficiente de traspasos a precios. Utilizando un conjunto de técnicas de datos de panel, los autores encuentran que el traspaso a precios se reduce en ambientes de baja inflación, tanto en los índices de precios de importación, 
productor y al consumidor. Gagnon e Ihrig (2004) analizan y estiman coeficientes de traspaso para un conjunto de 20 países industrializados entre 1971 y 2003 con datos trimestrales, considerando ambientes de baja inflación con un criterio externo. Para la mayor parte de los países, el quiebre entre ambos periodos de la muestra divide una primera etapa de mayor inflación y elevada volatilidad de precios (particularmente, entre 1970 y principios de 1990) y un período posterior de ambientes de baja inflación y relativa estabilidad. Una vez estimados los diferentes coeficientes de traspaso, los autores analizan los determinantes de los cambios en el mismo, encontrando que la volatilidad de la tasa de inflación se relaciona directamente con traspasos más bajos. Choudhri y Hakura (2006) utilizan un procedimiento similar, pero amplían la muestra a 71 países entre 1979 y 2000, lo que les permite incorporar tanto economías desarrolladas como no desarrolladas. Los autores agregan un umbral del $30 \%$ de inflación promedio para identificar cambios de regímenes hacia el interior de los países, así como también para los episodios de hiperinflación (aunque solamente 8 países de la muestra presentaron cambios de regímenes de acuerdo a su definición). Los autores estiman ecuaciones de formación de precios individuales y encuentran en este caso que el ambiente inflacionario incide en el coeficiente de traspaso. Devereux y Yetman (2010) estiman el coeficiente de traspaso para 119 países, utilizando datos anuales para ampliar la muestra y encuentran evidencia de que el nivel promedio de inflación incide en el coeficiente de traspaso, atribuyendo que el mismo se debe a un ajuste de precios más frecuente.

El hecho de que la economía utilice practicas indexatorias o la referencia del tipo de cambio no implica que los precios relativos se tornen más estables, sino más bien todo lo contrario. Existe evidencia de que los individuos revisan con mayor frecuencia los precios en ambientes de alta inflación (por ejemplo, Alvarez et al, 2019) y, en el extremo, estos se suceden a alta velocidad. Esta sincronía no ordena el sistema de precios, de hecho, la volatilidad de precios relativos se incrementa a medida que lo hace la tasa de inflación (Dabus, 2000). Esta volatilidad ha sido asociada a la imposibilidad de definir previamente la variación de precios de la economía en su conjunto (Lucas, 1973) o a la incapacidad de extraer señales adecuadas del proceso inflacionario (Cukierman, 1983). Tommasi (1994) analiza el efecto generado por la dispersión de precios en un contexto de búsqueda. En este caso, la información es menos valiosa y por lo tanto los individuos se encuentren peor informados, lo que a su vez genera en las firmas un poder de mercado que utilizan para aumentar sus márgenes. Una vez más aparece un proceso de causación acumulativa, donde la inflación genera incertidumbre que se traslada a los precios relativos, pero a su vez en 
este ambiente es más probable que las firmas tengan capacidad de establecer precios con poder de mercado dada la reducida capacidad informativa de los precios, lo que exacerba su dispersión.

En el largo plazo las distorsiones generadas por la inflación se traducirían en menores aumentos de la productividad, afectando la tasa de crecimiento del producto. La literatura ha explorado esta hipótesis desde diversos ángulos. Fischer (1995) encuentra una relación negativa entre el crecimiento económico y la variación de precios, cuyo canal principal es una disminución de la tasa de inversión. En este trabajo, el autor impone un umbral para considerar tasas de inflación por encima del $15 \%$ y del $40 \%$ respectivamente, encontrando que ambos límites resultan significativos para explicar la relación entre crecimiento e inflación. En todo caso, uno de los resultados del trabajo es que dicha relación depende de la inclusión de aquellos países que presentaron eventos de alta inflación. Bruno y Easterley (1998) revisaron este resultado, encontrando que dicha relación se ve afectada por los episodios de alta inflación, donde se observan fuertes contracciones del producto. De acuerdo a estos autores, la única relación significativa se encontraría en aquellas situaciones donde la tasa de inflación supera un umbral $40 \%$, pero los efectos son temporarios y se revierten rápidamente. De alguna forma, ambos trabajos incluyen la noción de que la relación entre la variación de precios y el crecimiento económico podría presentar discontinuidades. Sarel (1996), evaluó posibles no linealidades, encontrando un quiebre estructural a una tasa de inflación del $8 \%$, por debajo de la cual la inflación se asociaría positivamente al crecimiento y negativamente en valores superiores de la misma. De igual forma, Ghosh y Philips (1998) encuentran una relación positiva en un rango más bajo de inflación, de aproximadamente $2 \%$ a $3 \%$, que se transformaría en negativa posteriormente, aunque convexa (por lo que los efectos marginales son más fuertes en la transición hacia inflaciones intermedias que en los cambios que suceden una vez que la economía ya se encuentra en una inflación por encima de ella). Khan y Senhadji (2001) introducen por primera vez la posibilidad de que la inflación afecte de manera diferente a economías en desarrollo respecto de los países industrializados. En este sentido, encuentran un umbral considerablemente más bajo para las economías desarrolladas (entre $1 \%$ y $3 \%$ ) respecto de las economías en vías de desarrollo $(11 \%$ al 12\%). De manera similar, Kremer, Bick y Nautz (2013) ofrecen una metodología que permite establecer los umbrales sin que los mismos se vean afectados por la endogeneidad de los regresores. En este caso, los autores hallan un primer umbral para las economías industrializadas del $2 \%$ y uno superior para las economías en desarrollo. Más recientemente, Ibarra y Trupkin (2016) revisan los resultados encontrado una 
relación no lineal y negativa, pero más estrecha para aquellos países con menores desempeños institucionales.

En líneas generales, todo el sistema económico acorta el horizonte de planeamiento a medida que la inflación se torna más elevada. La imposibilidad de establecer planes a mediano plazo disminuye los incentivos para invertir en actividades de maduración lenta a favor de posiciones de corto plazo que, además, puedan ser revertidas ante un cambio en el contexto, estimulando las ganancias por arbitraje. Este tipo de dinámicas altera el destino de los recursos que se desvía desde actividades productivas hacia la obtención de rentas.

Considerando que existen fundamentos para considerar la tasa de inflación como una variable representativa de ciertas características de funcionamiento del sistema económico, la próxima sección se ocupará de intentar identificar que tan frecuentes y tan intensos han sido estos procesos a lo largo de la historia mundial reciente.

\section{IDENTIFICACIÓN Y CARACTERIZACIÓN DE REGÍMENES DE INFLACIÓN CRÓNICA}

\section{Identificación}

El objetivo de esta sección es caracterizar, identificar y contextualizar regímenes de inflación crónica. Heymann y Leijonhufvud (1995) establecen una regla práctica para identificar el régimen de inflación: considerando que el elemento central de estos procesos es el acortamiento del horizonte de planeamiento, los autores consideran que una inflación es "alta" cuando los individuos se refieren a la misma en términos mensuales, mientras que la inflación es "moderada" cuando los individuos se refieren a ella en términos anuales. Como contrapunto, un régimen de inflación "baja" sería aquel en el cual los individuos desconocen por completo la tasa de inflación o la misma no es un problema relevante de la política pública. Si bien este es un criterio útil a la hora de considerar la magnitud de los procesos inflacionarios, traducirla para identificar situaciones en la práctica requiere establecer, sin embargo, límites numéricos precisos.

En esta sección se propone realizar un ejercicio de identificación de los procesos de inflación crónica siguiendo el criterio establecido en Dornbusch y Fischer (1993), quienes definen al "régimen" a través de dos dimensiones: el nivel de la tasa de inflación y su persistencia en el tiempo. En este sentido, se definirá al régimen de inflación como un período de al menos tres años durante el cual una economía mantiene una tasa de inflación en un rango determinado. En otras palabras, se 
considera aquí que las economías ingresan a un "régimen" cuando mantienen al menos tres años consecutivos de inflación dentro de ciertos límites, a saber:

- Moderada: $15 \%$ - 30\%

- Moderada-Alta: $30 \%-100 \%$

- $\quad$ Alta: $>100 \%$

Volviendo sobre el planteo original de este trabajo, se considera aquí que la inflación es un fenómeno capaz de alterar la configuración del sistema económico. Estos cambios no operan de manera instantánea sino, por el contrario, requieren cierto grado de permanencia en el tiempo para desarrollarse. El hecho de establecer un umbral de al menos tres años se considera un número mínimo para evitar considerar como "regímenes" a cambios transitorios en la tasa de inflación, que pueden tener efectos en años consecutivos por un simple arrastre. En segundo lugar, si bien los umbrales se establecieron considerando trabajos previos en la materia (como por ejemplo, Fischer, Sahay y Végh, 2004), el uso de los mismos en los siguientes capítulos muestra regularidades que validan su uso como referencia.

El procedimiento planteado posee ciertas desventajas frente a las transiciones temporarias entre umbrales, ya que las mismas podrían considerarse como el final de un régimen, aunque el mismo se mantenga en el tiempo. Para evitar la mayor parte de estos casos, el algoritmo de identificación mantiene en un mismo régimen una economía que transitoriamente se encuentra por fuera del umbral durante un año, pero presenta un mismo régimen el año previo y el posterior.

Las estadísticas utilizadas corresponden a la Base de Indicadores del Desarrollo Mundial del Banco Mundial (WDI), con datos anuales sobre el Índice de Precios al Consumidor (IPC) para 144 países entre 1960 y $2017^{2}$.

Tabla 1. Regímenes de inflación crónica. Episodios identificados por tipo.

\begin{tabular}{cccc}
\hline Tipo & Eventos & Países & $\%$ Total obs. \\
\hline Moderada & 78 & 34 & $7 \%$ \\
Moderada-Alta & 38 & 30 & $4 \%$ \\
Alta & 22 & 21 & $2 \%$ \\
\hline TOTAL & 138 & 65 & $13 \%$ \\
\hline
\end{tabular}

Fuente: Elaboración propia en base a WDI

\footnotetext{
2 Para el caso de la Argentina se procedió a reconstruir un índice de precios para el período 2007-2015 a través de índices de precio publicados por los niveles subnacionales (provincias).
} 
En la Tabla 1 se presenta la distribución los 138 eventos de inflación persistente identificados en la muestra. Como puede observarse, la inflación moderada ha sido más frecuente que la inflación alta o moderada-alta y se ha extendido en un mayor número de países. Cabe notar en este caso que la literatura sobre procesos de alta y moderada-alta inflación han sido mucho más habituales que los fenómenos de inflación moderada, aunque en la práctica estos últimos han sido más frecuentes.

Tabla 2. Regímenes de inflación crónica. Estadísticas descriptivas.

\begin{tabular}{cccccc}
\hline \multirow{2}{*}{ Tipo } & \multicolumn{2}{c}{ Duración (años) } & \multicolumn{3}{c}{ Inflación (i.a.) } \\
\cline { 2 - 6 } & Media & Máxima & Media & Mediana & Desvío \\
\hline Moderada & 5,6 & 26 & 21 & 21 & 6 \\
Moderada-Alta & 6,1 & 25 & 57 & 52 & 22 \\
Alta & 5,9 & 17 & 978 & 276 & 2507 \\
\hline
\end{tabular}

Fuente: Elaboración propia en base a WDI

Como puede observarse en la Tabla 2 la duración media de los eventos no ha variado considerablemente entre los diferentes regímenes. Puede observarse en cada uno de ellos países que han registrado procesos de muy larga persistencia tales como Colombia (26 años de inflación Moderada), Turquía (25 años de inflación ModeradaAlta) y Argentina (17 años de Alta inflación). La noción de régimen asociada a eventos de Alta inflación parece difusa, en tanto la misma se ve afectada por episodios extremos (lo que hace que los desvíos sean extremadamente altos).

En el Gráfico 1 se detalla como el conjunto de estos episodios se han desarrollado desde una perspectiva histórica para todos los países de la muestra. Algunos de estos cambios se han dado de manera coincidente con episodios de gran magnitud a nivel internacional. Por ejemplo, es posible observar un importante incremento del número de países en regímenes de inflación crónica entre 1971y 1973, lo que coincide temporalmente con el quiebre de los tratados de Bretton Woods y la primera crisis del petróleo. A partir de ese máximo la serie mantiene cierta tendencia a la baja hasta 1980 y 1983, período que coincide con un cambio significativo en la política monetaria de los Estados Unidos (lo que suele ser conocido como el "Volcker shock") y la consecuente crisis de deuda de América Latina. Desde entonces los regímenes de inflación moderada se vuelven menos recurrentes y se incrementa la participación de los fenómenos de inflación en regímenes de moderada-alta y alta inflación. El último máximo se registra a principios de 1990, junto con la caída del muro de Berlín y la transición de las economías de Europa del Este (que llevaron a varias de estos países a 
procesos inflacionarios de duración prolongada). Entre 1995 y 2001 comienza una disminución importante del ambiente inflacionario entre las economías del mundo, lo que a nivel mundial estuvo marcado por un período de crisis sucesivas (la crisis del tequila, la crisis asiática, la crisis rusa, la crisis de la convertibilidad argentina y la burbuja de las “puntocom”). En la actualidad la inflación persistente es más bien una excepción entre los países del mundo.

Gráfico 1. Cantidad de países según regímenes de inflación (como \% total muestra)

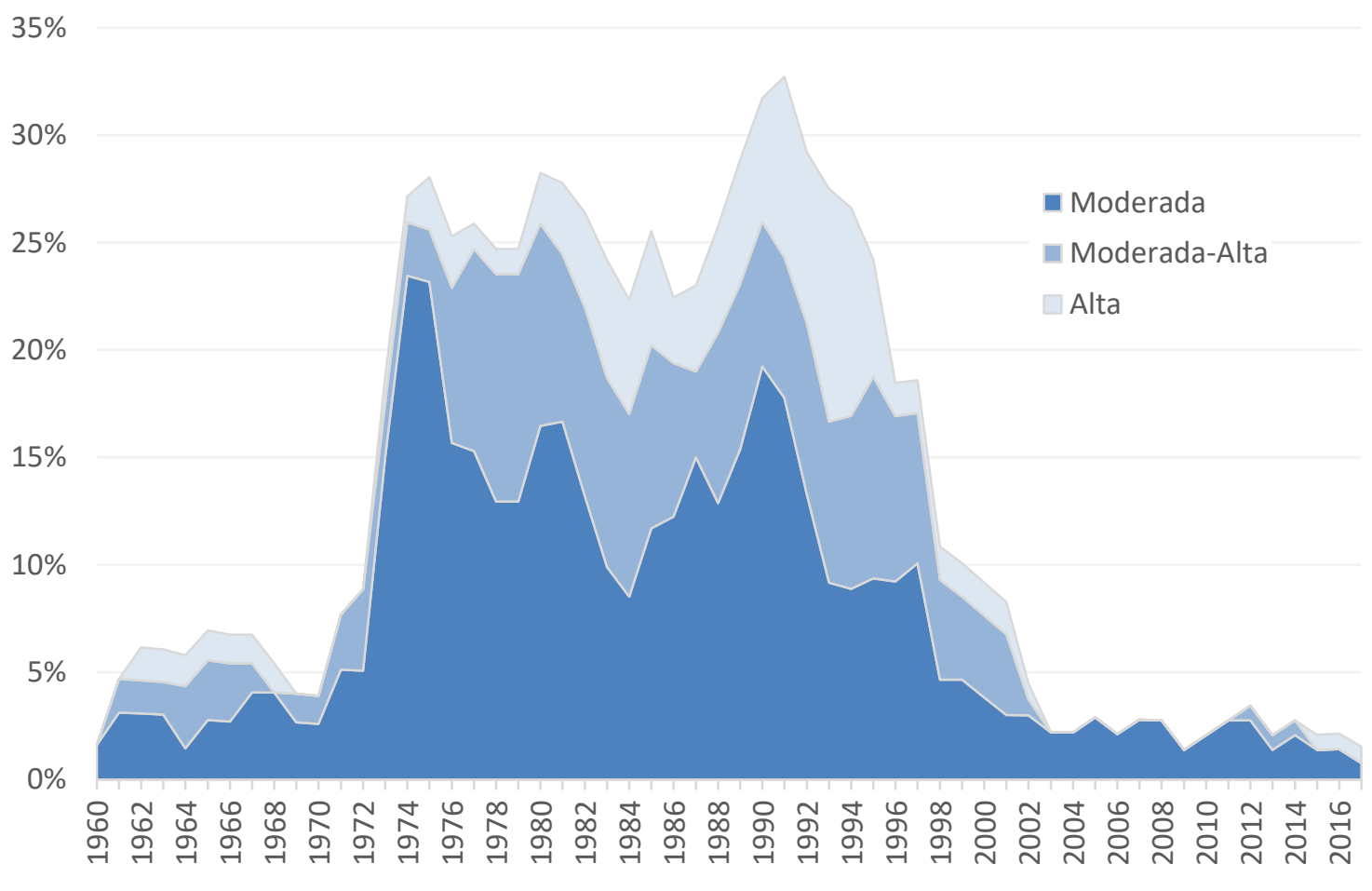

Fuente: Elaboración propia en base a WDI

En cuanto a su distribución geográfica, el Gráfico 2 muestra la cantidad de años promedio por país según región para el período analizado. El ejercicio en este gráfico muestra un promedio de años que los países de la región mantuvieron mientras se encontraban en regímenes de inflación crónica. En este sentido y a modo de ejemplo, cada uno de los países de América Latina y el Caribe mantuvo en promedio 13 años de inflación crónica, 7 de ellos en inflación moderada, 4 en moderada-alta y 2 en alta inflación. Esta región ha sido claramente la más afectada por los procesos de este tipo, seguida por África Subsahariana y Medio Oriente y Norte de África, que poseen menos de la mitad de años, en promedio. 


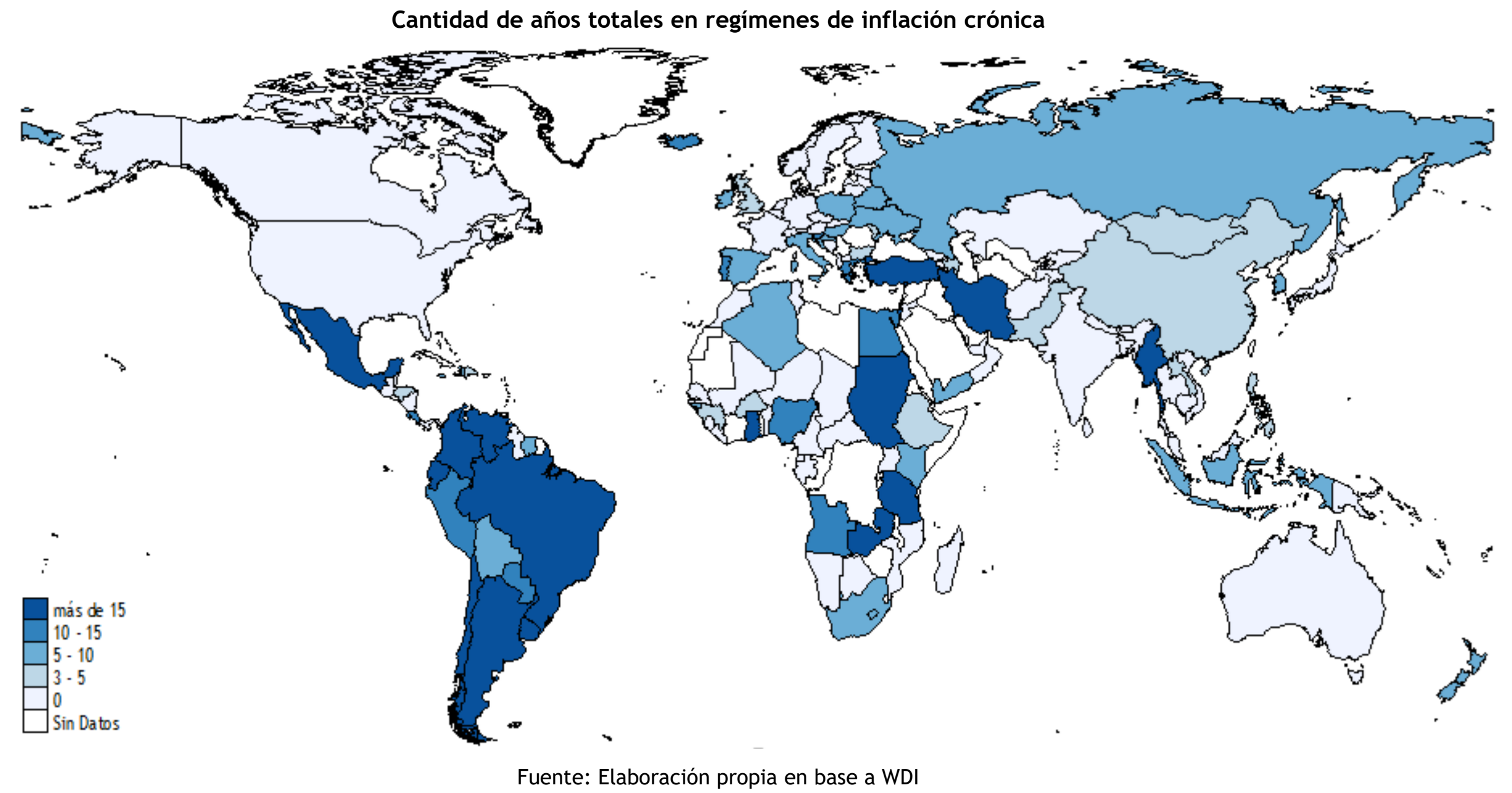


Gráfico 2. Años totales en regímenes de inflación persistente. Promedio por región.

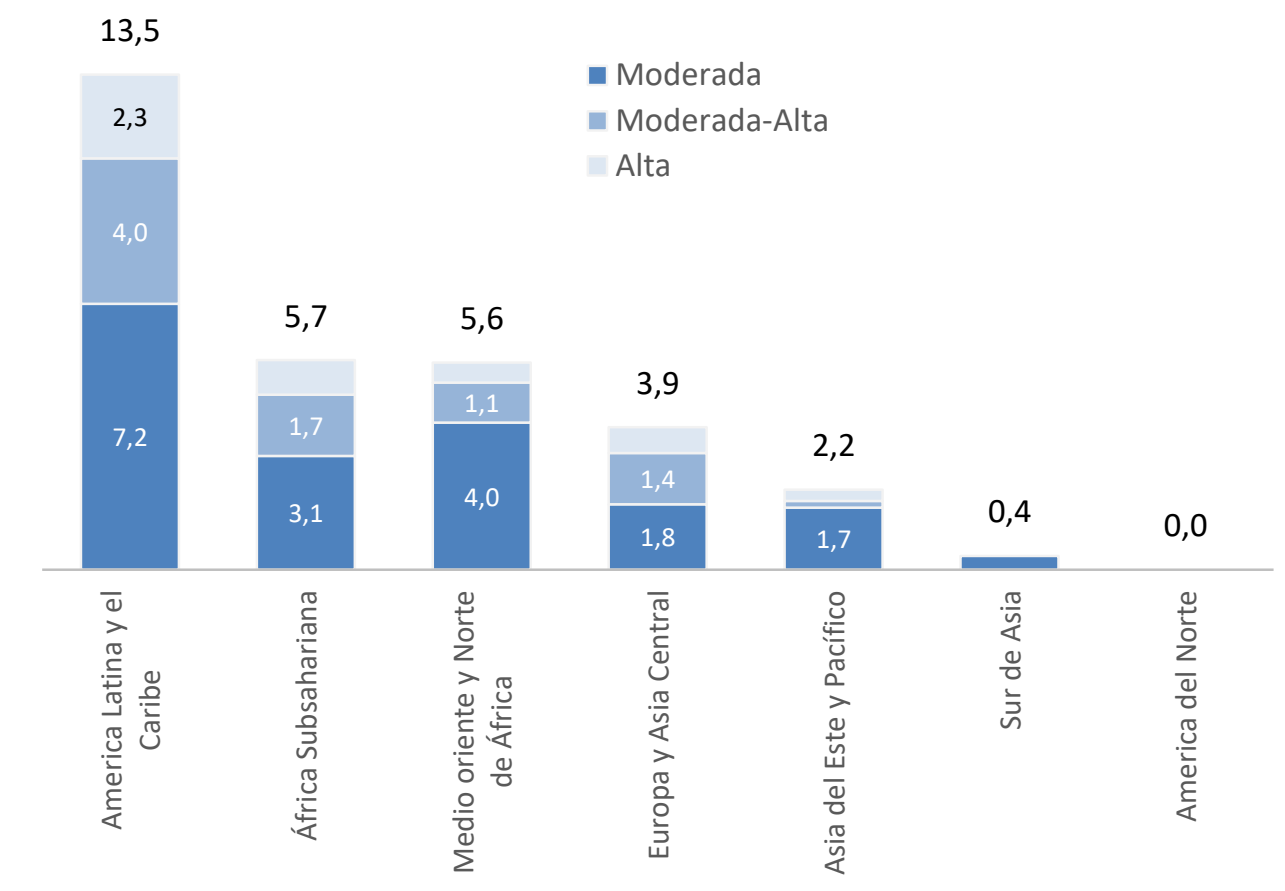

Fuente: Elaboración propia en base a WDI

Los promedios por región esconden, como se mencionó previamente, la existencia de fenómenos extremos: a modo de ejemplo, solo en América Latina existen un conjunto de observaciones extremas como Colombia y Uruguay, con casi un cuarto de siglo de inflación moderada y moderada-alta respectivamente, o Argentina con casi 17 años de alta inflación y una década de inflación moderada. Como puede observarse en el Gráfico 3 este fenómeno no se encuentra repartido de manera homogénea entre los países de cada región. Seis de los diez países con mayor cantidad de años en este tipo de situación que pertenecen a América Latina han presentado inflación persistente durante más de 20 años. Dos de los países más importantes de la región (Argentina y Brasil) son en términos mundiales los que han registrado mayor cantidad de años en este tipo de condiciones. Una situación similar ocurre con otras regiones, donde existen países (por ejemplo, la República Democrática del Congo, Turquía, Ghana, Sudán, Irán o Zambia) que poseen una exposición a fenómenos de inflación persistente muy superior al resto de la región.

A pesar de los contrastes y casos extremos, es posible observar que casi todos los principales países de América Latina casi sin distinciones han sido parte a lo largo de los años de procesos perdurables de inflación crónica, pasando por diferentes estados y períodos, pero marcando una clara tendencia regional. 


\section{Gráfico 3. Años totales por país según regímenes}

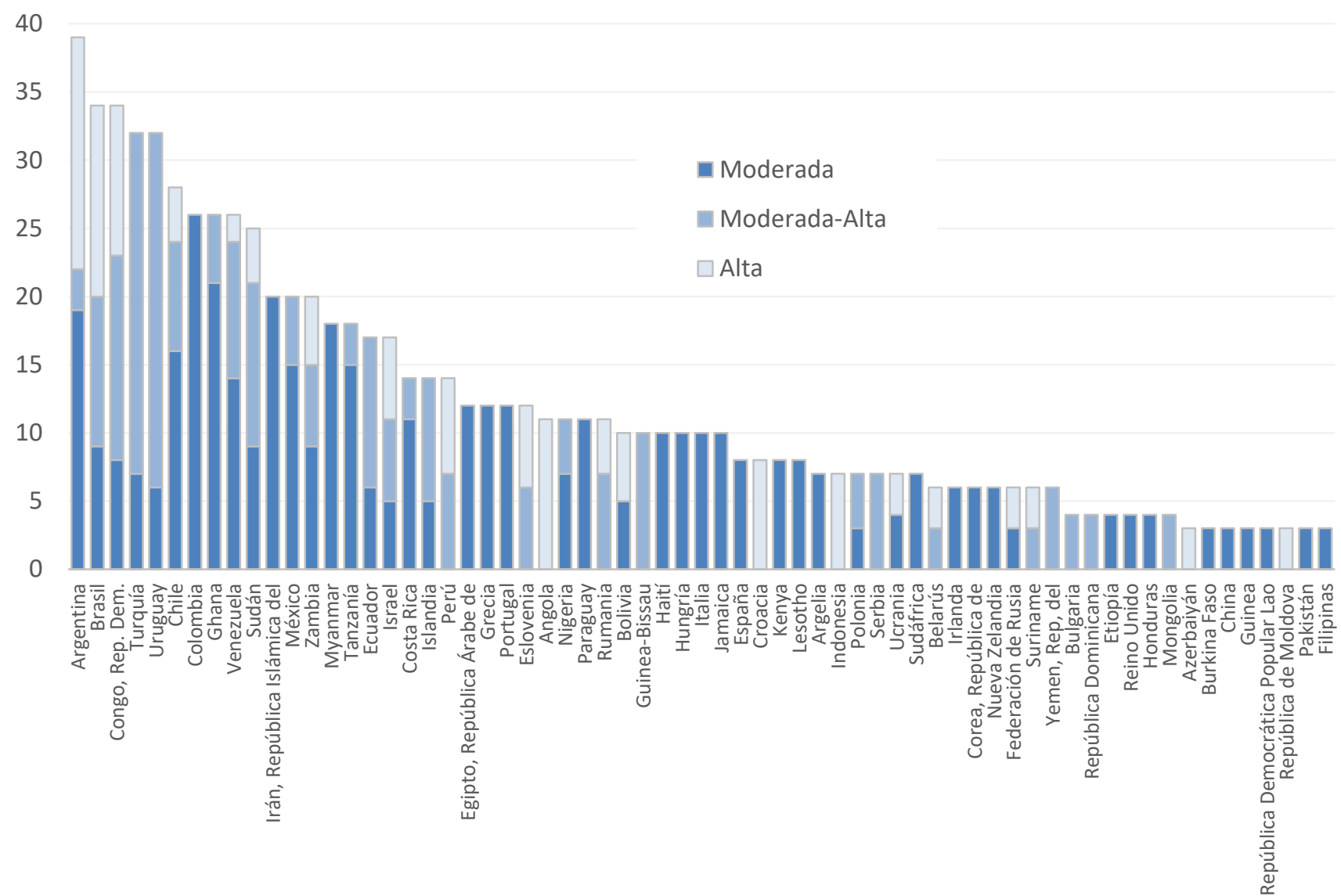

Fuente: Elaboración propia en base a WDI

\section{Transiciones entre regímenes}

La inflación crónica es un fenómeno que ha sido relativamente extendido entre las economías a lo largo de los años. Otra forma de observar la estructura de estos procesos es analizar qué tan elevada ha sido la frecuencia en que economías de diferentes regímenes han realizado transiciones a otros. Una forma de analizar esta dimensión es la de observar las matrices de transición entre estados condicionando por la situación o régimen original en el que se encontraban los países. En otras palabras, el ejercicio parte de observar la frecuencia relativa de países que desde un estado pasaron a otro diferente, por ejemplo, aquellos que desde una situación de alta inflación realizaron transiciones a inflación baja.

En el Gráfico 4 se muestra la frecuencia de transición hacia diferentes regímenes condicional a que la misma se encontrará originalmente en inflación baja. Como puede observarse dada una situación de este tipo, la frecuencia observada de transiciones 
hacia algún régimen de inflación crónica es acotada: en 5 años menos del $5 \%$ de los casos pasaron a regímenes de inflación crónica, de ellos casi dos terceras partes a moderadas.

Gráfico 4. Frecuencia de transición a regímenes de inflación crónica desde baja inflación

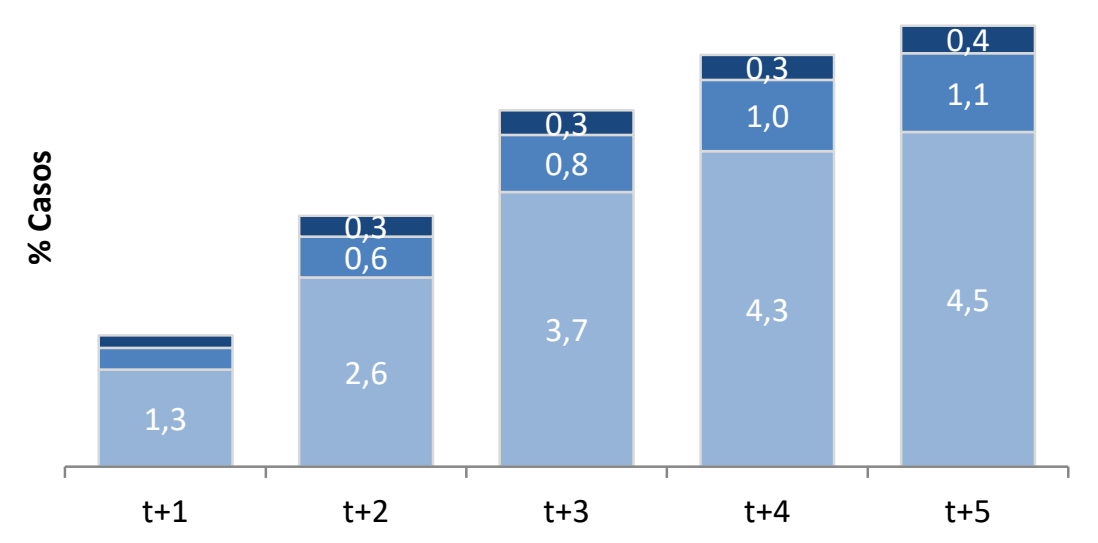

Fuente: Elaboración propia en base a WDI

Cabe aquí preguntarse sobre la relevancia de este resultado y si debería entenderse a la baja frecuencia de transición en la inflación baja como un síntoma de la relevancia acotada de los episodios de inflación para la política económica. Una respuesta aproximada a esta pregunta es que, si bien las transiciones hacia otros regímenes han sido poco frecuentes, una vez que una economía se encuentra dentro de este tipo de procesos los mismos resultan persistentes y las transiciones a baja inflación no se encuentran aseguradas.

En el Gráfico 5 se muestran las frecuencias de transición según el régimen de origen. Puede observarse en este caso que más de dos tercios de los episodios se mantenían en el mismo régimen al quinto año, lo que da cuenta de la relativa estabilidad de cada uno de estos procesos. En segundo lugar, independientemente del régimen de inflación crónica de origen, menos de la mitad $(\mathrm{y}$, en algunos casos, menos de un tercio) realizaron transiciones hacia estados de baja inflación. La relevancia de estos fenómenos no se encuentra tanto en su frecuencia, sino más bien en el hecho de que las economías que se han visto involucradas en este tipo de procesos se han mantenido allí por un tiempo prolongado y no necesariamente han realizado transiciones a ambientes de baja inflación. En este sentido, los regímenes muestran ser fenómenos relativamente persistentes y no necesariamente asociados a reversiones hacia ambientes de baja inflación, lo que será profundizado en el próximo capítulo. 
Gráfico 5. Frecuencia de transición entre regímenes por régimen de origen

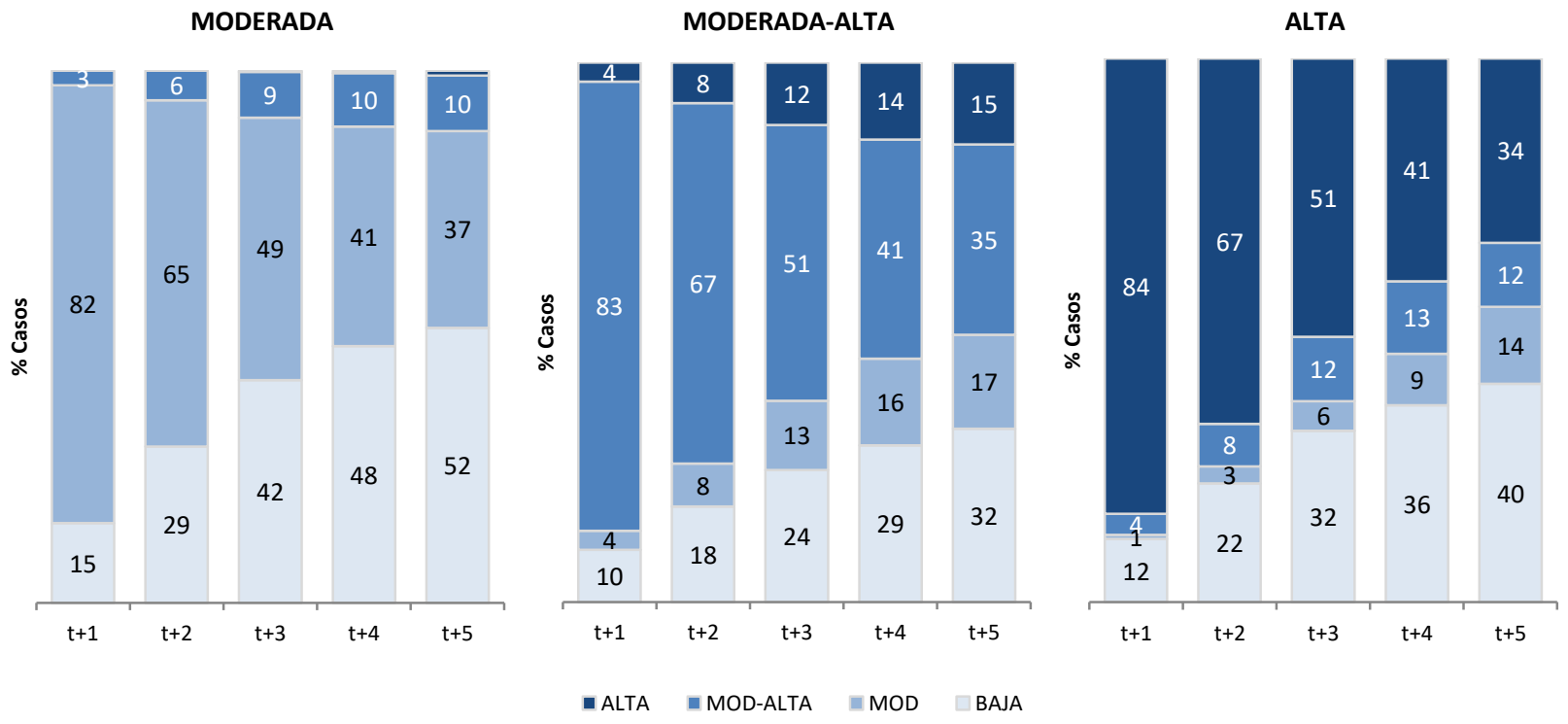

Fuente: elaboración propia en base a WDI

\section{CONCLUSIONES}

El capítulo presentado aquí parte de considerar que la inflación, cuando se presenta de manera persistente, es capaz de modificar ciertas características estructurales a nivel macroeconómico. Esta hipótesis no es novedosa y ha sido extensamente documentada en trabajos previos. La primera sección de este capítulo se ha ocupado de ofrecer una visión integrada de esta literatura, con el fin de obtener un panorama general sobre las modificaciones que ocurren en el funcionamiento de la economía cuando la inflación es un estado crónico. Existe evidencia de que mayores tasas de inflación se relacionan con ciertos patrones macroeconómicos específicos: una disminución de la profundidad de los mercados financieros incluyendo a la demanda de activos líquidos; dificultades para establecer un balance fiscal sostenible en el tiempo y, como contrapartida, una mayor propensión a recurrir al financiamiento monetario; la emergencia de prácticas indexatorias que aumentan la persistencia de los shocks; una mayor asociación entre las fluctuaciones del tipo de cambio y los precios internos; una amplificación de la volatilidad de precios relativos y una elevada dispersión de los mismos. En el largo plazo, estas distorsiones tienen efectos significativos sobre la tasa de crecimiento del producto, principalmente a través de una disminución de la tasa de inversión.

Se ha observado también que, desde el punto de vista teórico, gran parte de estos procesos incluyen alguna forma de causalidad circular: si bien el nivel de la inflación 
conlleva a que estos patrones sean más probables, una vez allí, los mismos convalidan y reafirman el proceso inflacionario y sirven para consolidar el régimen. El hecho de que estos cambios en el comportamiento refuercen el estado del sistema es un elemento central porque, cuando se intenta establecer una convergencia hacia otros estados, las condiciones generadas por la inflación crónica hacen que el mismo, tienda a retornar a su situación original. Las transiciones deben incluir, al menos transitoriamente, instrumentos para intervenir sobre cada uno de estos patrones con el fin de quebrar estas dinámicas, punto que será considerado en el siguiente capítulo cuando se analicen los procesos de desinflación de diferentes economías en América Latina.

En la segunda sección se analiza desde una perspectiva histórica la dimensión y magnitud de los procesos de inflación persistente. Lejos de resultar episodios aislados atribuibles a un número reducido de países, los mismos han sido un fenómeno particularmente difundido, al menos en ciertos períodos de tiempo a fines del siglo XX. Entre mediados de 1970 y fines de 1990 los procesos inflacionarios continuos afectaron por lo menos a un tercio de los países del mundo en cada uno de los años de la muestra. Es importante resaltar también que los fenómenos de inflación moderada, tal como fueron descriptos por ejemplo en Dornbusch y Fischer (1991), han tenido igual o mayor incidencia que los de más alta inflación, a pesar de tener un peso mucho más reducido en la literatura. Por otra parte, estos fenómenos se presentan como situaciones persistentes en el tiempo, lo que convalida la noción de "régimen" con la que se aborda el concepto de inflación en este trabajo.

\section{REFERENCIAS}

Alvarez, F; M. Beraja; M. Gonzalez-Rozada y Neumeyer, P. A. (2019) "From Hyperinflation to Stable Prices: Argentina's Evidence on Menu Cost Models," The Quarterly Journal of Economics, Volume 134, Issue 1, February 2019, pp. 451-505.

Barro, R. (1995) “Inflation and Growth” NBER Working Paper W5326 (Cambridge MA: National Bureau of Economic Research).

Boyd, John H.; R. Levine y Bruce D. Smith (2001) "The impact of inflation on financial sector performance”. Journal of Monetary Economics, Volume 47, Issue 2, 2001, Pages 221-248, ISSN 0304-3932, 
Bruno, M., and W. Easterley (1998) "Inflation crises and long-run growth" Journal of Monetary Economics, Volume 41, Issue 1, p. 3-26, ISSN 0304-3932

Bruno, Michael (1989) "Econometrics and the Design of Economic Reform" Econometrica, Vol. 57, No. 2 (Mar., 1989), pp. 275-306

Cagan, Phillip D. (1956) “The Monetary Dynamics of Hyperinflation”. En: Friedman, M., Ed., "Studies in the Quantity Theory of Money", The University of Chicago Press, Chicago, p. 25-117.

Choudhri, E.U., Hakura, D.S. (2006). “Exchange rate pass-through to domestic prices: does the inflationary environment matter?" Journal of International Money and Finance 25(4), 614-639.

Cukierman, A. (1984) "Inflation, stagflation, relative prices, and imperfect information". Cambridge: Cambridge University Press.

Dabús, C. (2000) "Inflationary Regimes and Relative Price Variability: Evidence from Argentina", Journal of Development Economics 62 (2): 535-547.

De Grauwe, P. y M. Polan (2005) "Is Inflation Always and Everywhere a Monetary Phenomenon?” The Scandinavian Journal of Economics, Vol. 107, No. 2 (Jun., 2005), pp. 239-259

Devereux, M., y Yetman, J. (2010). "Price adjustment and exchange rate passthrough”. Journal of International Money and Finance, 29, 181-200.

Devereux, Michael B. \& Yetman, James (2010). "Price adjustment and exchange rate pass-through," Journal of International Money and Finance, Elsevier, vol. 29(1), pages 181-200, February.

Dornbusch, Rüdiger and Fischer, Stanley, (1993) “Moderate Inflation” World Bank Economic Review, 7, issue 1, p. 1-44.

Edwards S. y F. Lefort (2002). "Stabilization, Persistence, and Inflationary Convergence: A Comparative Analysis," Central Banking, Analysis, and Economic 
Policies Book Series, in: Fernando Lefort, Klaus Schmidt-Hebbel y Norman Loayza (Series Editor) “Indexation, Inflation and Monetary Policy", edition 1, volume 2, chapter 3, pages 065-104. Central Bank of Chile.

Evans, M. (1991). "Discovering the link between inflation rates and inflation uncertainty”. Journal of Money, Credit, and Banking. No. 23, pp. 169-84.

Fischer, S.; Sahay, R. y C. Vegh (2002). “Modern Hyper- and High Inflations” Journal of Economic Literature, 40, issue 3, p. 837-880.

Friedman, M. (1977) 'Nobel lecture: Inflation and unemployment', Journal of Political Economy, 85 p. 451-472.

Fuji, Eiji y Jeannine Bailliu (2004). "Exchange Rate Pass-Through and the Inflation Environment in Industrialized Countries: An Empirical Investigation," Computing in Economics and Finance 2004 135, Society for Computational Economics.

Gagnon, Joseph y Jane Ihrig (2004) "Monetary policy and exchange rate pass-through" International Journal of Finance and Economics. Volume9, Issue4, p. 315-338 Ghosh, A. y Phillips, S. (1998) “Warning: Inflation May Be Harmful to Your Growth” IMF Staff Papers, Vol. 45, pp. 672-710.

Heymann, D. y A. Leijonhufvud (1995). "High inflation”. Oxford, New York, Clarendon Press ; Oxford University Press.

Heymann, D.; F. Navajas e I. Warnes (1991). "Conflicto distributivo y déficit fiscal algunos juegos inflacionarios” El Trimestre Económico, LVIII (1), issue 229, p. 101-137

Ibarra, R. y D. Trupkin (2016) "Reexamining the relationship between inflation and growth: Do institutions matter in developing countries?" Economic Modelling. Volume 52, Part B, Pages 332-351, ISSN 0264-9993

Julio G. H. Olivera (1967). "Money, Prices and Fiscal Lags: A Note on the Dynamics of Inflation". Quarterly Review. Banca Nazionale del Lavoro. 20: 258-267. 
Khan, M. S., and A.S. Senhadji (2001) "Threshold Effects in the Relationship Between Inflation and Growth," IMF Staff Papers, Vol. 48, pp 1-21.

Kocherlakota, N. y C. Phelan (1999). "Explaining the fiscal theory of the price level," Quarterly Review, Federal Reserve Bank of Minneapolis, issue Fall, pages 14-23.

Kremer, S.; Bick, A. y Nautz D. (2013) "Inflation and growth: new evidence from a dynamic panel threshold analysis" Empirical Economics. Volume 44, Issue 2, pp 861878.

Leijonhufvud, Axel (1997) “Macroeconomics and Complexity: Inflation Theory" In Brian Arthur, Steven Durlauf and David Lane, eds., The Economy as an Evolving Complex System II, Santa Fe Institute Studies in the Sciences of Complexity, Vol. XXVII, New York: Addison-Wesley, 1997

Lucas, R. E., Jr. (1973) “Some International Evidence on Output-Inflation Trade-offs", American Economic Review, 63, 326-334

Noriega, A. E.; C. Capistrán y M. Ramos-Francia (2012) “On the dynamics of inflation persistence around the world" Empirical Economics (2013) 44:1243-1265

Sarel, M. (1996) “Nonlinear Effects of Inflation on Economic Growth," IMF Staff Papers, Vol. 43, pp. 199-215.

Tanzi, Vito (1977) "Inflation, Lags in Collection, and the Real Value of Tax Revenue", Staff Papers, vol. 24. pp. 154-167.

Taylor, J.B. (2000). "Low inflation, pass-through, and the pricing power of firms". European economic review 44(7), 1389-1408.

Teles, P.; H. Uhlig y J. Valle e Azevedo (2016) “Is quantity theory still alive?" The Economic Journal,126 (March), 442-464.

Tommasi, M. (1994). "The Consequences of Price Instability on Search Markets: Toward Understanding the Effects of Inflation," American Economic Review, American Economic Association, vol. 84(5), pages 1385-96, December. 
ANEXO

Tabla 3. Regímenes de inflación moderada.

\begin{tabular}{|c|c|c|c|}
\hline País & Inicio & Fin & Duración \\
\hline \multirow[t]{2}{*}{ Argentina } & 1960 & 1968 & 9 \\
\hline & 2007 & 2017 & 11 \\
\hline Burkina Faso & 1977 & 1979 & 3 \\
\hline Bolivia & 1987 & 1991 & 5 \\
\hline Brasil & 1967 & 1975 & 9 \\
\hline \multirow[t]{2}{*}{ Chile } & 1965 & 1968 & 4 \\
\hline & 1981 & 1992 & 12 \\
\hline China & 1993 & 1995 & 3 \\
\hline \multirow[t]{2}{*}{ Congo, República Democrática del } & 1972 & 1975 & 4 \\
\hline & 2005 & 2008 & 4 \\
\hline Colombia & 1973 & 1998 & 26 \\
\hline \multirow[t]{2}{*}{ Costa Rica } & 1973 & 1975 & 3 \\
\hline & 1985 & 1992 & 8 \\
\hline Argelia & 1990 & 1996 & 7 \\
\hline \multirow[t]{2}{*}{ Ecuador } & 1985 & 1987 & 3 \\
\hline & 1994 & 1996 & 3 \\
\hline Egipto, República Árabe de & 1980 & 1991 & 12 \\
\hline España & 1974 & 1981 & 8 \\
\hline Etiopía & 1976 & 1979 & 4 \\
\hline Reino Unido & 1974 & 1977 & 4 \\
\hline \multirow[t]{4}{*}{ Ghana } & 1973 & 1975 & 3 \\
\hline & 1989 & 1994 & 6 \\
\hline & 1997 & 2005 & 9 \\
\hline & 2014 & 2016 & 3 \\
\hline Guinea & 2010 & 2012 & 3 \\
\hline \multirow[t]{2}{*}{ Grecia } & 1979 & 1987 & 9 \\
\hline & 1990 & 1992 & 3 \\
\hline Honduras & 1994 & 1997 & 4 \\
\hline \multirow[t]{3}{*}{ Haití } & 1973 & 1975 & 3 \\
\hline & 1990 & 1993 & 4 \\
\hline & 1995 & 1997 & 3 \\
\hline Hungría & 1988 & 1997 & 10 \\
\hline \multirow[t]{2}{*}{ Irlanda } & 1974 & 1976 & 3 \\
\hline & 1980 & 1982 & 3 \\
\hline \multirow[t]{4}{*}{ Irán, República Islámica del } & 1980 & 1983 & 4 \\
\hline & 1986 & 1993 & 8 \\
\hline & 1996 & 1999 & 4 \\
\hline & 2011 & 2014 & 4 \\
\hline Islandia & 1986 & 1990 & 5 \\
\hline Israel & 1987 & 1991 & 5 \\
\hline Italia & 1974 & 1983 & 10 \\
\hline \multirow[t]{3}{*}{ Jamaica } & 1973 & 1975 & 3 \\
\hline & 1984 & 1986 & 3 \\
\hline & 1993 & 1996 & 4 \\
\hline
\end{tabular}




\begin{tabular}{|c|c|c|c|}
\hline \multirow[t]{2}{*}{ Kenya } & 1974 & 1978 & 5 \\
\hline & 1990 & 1992 & 3 \\
\hline \multirow[t]{2}{*}{ Corea, República de } & 1974 & 1976 & 3 \\
\hline & 1979 & 1981 & 3 \\
\hline República Democrática Popular Lao & 1995 & 1997 & 3 \\
\hline \multirow[t]{2}{*}{ Lesotho } & 1977 & 1980 & 4 \\
\hline & 1989 & 1992 & 4 \\
\hline \multirow[t]{3}{*}{ México } & 1974 & 1981 & 8 \\
\hline & 1989 & 1992 & 4 \\
\hline & 1997 & 1999 & 3 \\
\hline \multirow[t]{3}{*}{ Myanmar } & 1973 & 1976 & 4 \\
\hline & 1987 & 1997 & 11 \\
\hline & 2006 & 2008 & 3 \\
\hline \multirow[t]{2}{*}{ Nigeria } & 1976 & 1978 & 3 \\
\hline & 1981 & 1984 & 4 \\
\hline \multirow[t]{2}{*}{ Nueva Zelandia } & 1980 & 1982 & 3 \\
\hline & 1985 & 1987 & 3 \\
\hline Pakistán & 1973 & 1975 & 3 \\
\hline Filipinas & 1971 & 1973 & 3 \\
\hline Polonia & 1995 & 1997 & 3 \\
\hline Portugal & 1974 & 1985 & 12 \\
\hline Paraguay & 1984 & 1994 & 11 \\
\hline Federación de Rusia & 2000 & 2002 & 3 \\
\hline \multirow[t]{2}{*}{ Sudán } & 1973 & 1975 & 3 \\
\hline & 1977 & 1982 & 6 \\
\hline Turquía & 1971 & 1977 & 7 \\
\hline \multirow[t]{2}{*}{ Tanzanía } & 1980 & 1983 & 4 \\
\hline & 1987 & 1997 & 11 \\
\hline Ucrania & 1997 & 2000 & 4 \\
\hline \multirow[t]{2}{*}{ Uruguay } & 1961 & 1963 & 3 \\
\hline & 1969 & 1971 & 3 \\
\hline Venezuela & 1999 & 2012 & 14 \\
\hline Sudáfrica & 1985 & 1991 & 7 \\
\hline Zambia & 1997 & 2005 & 9 \\
\hline
\end{tabular}

Tabla 4. Regímenes de inflación moderada-alta.

\begin{tabular}{lrrc} 
País & Inicio & Fin & Duración \\
\hline Argentina & 1971 & 1973 & 3 \\
Bulgaria & 1992 & 1995 & 4 \\
Belarús & 1996 & 1998 & 3 \\
Brasil & 1961 & 1966 & 6 \\
& 1976 & 1980 & 5 \\
Chile & 1969 & 1972 & 4 \\
& 1977 & 1980 & 4 \\
Congo, República Democrática del & 1976 & 1990 & 15 \\
Costa Rica & 1981 & 1983 & 3 \\
República Dominicana & 1988 & 1991 & 4 \\
Ecuador & 1988 & 1993 & 6 \\
& 1997 & 2001 & 5 \\
Ghana & 1976 & 1980 & 5
\end{tabular}




\begin{tabular}{lccc} 
Guinea-Bissau & 1988 & 1997 & 10 \\
Islandia & 1977 & 1985 & 9 \\
Israel & 1974 & 1979 & 6 \\
México & 1982 & 1986 & 5 \\
Mongolia & 1994 & 1997 & 4 \\
Nigeria & 1992 & 1995 & 4 \\
Perú & 1976 & 1982 & 7 \\
Polonia & 1991 & 1994 & 4 \\
Rumania & 1995 & 2001 & 7 \\
Sudán & 1983 & 1985 & 3 \\
& 1988 & 1990 & 3 \\
& 1995 & 1997 & 3 \\
Serbia & 2012 & 2014 & 3 \\
Suriname & 1995 & 2001 & 7 \\
Eslovenia & 1999 & 2001 & 3 \\
Turquía & 1981 & 1986 & 6 \\
Tanzanía & 1978 & 2002 & 25 \\
Uruguay & 1984 & 1986 & 3 \\
& 1964 & 1967 & 4 \\
Venezuela & 1972 & 1989 & 18 \\
Yemen, Rep. del & 1992 & 1995 & 4 \\
Zambia & 1989 & 1998 & 10 \\
& 1991 & 1996 & 6 \\
\hline
\end{tabular}

Tabla 5. Regímenes de inflación alta.

\begin{tabular}{lccc} 
País & Inicio & Fin & Duración \\
\hline Angola & 1992 & 2002 & 11 \\
Argentina & 1975 & 1991 & 17 \\
Azerbaiyán & 1993 & 1995 & 3 \\
Belarús & 1993 & 1995 & 3 \\
Bolivia & 1982 & 1986 & 5 \\
Brasil & 1981 & 1994 & 14 \\
Chile & 1973 & 1976 & 4 \\
Congo, República Democrática & & & \\
del & 1991 & 2001 & 11 \\
Croacia & 1987 & 1994 & 8 \\
Indonesia & 1962 & 1968 & 7 \\
Israel & 1980 & 1985 & 6 \\
República de Moldova & 1992 & 1994 & 3 \\
Perú & 1983 & 1985 & 3 \\
& 1988 & 1991 & 4 \\
Rumania & 1991 & 1994 & 4 \\
Federación de Rusia & 1993 & 1995 & 3 \\
Sudán & 1991 & 1994 & 4 \\
Suriname & 1993 & 1995 & 3 \\
Eslovenia & 1987 & 1992 & 6 \\
Ucrania & 1993 & 1995 & 3 \\
Venezuela & 2015 & 2017 & 3 \\
Zambia & 1989 & 1993 & 5 \\
\hline & & & \\
\hline
\end{tabular}




\title{
Capítulo II: Inflación Crónica Y Procesos de Desinflación en AMÉRICA LATINA
}

\author{
INTRODUCCIÓN
}

América Latina ha sido una de las regiones del mundo con mayor cantidad y duración de episodios de inflación crónica. Las trayectorias históricas de los países de la región son el lugar propicio para la identificación de tendencias que, al menos potencialmente, sirvan como guía para una comprensión más acabada de los desafíos a los que se enfrenta la política económica a la hora de establecer senderos permanentes hacia ambientes de baja inflación.

El estudio que se presenta a continuación aborda el análisis de 11 países de América Latina (Argentina, Bolivia, Brasil, Chile, Colombia, Ecuador, México, Perú, Uruguay y Venezuela) entre 1960 y 2017 . El capítulo se dividirá en dos partes: en la primera de ellas se analiza la recurrencia de ciertos patrones macroeconómicos en procesos de inflación crónica. En particular, se intentará observar la tendencia y persistencia de la inflación entre diferentes regímenes, la incidencia del mismo en la relación entre el tipo de cambio y los precios internos y, por último, las posibles interacciones entre la política monetaria y fiscal. El interés de esta sección no será, sin embargo, la mera identificación de estos fenómenos sino como elementos útiles para abordar el análisis de los procesos de transición entre diferentes estados. En otras palabras, el hecho de que estos patrones hayan formado parte relevante de los procesos de inflación crónica hace que los mismos deban posicionarse como un desafío para las transiciones hacia ambientes de baja inflación.

En la segunda sección se identifican los procesos de desinflación, entendiendo a los mismos como las desaceleraciones de cierta magnitud en la tasa de inflación. Dado que el interés está en distinguir aquellos que han sido capaces de establecer senderos hacia condiciones de inflación baja, se propone una clasificación de cada uno de estos episodios considerando el régimen de origen y al que llegaron una vez finalizado el proceso de desinflación. Con esta clasificación se intentará observar elementos comunes en las transiciones en función de los patrones macroeconómicos observados en la primera sección. En particular se analizarán tres elementos: el resultado fiscal al inicio de las desinflaciones, el rol del tipo de cambio durante las mismas y la velocidad. Se intentará con ello dar un panorama general sobre ciertas características observables de las transiciones hacia regímenes de inflación baja. 


\section{PATRONES MACROECONÓmicos OBSERVAdOS}

Los países de América Latina han registrado procesos recurrentes de inflación elevada en la segunda mitad del siglo XX. Como puede observarse en el Gráfico 6, la inflación no ha sido un fenómeno esporádico, sino que generalmente se ha prolongado en el tiempo a diferentes niveles entre los diferentes países de la región. Por otra parte, un conjunto significativo de estas economías realizó transiciones plenas hacia regímenes de baja inflación, lo que ofrece experiencia útil sobre el diseño de las mismas.

Gráfico 6. Regímenes de inflación por país según año

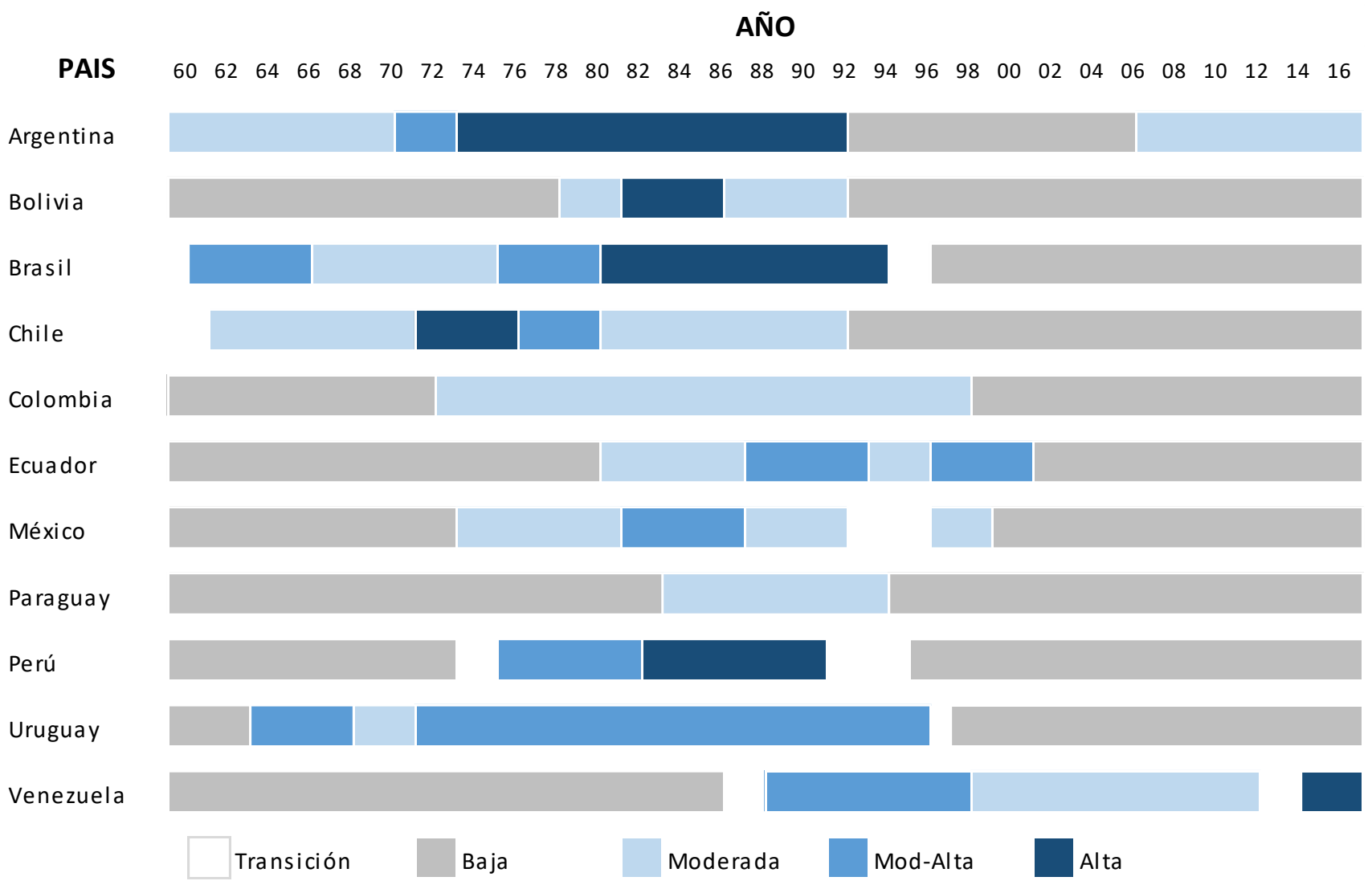

Fuente: Elaboración propia

Una de las características observables de estos procesos, al menos de la forma en la que se han presentado en estos países, es que las transiciones a estados de alta inflación fueron en todos los casos precedidas por un proceso de inflación crónica previo: Argentina mostró dinámicas de inflación moderada durante toda la década del 60 , haciendo una transición breve a moderada-alta antes de registrar casi dos décadas de alta inflación (la más prolongada de la región). Fenómenos similares ocurrieron en 
Bolivia, Brasil, Perú y Venezuela. Las condiciones que hacen que una economía ingrese en un régimen de alta inflación parecen, con esto, no emerger de la nada, sino más bien estar precedidas por un proceso paulatino que le sirve de transición.

A continuación, se aborda el análisis de los procesos de inflación crónica en estas economías a través de tres dimensiones (la tendencia y persistencia de los procesos de inflación, la asociación entre la tasa de devaluación y los precios internos y las interacciones fiscales y monetarias) con el fin de extraer elementos útiles para el análisis de los procesos de desinflación.

\section{Tendencia y persistencia}

El estudio de la evolución del proceso inflacionario y su tendencia ofrece información relevante del comportamiento de esta variable en cada uno de los regímenes. Siguiendo a Andrews y Chen (1992) una aproximación estadística a los problemas de convergencia surge de considerar a la tasa de inflación como un proceso de orden $p(A R(p))$ que puede definirse como:

$$
\pi_{t}=\alpha+\sum_{j=1}^{p} \psi_{j} \pi_{t-j}+\epsilon_{t}
$$

Donde $\pi_{t}$ es la tasa de inflación. Trabajando sobre los términos es posible reescribir esta ecuación como:

$$
\Delta \pi_{t}=\sum_{j=1}^{p-1} \delta_{j} \Delta \pi_{t-j}+(\rho-1)\left(\pi_{t-1}-\mu\right)+\epsilon_{t}
$$

Donde:

$$
\rho=\sum_{j=1}^{p} \psi_{j} \quad \delta_{j}=-\sum_{i=1+j}^{p} \psi_{i} \quad \mu=\alpha /(1-\rho)
$$

La ecuación (2) ha sido habitual para considerar la persistencia de los procesos inflacionarios. En particular, si el proceso es convergente $(0<\rho<1)$ un incremento de $\rho$ hace que los desvíos respecto de la media se corrijan más lentamente 0 , en otras palabras, ante un shock en la tasa de inflación la misma converge a la media a menor velocidad cuanto mayor es el tamaño de este coeficiente. Existen sin embargo dos problemas asociados a esta forma de considerar la persistencia, relacionados con la identificación precisa del proceso generador de datos subyacente a la estimación. 
En el contexto de la ecuación (2) la persistencia es, básicamente, una propiedad de reversión a la media, por lo que el primer desafío a considerar es si estos procesos se caracterizan por mantener una misma media a lo largo del tiempo. Noriega y Capistran (2012) muestran que a medida que la inflación se incrementa los procesos inflacionarios tienden a no converger a una media constante (en términos estadísticos, no es posible caracterizar a esta variable como un proceso integrado de orden cero). La alternativa analítica propuesta es analizar si la aceleración de dicha variable es estable (es decir, si la inflación es un proceso integrado de primer orden), lo que se cumple en episodios donde se incrementa la tasa de inflación.

En el Gráfico 7 se presenta la variación interanual del Índice de Precios al Consumidor para cada una de las 11 economías de América Latina expresada de manera mensual (es decir, aplicando una media geométrica para los doce meses del año). Esta expresión de las tasas permite analizar tendencias evitando los grandes picos ocasionados por los procesos de muy alta inflación. Adicionalmente, se calculó para cada uno de estos países una tendencia de Hodrick-Prescott, con el fin de analizar la posibilidad de considerar a la media de estos procesos como un elemento constante, lo que resulta necesariamente rechazado por el análisis de cada una de estas series.

Analizando solamente la tendencia, se observa que las economías han mantenido diferencias muy significativas del nivel de la tasa de inflación "media" o "tendencial" a lo largo del tiempo. Las aceleraciones y desaceleraciones de las mismas han sido una regla mucho más que la excepción. Esto no sería un problema, si se considera que hacia el interior de cada régimen el proceso resulta convergente, pero esto no parece adecuarse a los fenómenos observados. En general, durante los procesos de alta inflación se observan grandes oscilaciones de la tasa de crecimiento de los precios, donde la tendencia o la media en sí misma es una referencia más bien difusa del comportamiento de la variable. Los procesos de alta inflación pueden caracterizarse mejor como situaciones donde la tasa de inflación carece de una media constante, las fluctuaciones ocurren en gran magnitud y a diferentes velocidades (esto se observa claramente en las fuertes oscilaciones registradas en Argentina, Brasil, Bolivia, Chile, Perú y, en menor medida, Venezuela). En los países o momentos donde la inflación se mantuvo en regímenes de moderada-alta (principalmente Ecuador y Uruguay) y moderada (principalmente en Colombia y durante un tiempo en Chile y recientemente en Argentina) los procesos mantienen una elevada volatilidad, pero la tendencia se mantiene como una referencia más próxima al proceso inflacionario. En el extremo, los países donde se consiguieron transiciones a baja inflación el proceso d2 pueden caracterizarse como una convergencia a una media constante. 


\section{Gráfico 7. Inflación interanual mensualizada y tendencia.}
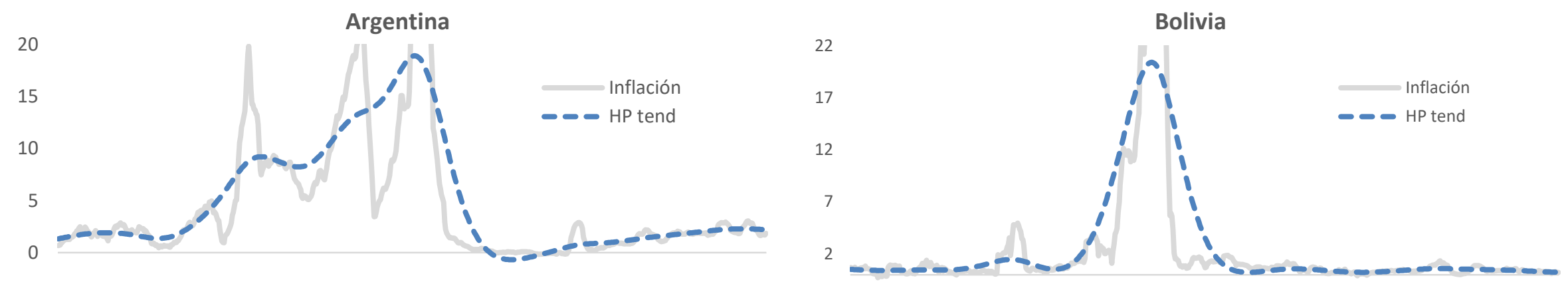

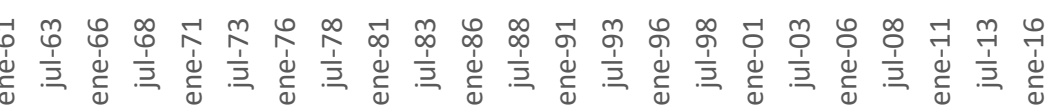

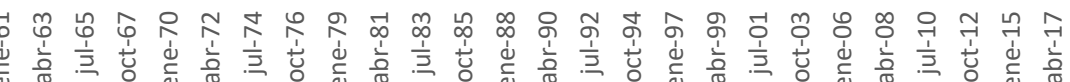

Chile

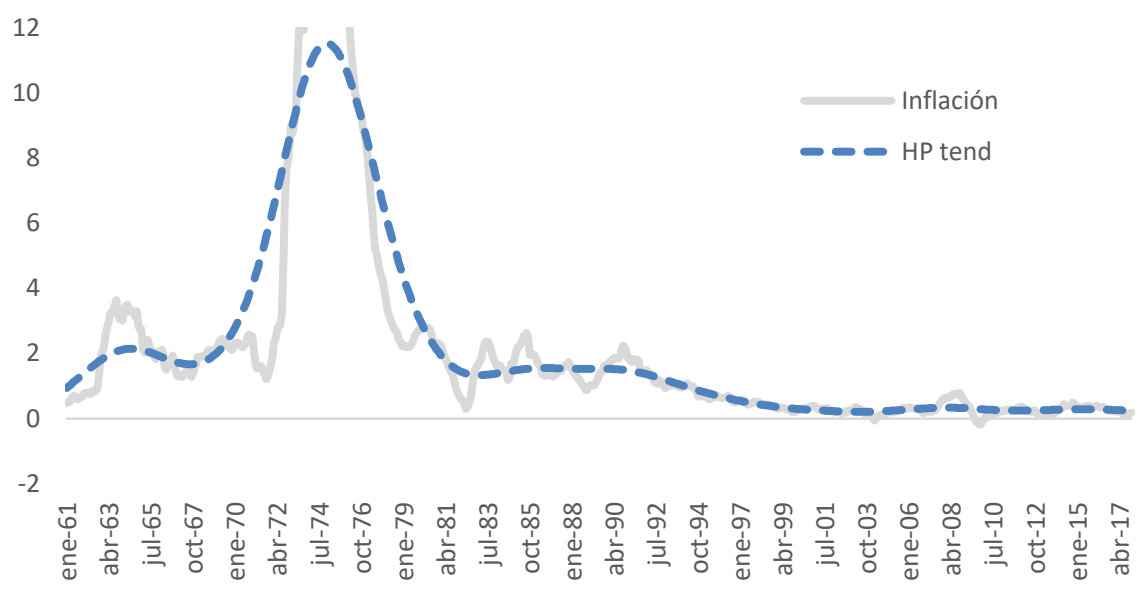

Fuente: Elaboración propia 


\section{Gráfico 7 (continuación). Inflación interanual mensualizada y tendencia.}
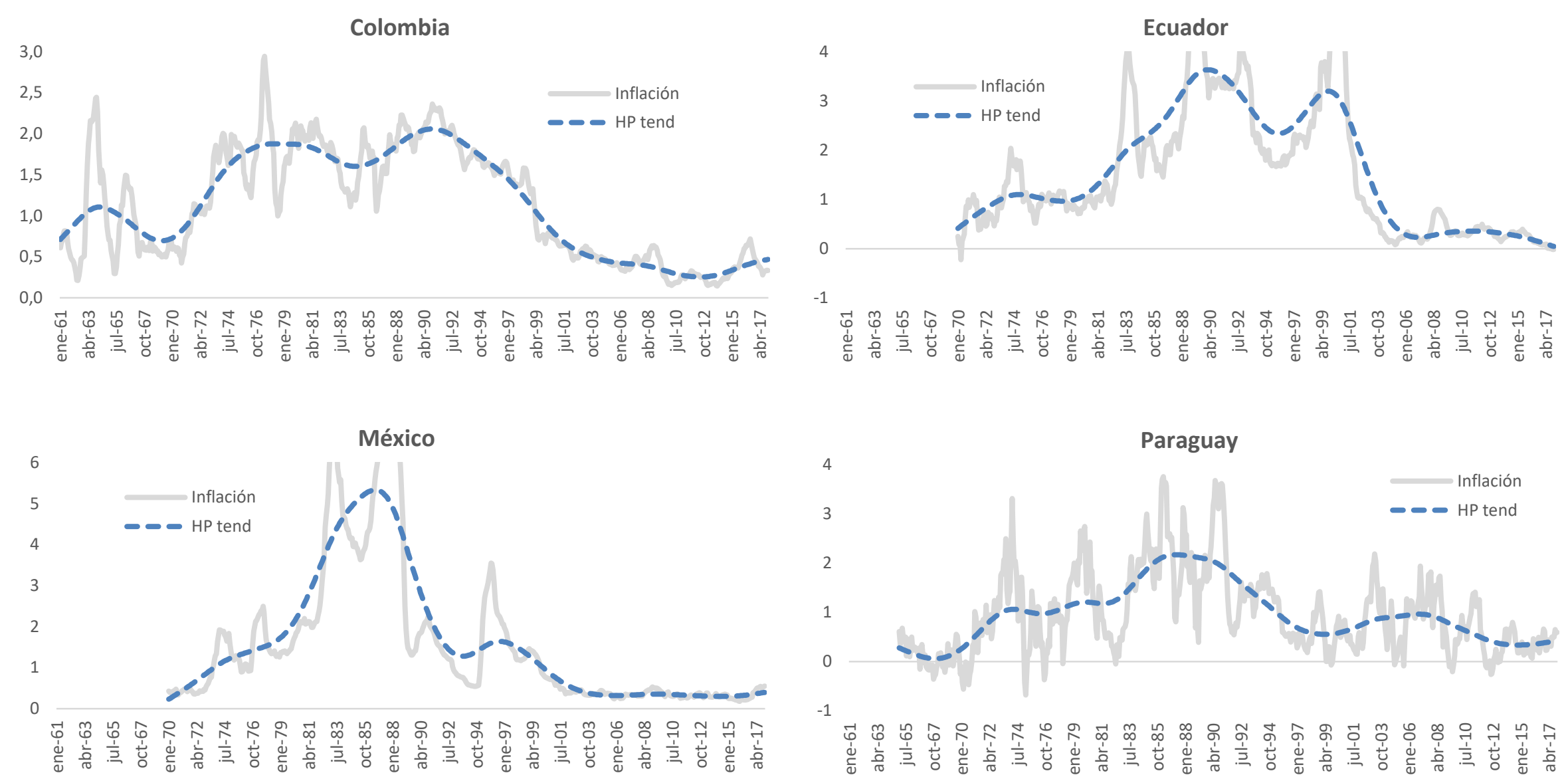

Fuente: Elaboración propia 


\section{Gráfico 7 (continuación). Inflación interanual mensualizada y tendencia.}
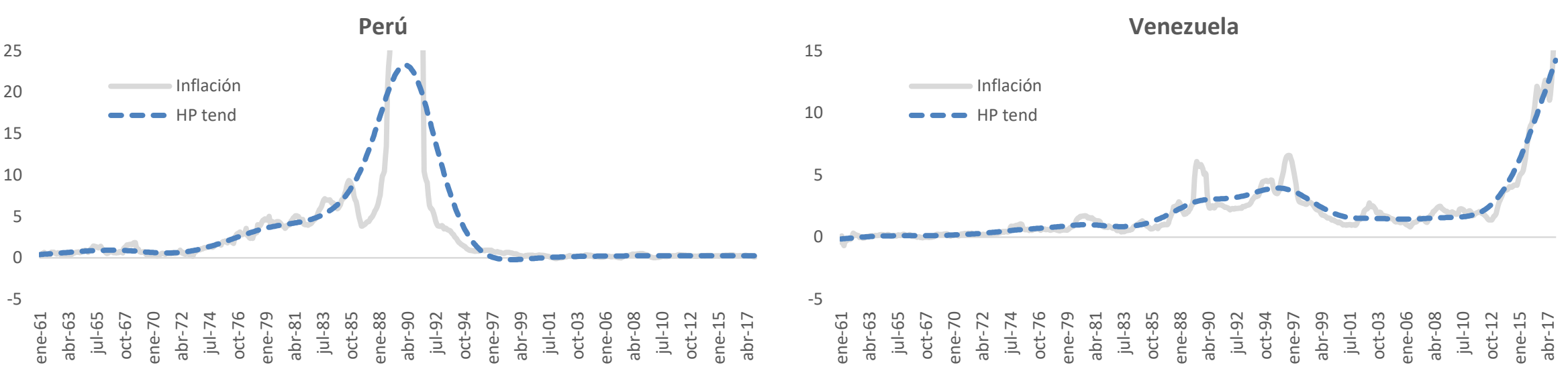

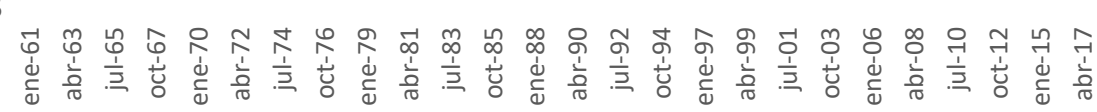

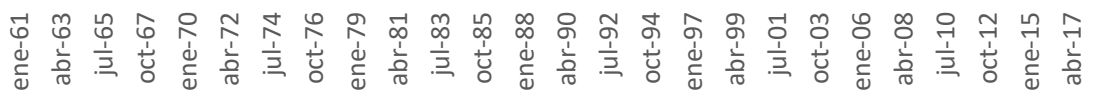

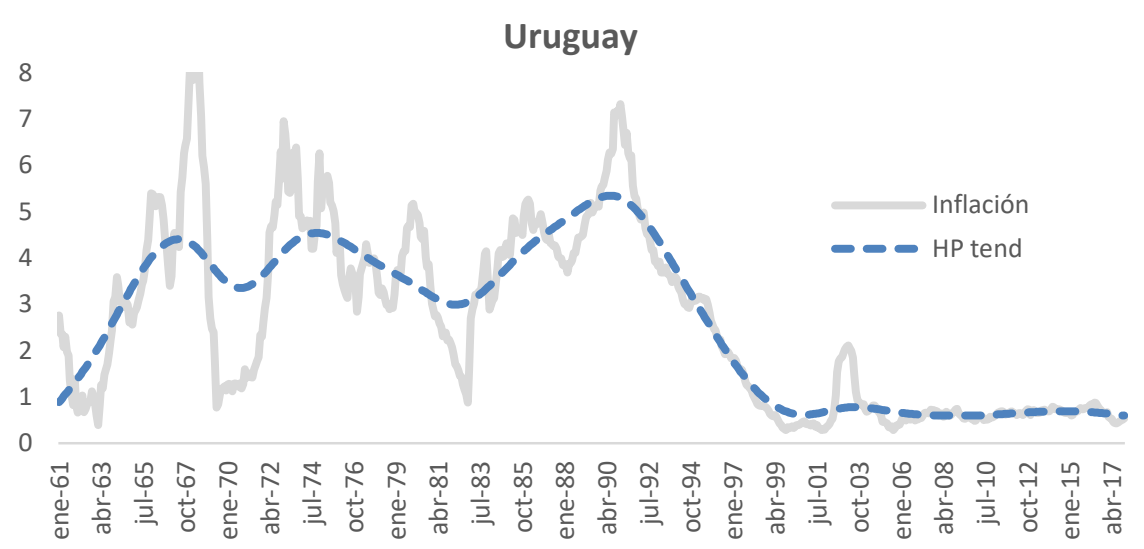

Fuente: Elaboración propia 
La variabilidad de la tendencia de estos procesos y su dispersión tienen efectos sobre la forma en la que se determina la medición de la persistencia. Una vez más, este concepto necesariamente está asociado a la velocidad de convergencia a la media o, en este caso, a la tendencia del proceso, que se encuentra implícita en la estimación del coeficiente $\rho$. La medición de este coeficiente es sensible tanto a la estimación de la tendencia como al número de rezagos incluidos en la estimación. Con el fin de evitar este inconveniente, Marques (2005) propone una medida de persistencia alternativa dada por:

$$
\hat{\gamma}=1-n / T
$$

Donde $n$ es el número de veces que en un periodo $T$ de tiempo en la que el proceso inflacionario cruza la tendencia.

En el Gráfico 8 se muestran los resultados de la estimación del coeficiente en ventanas móviles de 5 años y su tendencia suavizada. Confirmando los resultados obtenidos de manera visual en las estimaciones de tendencia, la alta inflación y, en menor medida, la inflación moderada-alta, muestran oscilaciones de gran magnitud que desaparecen solo paulatinamente en el tiempo, lo que se asocia con un aumento de la persistencia. Los regímenes de mayor inflación se asocian necesariamente a un incremento de la persistencia observada de los shocks.

Como contrapunto, la inflación baja no necesariamente es sinónimo de menor persistencia: existen en ambientes de baja inflación oscilaciones de gran magnitud que se prolongan en el tiempo, lo que en la práctica hace que se observe un incremento de la persistencia: Chile y Colombia en 1998 muestran patrones de aumento de la persistencia en el contexto de la crisis asiática o Bolivia y Colombia en el año 2008. Por otra parte, existen economías donde el descenso de la tendencia en la tasa de inflación está asociado a una menor persistencia, pero la misma se encuentra en niveles elevados respecto de otras economías en esta misma situación (por ejemplo: Brasil, Chile y Ecuador en las últimas décadas).

En líneas generales, a medida que la economía se posiciona en regímenes de más alta inflación no solo se altera la tendencia del proceso inflacionario sino también la amplitud de las oscilaciones. El hecho de que las fluctuaciones se conviertan en fenómenos más amplios y duraderos hace que las mediciones convencionales de persistencia se incrementen, pero este resultado debería tomarse con precaución, considerando que, por lo dicho previamente, los regímenes de mayor inflación no se caracterizan por procesos lineales de reversión a una media estable sino más bien por una amplia volatilidad y cambios en la tendencia. 
Gráfico 8. Estimación del coeficiente de persistencia en ventanas móviles (5 años) y tendencia suavizada.
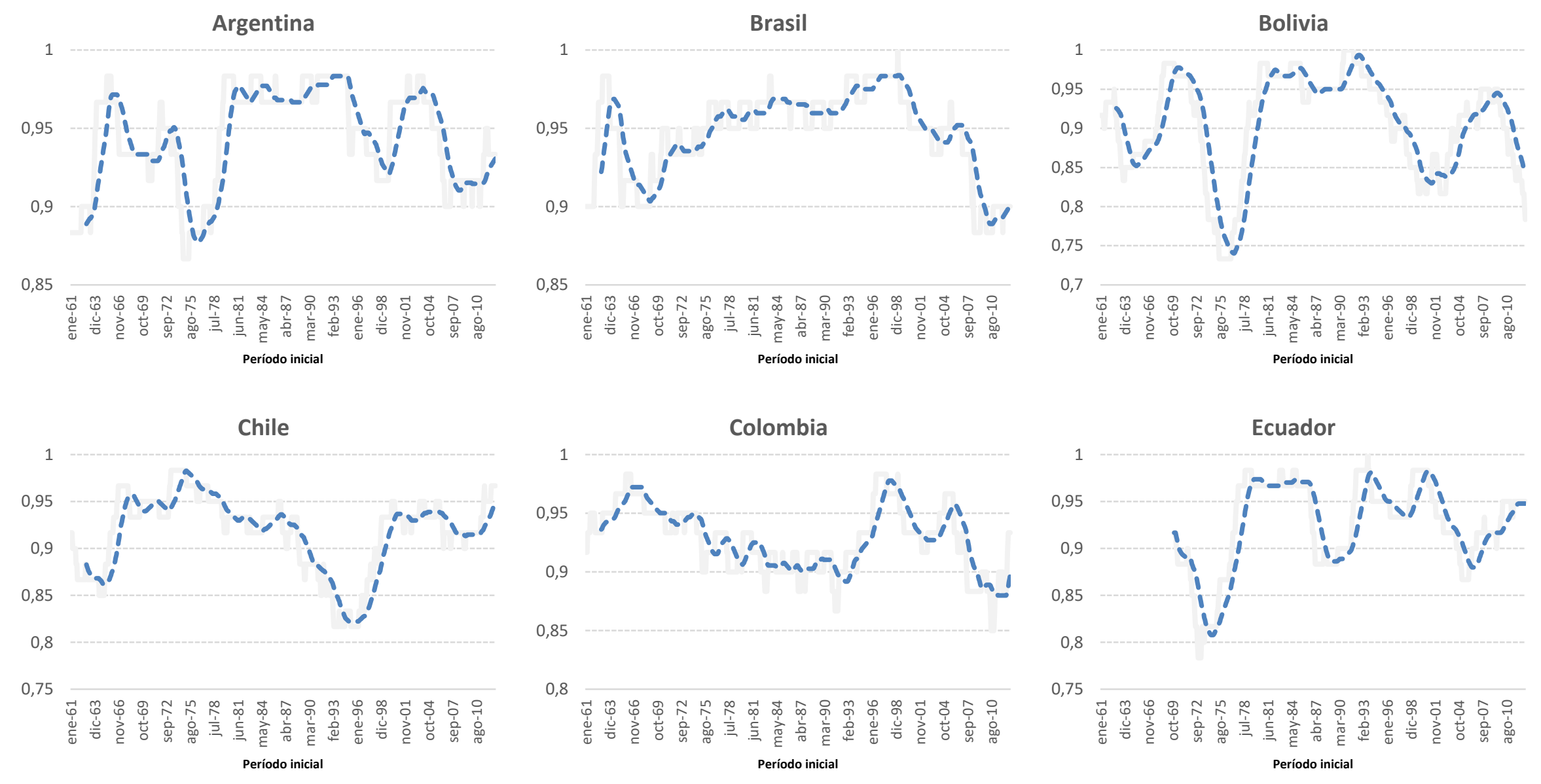

Fuente: Elaboración propia 
Gráfico 8 (continuación). Estimación del coeficiente de persistencia en ventanas móviles (5 años) y tendencia suavizada.
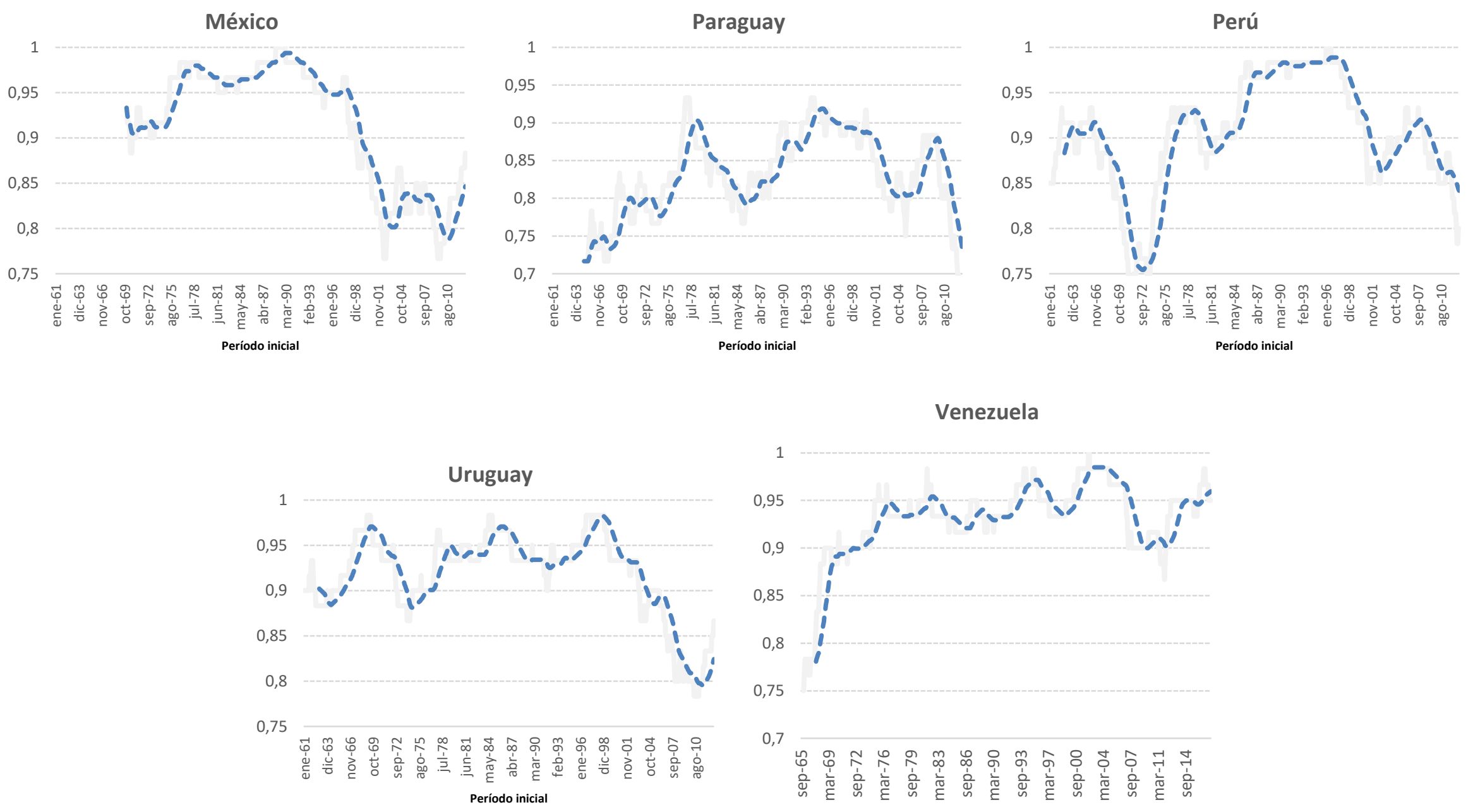

Fuente: Elaboración propia 


\section{Interacciones fiscales y monetarias}

Considerar a la inflación como un proceso sujeto a shocks exógenos deja pocos elementos para la definición sobre aquellos elementos que son relevantes en la formación de precios o que, al menos desde la práctica, deberían considerarse con atención a la hora de caracterizar su comportamiento en diferentes condiciones.

En el primer capítulo se consideró que establecer una relación causal que vincule el financiamiento monetario del déficit fiscal a la tasa de inflación resulta difuso, en tanto existen razones para considerar que la dirección de la relación puede revertirse. En todo caso, en estados de inflación crónica los desequilibrios fiscales deberían ser más recurrentes (y posiblemente más agudos) y, dado el progresivo estrangulamiento de los mercados financieros, el financiamiento de los mismos a través del señoreaje debería ser una condición más frecuente.

La relación entre la política fiscal y la política monetaria, puede identificarse a través de la restricción presupuestaria del sector público consolidado (esto es, incluyendo al Banco Central):

$$
D_{t}+R_{t-1} B_{t-1}=\left(B_{t}-B_{t-1}\right)+\left(M_{t}-M_{t-1}\right)
$$

Donde $D_{t}$ es el desahorro corriente, $B_{t}$ los activos netos del sector público consolidado, $R_{t}$ la tasa de interés promedio ponderada de los mismos y $M_{t}$ la base monetaria. Una forma de observar esta relación es el hecho de que, ante la ausencia de financiamiento mediante los mercados de crédito, el déficit financiero (termino que se encuentra a la izquierda de la ecuación) debe ser financiado a través del señoreaje.

Esta restricción de presupuesto ha sido utilizada para argumentar que la posibilidad de disociar la política fiscal de la política monetaria depende de la capacidad de endeudamiento del sector público, lo que se conoce habitualmente como la "desagradable aritmética monetarista" (debido al trabajo de Sargent y Wallace, 1981). El principal desafío en este caso es que las relaciones presupuestarias no necesariamente conllevan a una identificación precisa de causalidad. Como fue detallado en el capítulo anterior, los estados de inflación crónica deberían ser situaciones donde el sistema presupuestario es más débil y existen más chances de incurrir en desbalances fiscales, pero además donde es más complejo acceder a los mercados financieros por el acortamiento del horizonte de planeamiento. Independientemente de la relación causal, las interacciones entre déficit fiscal y 
señoreaje deberían resultar más estrechas en ambientes de inflación crónica. Para evaluar esta hipótesis, se estima una regresión del tipo

$$
s_{i t}=\tau+\left(\theta+\sum_{j} \theta^{j} D_{i, t}^{j}\right) d_{t}+\epsilon
$$

Donde $s_{i t}$ es el señoreaje y $d_{i t}$ déficit financiero, ambos como porcentaje del producto, para el país $i$ en el año $t, D_{i, t}^{j}$ es una variable dicotómica que identifica el régimen de inflación (moderada, moderada-alta, alta) para cada país y período del tiempo $^{3}$. Los resultados de la regresión se detallan en el anexo, mientras que en el Gráfico 9 se ilustran los mismos. Se encuentra evidencia a favor de la relación más estrecha entre ambas variables en contextos de inflación crónica, que a su vez resulta creciente con la intensidad del proceso inflacionario. Esta regularidad empírica agrega un elemento adicional a los desafíos de la transición que, al igual que las oscilaciones respecto de la paridad cambiaria, parecen agravarse a medida que la economía ingresa en estados de mayor inflación.

Gráfico 9. Relación entre inflación y señoreaje según régimen.

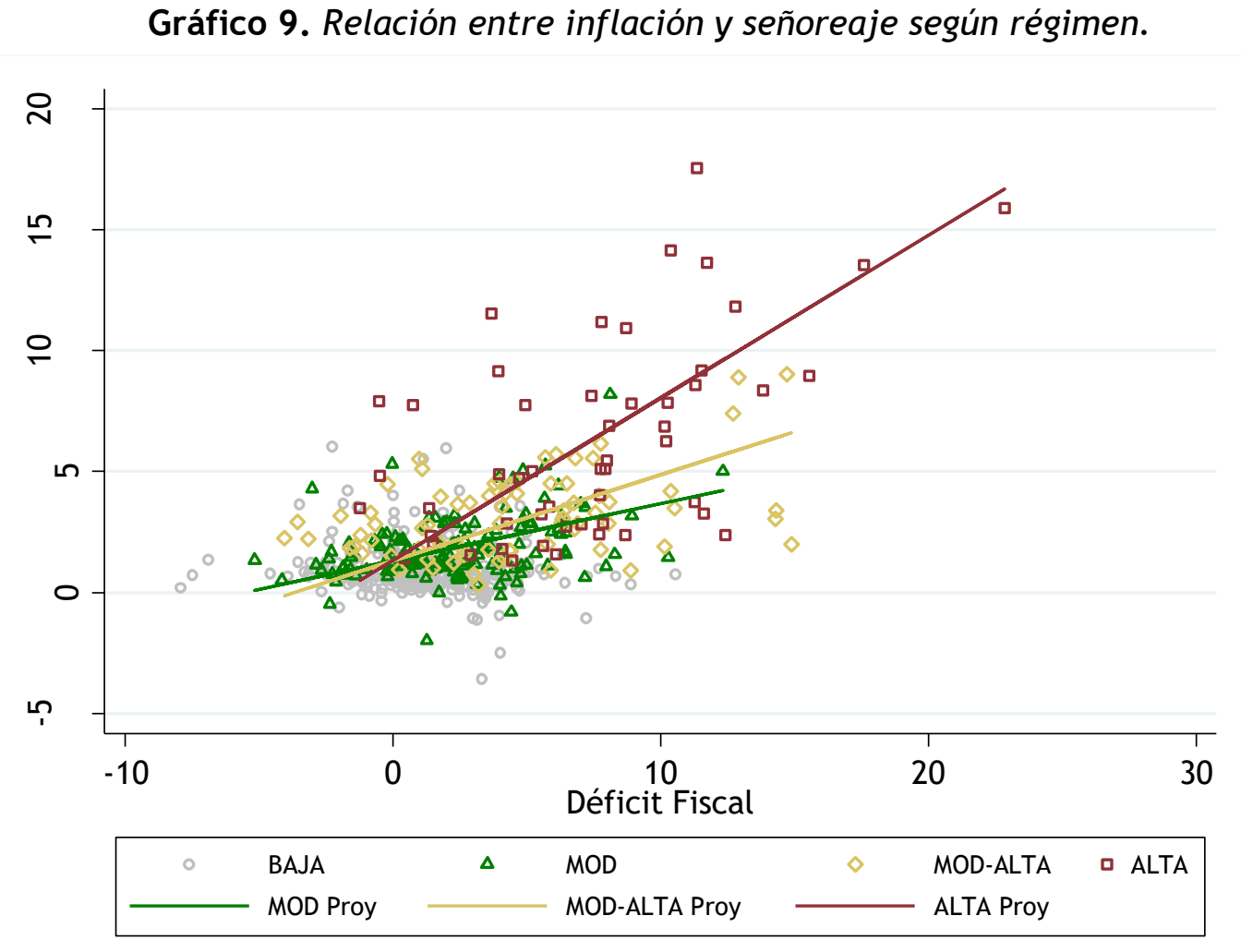

Fuente: Elaboración propia

\footnotetext{
${ }^{3}$ La información para estas variables fue obtenida de fuentes nacionales combinadas con los datos de proyecto "The Monetary and Fiscal History of Latin America" del Becker Friedman Institute de la Universidad de Chicago.
} 
Trabajando con la restricción de presupuesto planteada en (6) para desarrollarla en términos reales es posible observar:

$$
d_{t}+r_{t-1} b_{t-1}=\left(b_{t}-b_{t-1}\right)+\left(m_{t}-m_{t-1}\right)+\frac{\pi_{t}}{\left(1+\pi_{t}\right)} m_{t-1}
$$

Donde las variables en minúscula representan las magnitudes reales. Como puede observarse es posible descomponer el señoreaje en dos términos: la variación en la demanda de dinero y el así llamado "impuesto inflacionario". Si la política fiscal decide financiarse a través del señoreaje y la demanda de dinero no es infinitamente elástica, una parte de la extracción de recursos debería provenir de la pérdida de poder adquisitivo del dinero. Como puede observarse en el Gráfico 10, no es posible rechazar que la demanda de dinero haya mostrado límites frente a la obtención de señoreaje.

Gráfico 10. Señoreaje e Impuesto inflacionario.

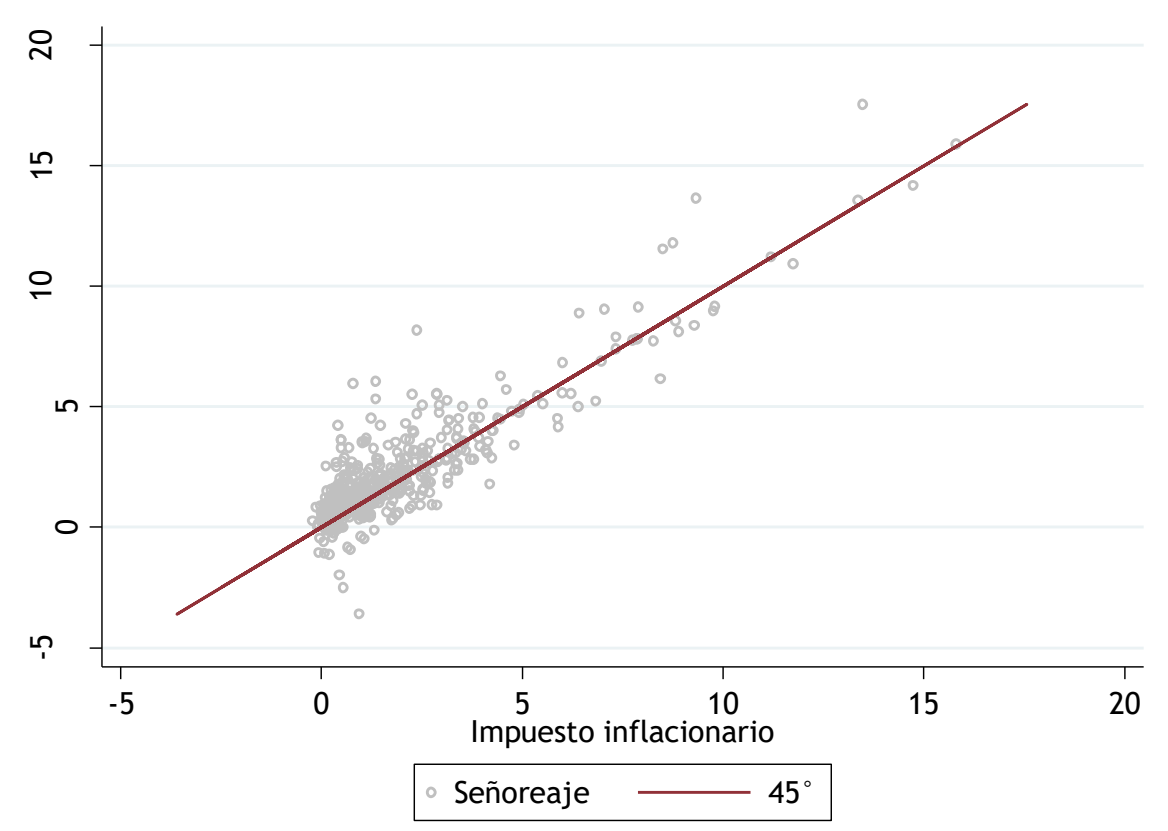

Fuente: Elaboración propia

\section{Devaluación y precios internos}

Si bien el manejo de la liquidez es un elemento central para el manejo de la política monetaria, existen otros elementos relevantes que inciden sobre la formación de precios en procesos de inflación crónica y afectan su diseño. Existen en este sentido ciertos precios relativos que cumplen un rol central en la coordinación del proceso de 
formación de precios, de los cuales sin dudas el tipo de cambio ha sido uno de los más importantes. Un fenómeno documentado en la literatura es el hecho de que, a medida que la inflación se incrementa, los precios internos suelen tener una mayor asociación con las oscilaciones del tipo de cambio.

Los países de la región no parecen haber sido la excepción a esta regularidad empírica. En el Gráfico 11 se presentan los coeficientes de correlación entre la tasa de inflación y la tasa de devaluación interanual que surgen de una estimación lineal de una regresión simple en ventanas móviles de quince años para cada uno de los once países de la región. Durante los períodos de alta inflación, países como Argentina, Bolivia, Brasil, Chile y Perú muestran un fuerte incremento de la asociación entre ambas variables, con valores cercanos a la unidad. Una situación similar se observa en el caso de economías que mostraron regímenes de inflación moderada-alta como México, Ecuador y Uruguay, en los dos primeros casos con asociaciones que no alcanzaron los niveles observados en países de alta inflación. En el caso de las economías que permanecieron durante períodos prolongados en inflación moderada, como Colombia o Paraguay y en algunos períodos en Chile las correlaciones suelen encontrarse en un rango positivo, pero marcadamente inferior al de los restantes regímenes.

Las estabilizaciones a ambientes de baja inflación muestran disminuciones de las correlaciones, mostrando en la actualidad valores cercanos a cero para la mayor parte de los países que consiguieron mantener períodos prolongados de inflación baja (como Brasil, Chile, Colombia, México, Perú o Uruguay) o aún la particularidad de mostrarse negativos (como Paraguay y Bolivia) ${ }^{4}$. En las economías que volvieron a encontrarse en ambientes de inflación crónica, como Argentina (moderada) y Venezuela (alta), vuelve a observarse un incremento de las correlaciones entre las fluctuaciones del tipo de cambio y los precios internos.

Una forma diferente de observar la relación entre la tasa de devaluación y la inflación es considerar la muestra de todos los países de manera conjunta. El Gráfico 12 muestra los coeficientes de correlación incluyendo los intervalos de confianza para el total de los países de la muestra considerados de manera conjunta de acuerdo al régimen de inflación. La evidencia muestra un incremento significativo de los coeficientes a medida que las economías se encuentran en regímenes de inflación más agudos, lo que solo sirve para reafirmar la evidencia observacional encontrada para cada una de las economías por separado.

\footnotetext{
${ }^{4}$ Se excluyen aquí los últimos años de Ecuador por considerar que las correlaciones pierden sentido en el contexto de un país dolarizado.
} 


\section{Gráfico 11. Correlación entre tasa de devaluación e inflación (ventanas móviles 15 años).}

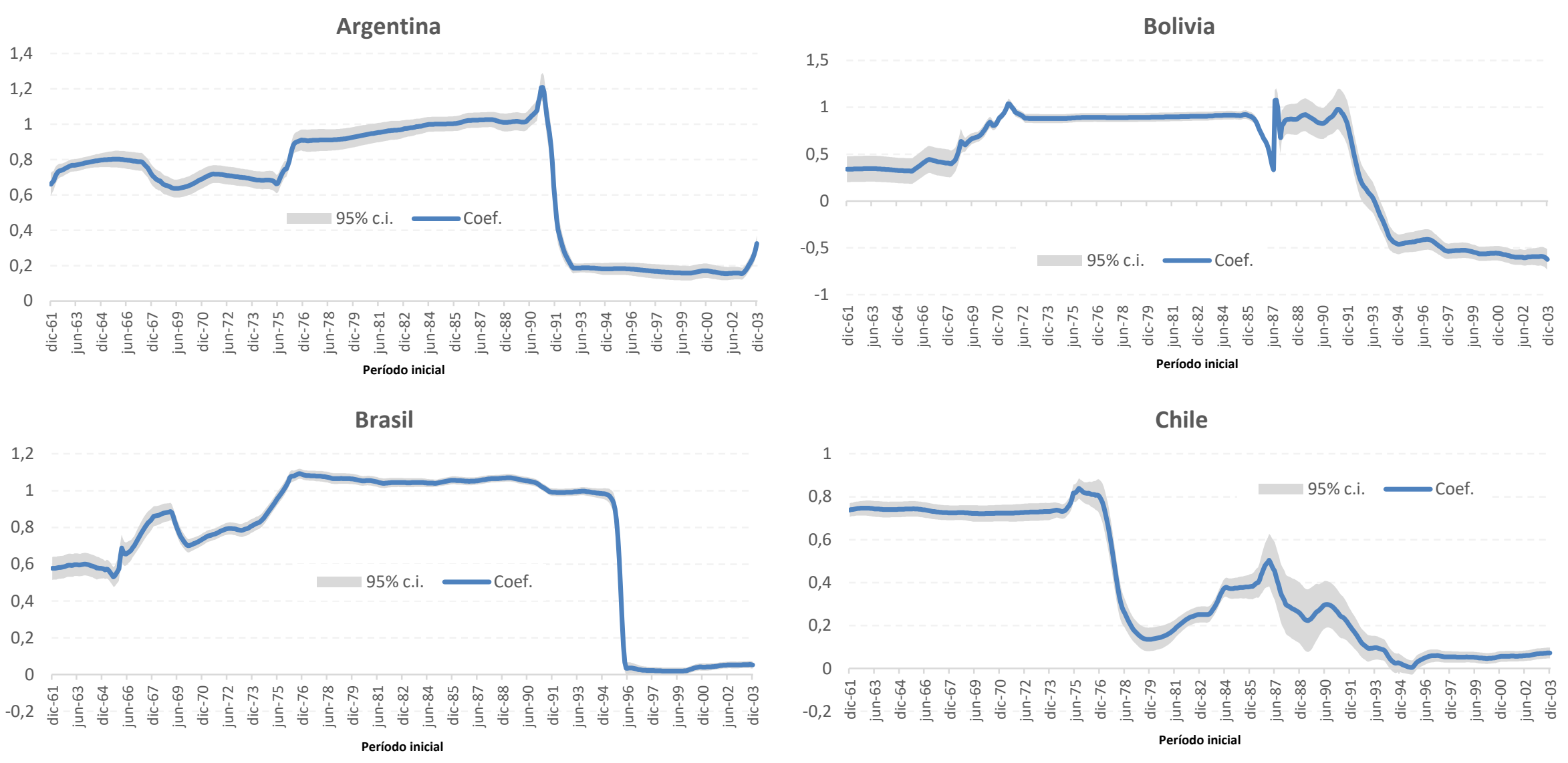

Fuente: Elaboración propia 
Gráfico 11 (continuación). Correlación entre tasa de devaluación e inflación (ventanas móviles 15 años).
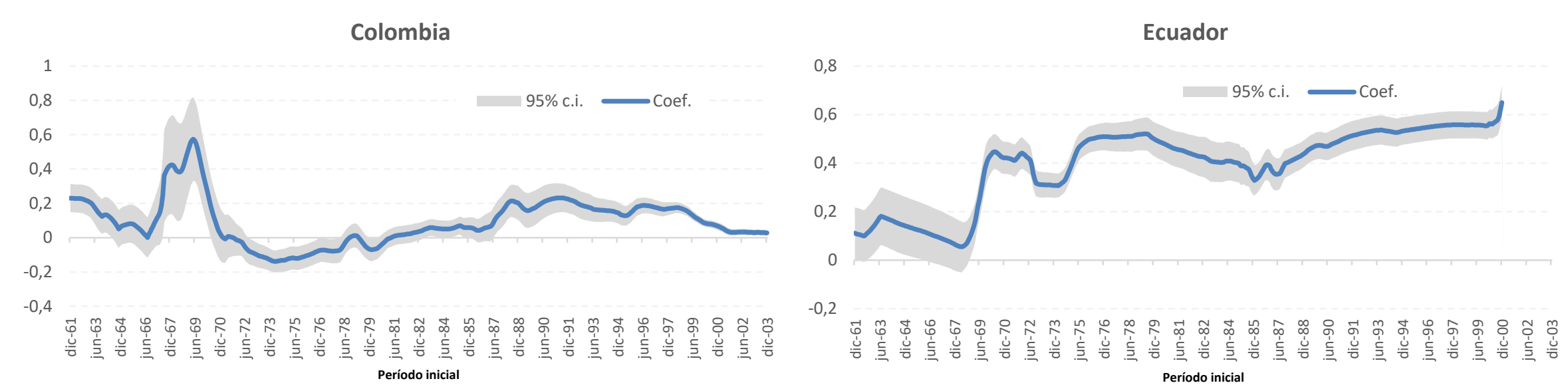

México
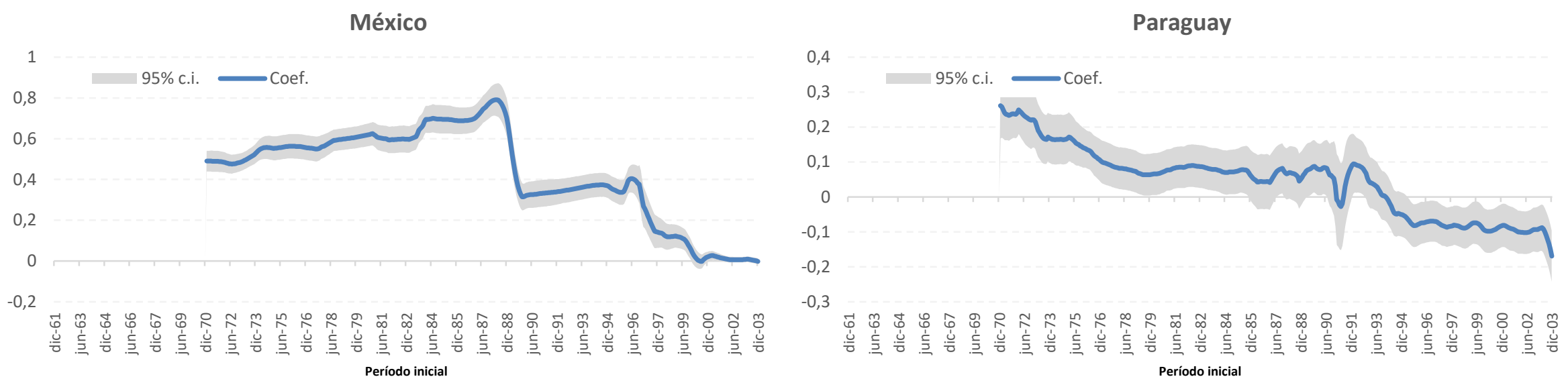

Fuente: Elaboración propia 
Gráfico 11 (continuación). Correlación entre tasa de devaluación e inflación (ventanas móviles 15 años).
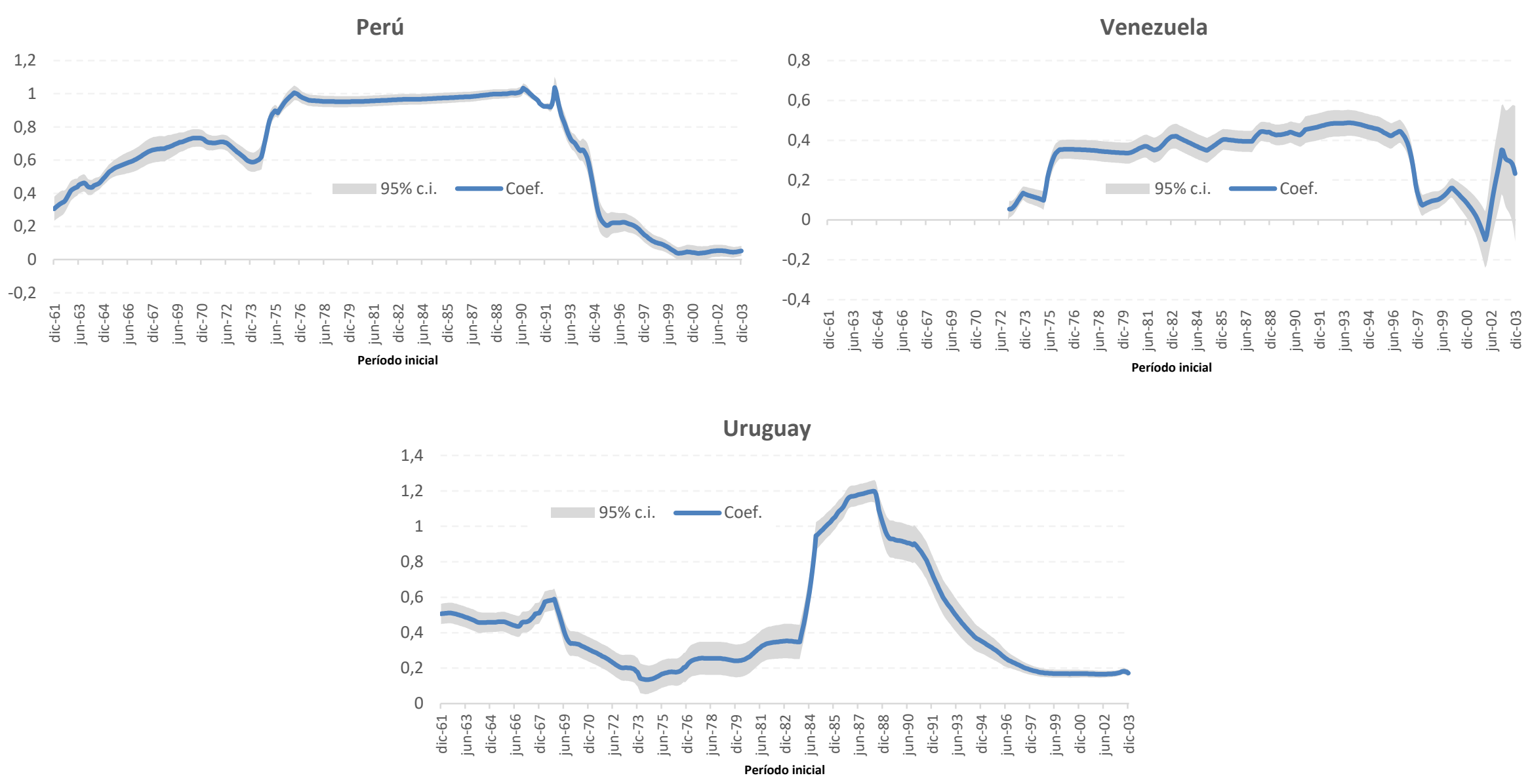

Fuente: Elaboración propia 
Gráfico 12. Coeficiente de correlación entre inflación y devaluación por régimen.

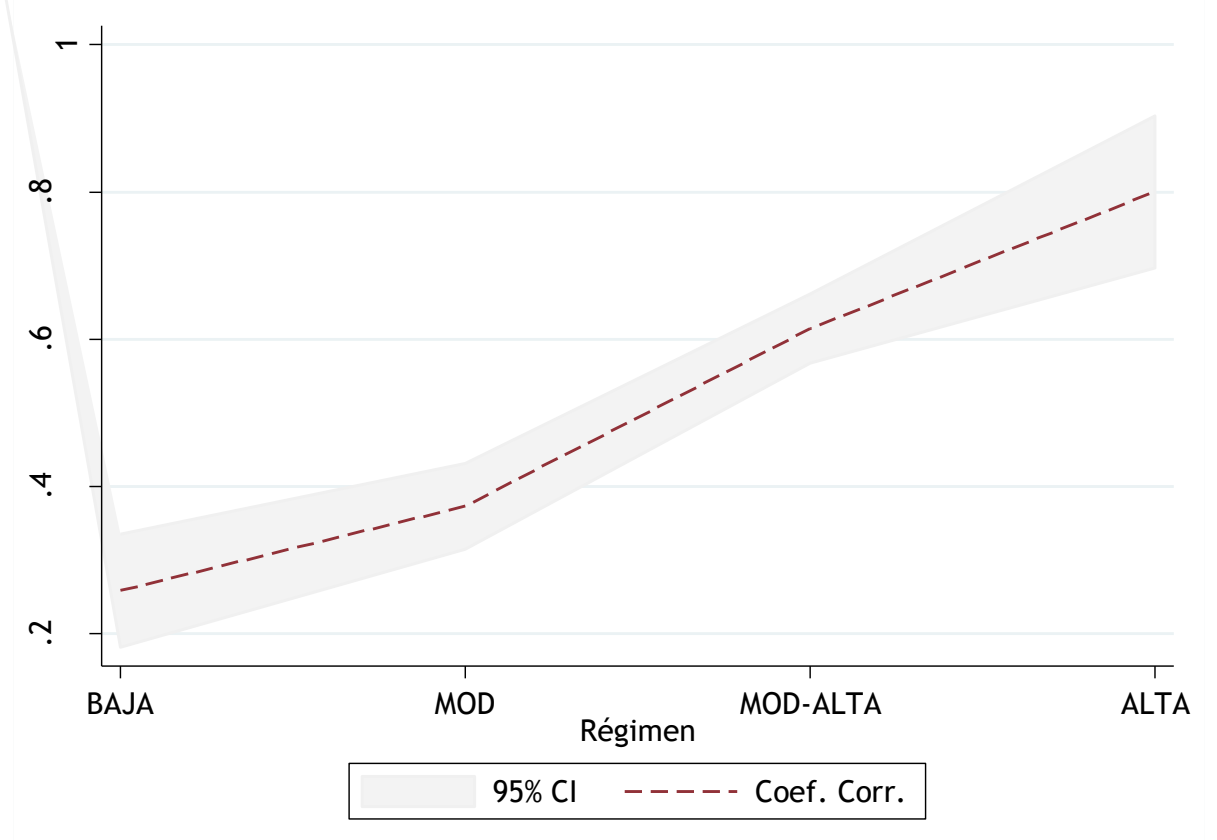

Fuente: Elaboración propia

Los patrones observados hasta aquí serán utilizados en la próxima sección para analizar las regularidades empíricas de los procesos de transición.

\section{PROCESOS DE DESINFLACIÓN Y ESTABILIZACIÓN}

Si la inflación altera el funcionamiento de la economía, es natural que los países hayan intentado realizar transiciones hacia ámbitos de baja inflación. La mayor parte de los estudios se han concentrado en aquellos períodos en los que se desarrollaron políticas para disminuir la inflación desde niveles muy elevados, lo que se conoce convencionalmente como "programas de estabilización”. Estos programas han estado asociados a la implementación de un conjunto de políticas de gran magnitud con el objetivo de llevar a la economía a un régimen de baja inflación. En este trabajo se reservará el término "estabilización inflacionaria", en cambio, para todos aquellos procesos donde la economía transita un sendero de disminución de la tasa de inflación desde regímenes de inflación crónica hacia baja inflación.

El interés de esta sección se centrará en considerar a los procesos de desinflación de manera amplia, tomando todos los períodos donde la misma disminuye de manera significativa desde situaciones donde la economía se encuentra en condiciones de inflación crónica, independientemente de si es posible asociar a los mismos con un “programa de estabilización" específico. Se desea, en este sentido, observar todas las desaceleraciones persistentes y significativas de la tasa de inflación, distinguiendo 
aquellas que alcanzaron una estabilización plena de las que no pudieron conseguirla con el fin de establecer diferencias y similitudes entre dichos procesos.

Siguiendo a Ball (1994) se define la desinflación como el lapso de tiempo en el cual la tasa de inflación pasa de un máximo (pico) a un mínimo (valle). El inicio de la desinflación se identifica como el momento donde la inflación comienza a disminuir, mientras que el final del proceso se puede dar por dos razones: una aceleración de la tasa de inflación o la ausencia de cambios en la misma. Dados los objetivos del análisis, se consideraron aquí solamente aquellas variaciones de gran amplitud en la tasa de inflación, eliminando las fluctuaciones que entre el pico y el valle tengan una diferencia menor al $10 \%$ así como también las oscilaciones menores a un año de duración. Se procedió a su vez a clasificar a estos procesos en función del régimen de inflación inicial y el que se encontraba la economía una vez terminadas (considerando los dos años posteriores a su finalización). A partir de ello, se identificaron tres tipos de transiciones:

- Plenas: aquellas que, desde un estado de inflación crónica permitieron una transición hacia un estado de baja inflación

- Parciales: son aquellas en las cuales la transición se obtuvo hacia un estado de menor inflación (de alta a moderada-alta o moderada, o de moderada-alta a moderada) pero no alcanzan un estado de inflación baja.

- Reversibles: situaciones donde el proceso de desinflación deriva con posterioridad en el mismo régimen de inflación o en uno superior.

La clasificación permitió identificar 75 procesos de desinflación, (detalle por país y período se desarrollan en el anexo).

Tabla 6. Desinflaciones identificadas según régimen de origen y tipo de transición.

\begin{tabular}{lcccc}
\hline \multicolumn{1}{c}{ TIPO } & MOD & MOD-ALTA & ALTA & TOTAL \\
\hline Reversibles & 24 & 8 & 7 & 39 \\
Parciales & & 4 & 2 & 6 \\
Plenas & 5 & 2 & 3 & 10 \\
\hline TOTAL & 29 & $\mathbf{1 4}$ & $\mathbf{1 2}$ & $\mathbf{5 5}$ \\
\hline
\end{tabular}

Fuente: Elaboración propia

Los resultados muestran que la inflación moderada es un proceso relativamente difícil de enfrentar: de las 29 desinflaciones identificadas, solo 5 permitieron una transición hacia inflación baja, mientras que más del $80 \%$ revirtieron al mismo estado o a uno de mayor inflación. En general, las transiciones plenas hacia baja inflación 
desde inflación crónica fueron eventos poco frecuentes: menos de una quinta parte del total de desinflaciones desde inflación crónica fueron a inflación baja.

El objetivo a continuación es obtener, a través de la identificación previa, una caracterización general de grandes elementos comunes a los procesos de desinflación desde inflación crónica en América Latina. Se intentará observar la existencia de patrones generales en las transiciones que sirvan para distinguir aquellos procesos que permitieron un pasaje hacia situaciones de inflación baja respecto de los demás. Existe, como en todo análisis, un problema de representación y una tensión entre la cantidad de información a incorporar y la capacidad de síntesis. Podría pensarse que la mejor definición de cada uno de estos estados es una descripción precisa de sus condiciones iniciales y sus variantes, pero al incrementar la cantidad de características analizadas cada evento posee una particularidad propia que lo distingue de los demás. Obtener elementos comunes es, de alguna forma, resignarse a simplificar el problema obviando otras cuestiones que pueden incidir en el proceso analizado. Considerando que esto es un hecho inevitable, la selección de aquellas dimensiones a analizar y que sirven como síntesis toma mayor relevancia y debe ser adecuadamente fundamentada.

Las variables que serán consideradas aquí son aquellas que emergen como regularidades empíricas del análisis anterior, a saber: el desempeño fiscal durante las desinflaciones (informativo sobre la necesidad de acotar los riesgos de interacciones fiscales y monetarias al momento de la desinflación), el rol del tipo de cambio (dado que su asociación a las fluctuaciones de los precios internos se acentúa en regímenes de inflación crónica) y, por último, la velocidad de las transiciones (como elemento informativo de la posibilidad de romper la inercia de los procesos inflacionarios). Estas tres dimensiones serán analizadas con el fin de observar denominadores comunes en las transiciones, aun a sabiendas de que, si bien se considera a estos elementos como relevantes durante los procesos de inflación crónica, el ejercicio no es una guía exacta de los procesos de desinflación sino una primera aproximación sobre ciertas cuestiones que deberían considerarse importantes en cada una de las mismas.

\section{Desempeño fiscal al inicio}

La pregunta en este caso es si los procesos de desinflación estuvieron asociados a grandes desbalances fiscales 0 , por el contrario, con situaciones donde este se encontraba relativamente acotado. La noción implícita es que parte de los desafíos de los procesos inflacionarios se pueden asociar con deterioros muy pronunciados en las cuentas públicas. La desinflación, si es exitosa, debería encontrarse en situaciones 
donde exista una mejora del balance fiscal de manera tal de despejar dudas sobre la sostenibilidad del proceso de desinflación (o, al menos, sobre la necesidad de recurrir al señoreaje para el financiamiento del sector público) y, a la inversa, los menores niveles de inflación permitirían mejorar la contabilidad pública, la capacidad de negociar un presupuesto de manera global y no bilateral y hacer más eficiente la recaudación evitando la pérdida de recursos originada en la licuación de las obligaciones tributarias. Para analizar esta asociación se considera el resultado fiscal al inicio del proceso de desinflación, considerando al mismo como el menor déficit fiscal entre el año de implementación y el siguiente.

Como puede observarse en el Gráfico 13 en alta inflación hay significativas diferencias entre los procesos de desinflación según los mismos hayan permitido alcanzar un régimen de baja inflación respecto de los que no lo hicieron. En todo caso, las transiciones plenas desde alta inflación se distinguen de las reversibles en que en estas el resultado fiscal es marcadamente menos deficitario que en las restantes. Cuando se trata de desinflaciones de moderada-alta (Gráfico 14) el equilibrio fiscal aparece nuevamente como un elemento común a las transiciones plenas, pero también en el caso de las parciales y algunas de los casos de transiciones reversibles, fenómeno que se observa con aun mayor amplitud en el caso de las inflaciones moderadas (Gráfico 15).

Gráfico 13. Déficit al inicio de la desinflación (como \% PIB). Desde inflación alta.

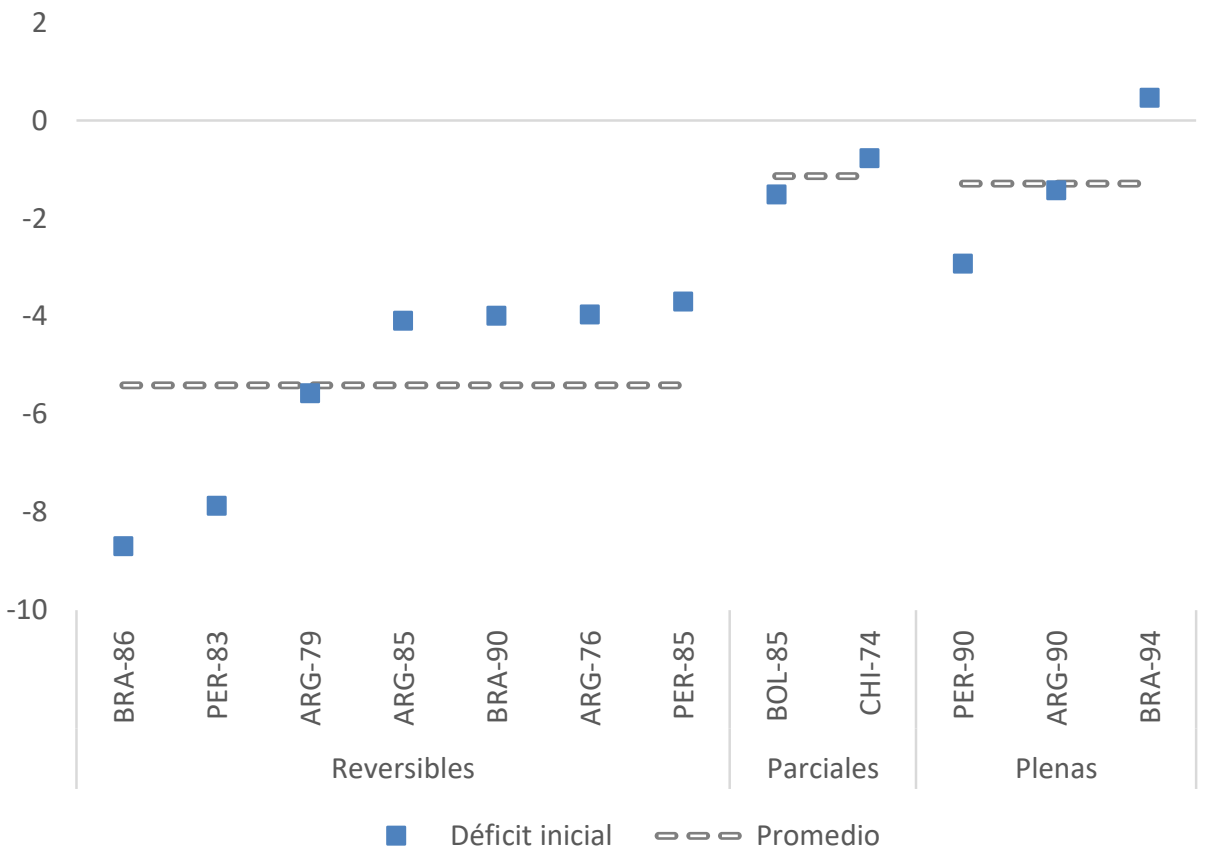

Fuente: Elaboración propia 
Gráfico 14. Déficit al inicio de la desinflación (como \% PIB). Desde inflación moderada-Alta.

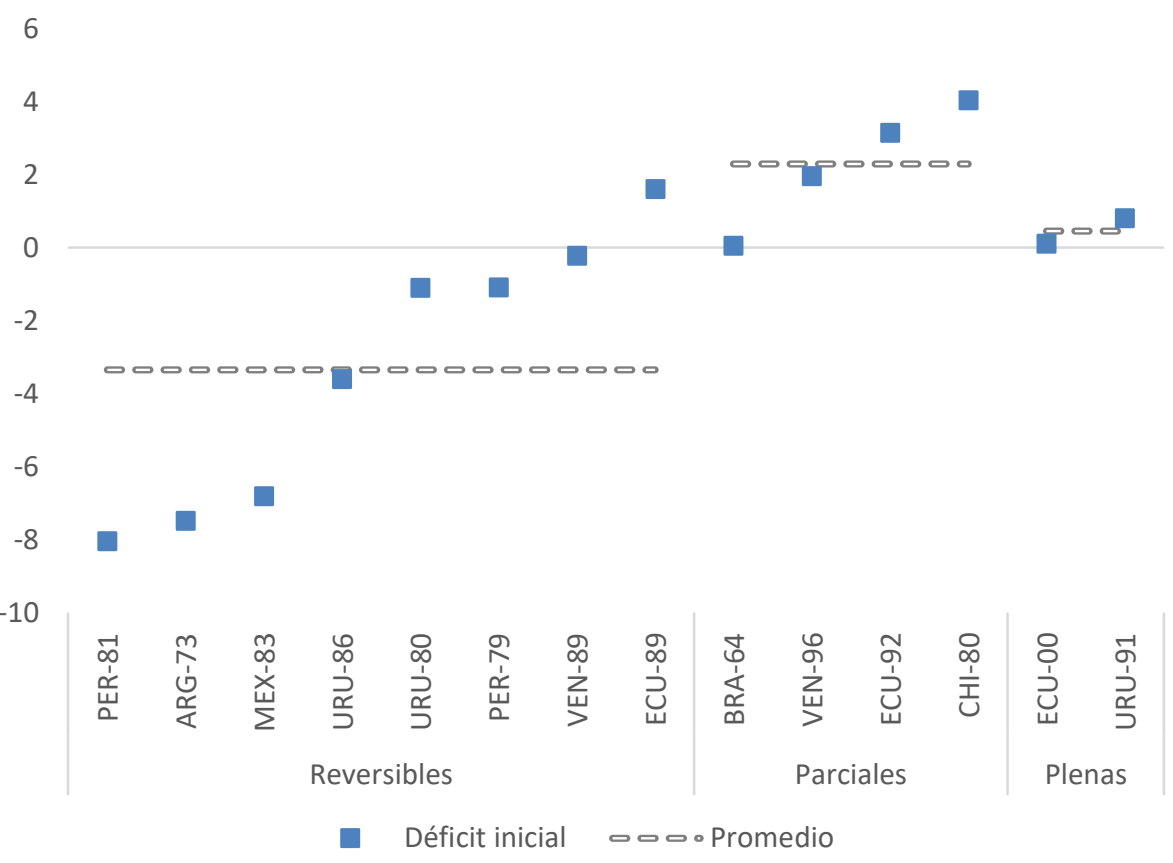

Fuente: Elaboración propia

Gráfico 15. Déficit al inicio de la desinflación (como \% PIB). Desde inflación moderada.

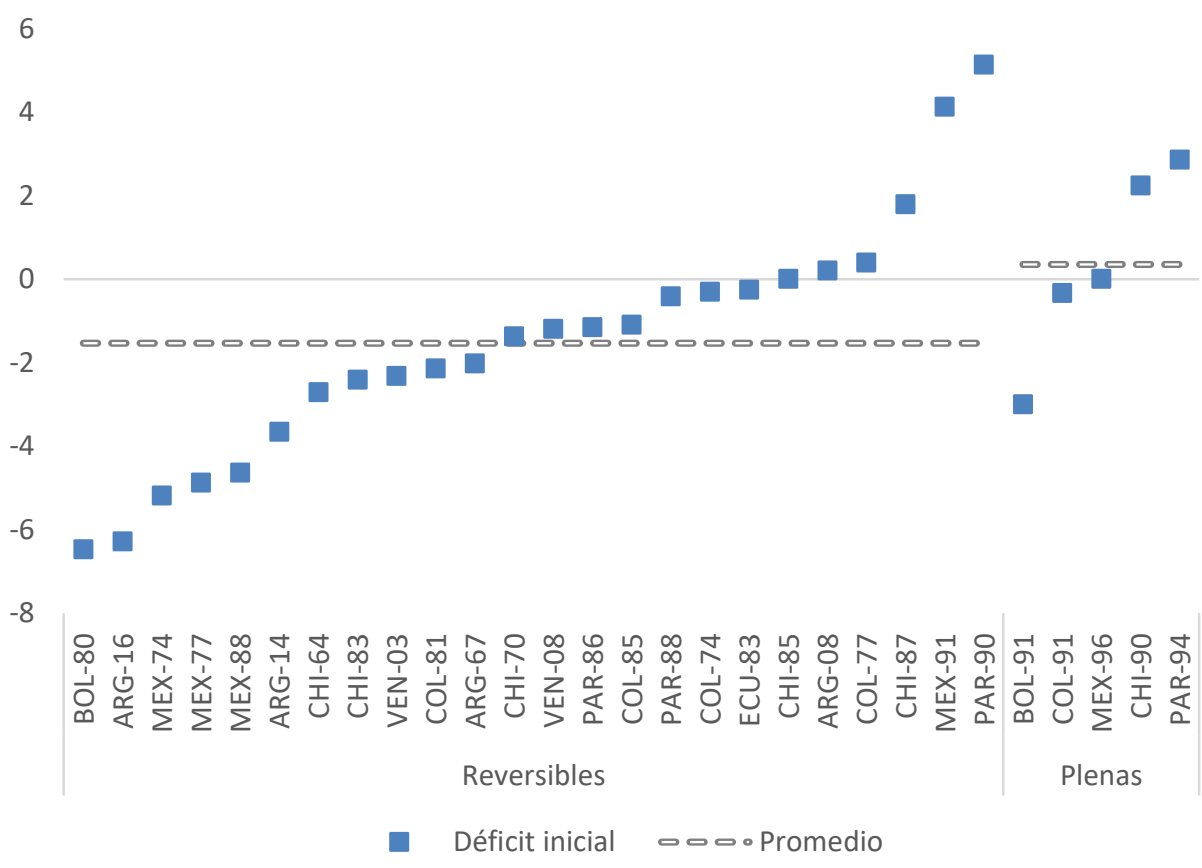

Fuente: Elaboración propia 
En líneas generales, cierto grado de equilibrio fiscal está asociado a las transiciones plenas independientemente del régimen de inflación crónica o, dicho de otra forma, no existe evidencia de transiciones plenas sin una aproximación al equilibrio fiscal. Sin embargo, debe resaltarse que existen transiciones reversibles y parciales en inflación moderada-alta y moderada que mostraron un balance fiscal equilibrado al inicio de la desinflación. En otras palabras, este elemento no resulta suficiente para distinguir entre las transiciones plenas y las demás en este tipo de circunstancias.

\section{Comportamiento del tipo de cambio}

Existe evidencia de que las oscilaciones del tipo de cambio se encuentran más directamente asociadas con cambios en los precios internos frente a regímenes de inflación crónica de mayor magnitud. En este contexto, existe la posibilidad de que las transiciones rompan esta asociación, lo que significaría la posibilidad de que durante la transición el tipo de cambio real pueda incrementarse. Por el contrario, si esta relación se mantiene, es probable que se observe un retraso relativo del valor real del tipo de cambio durante la desinflación

Para observar el comportamiento del tipo de cambio en las transiciones se calculó un indicador que mide la diferencia entre el tipo de cambio real al inicio del proceso de desinflación respecto del valor promedio del mismo durante la desinflación. Al estar calculado como un promedio sobre todo el período lo que muestra el mismo es el ritmo de crecimiento en promedio del tipo de cambio en relación con los precios internos.

Como se observa en el Gráfico 16, Gráfico 17 y Gráfico 18, el nivel del tipo de cambio real durante la desinflación fue, en todos los casos, inferior al original en las transiciones plenas. Al igual que en el caso anterior, esta característica es propia de las transiciones plenas, aun así y de manera similar a la condición sobre el resultado fiscal al inicio, no necesariamente es capaz de distinguir entre estas y las que no alcanzaron ambientes de baja inflación. En todo caso, lo que es posible afirmar es que no existieron transiciones plenas a regímenes de baja inflación en situaciones donde el proceso de desinflación se encontró asociado a una tasa de devaluación que fuese por encima de los precios internos. Como contrapartida, podría observarse que las correcciones de precios relativos, cuando deben realizarse en ambientes de inflación crónica, son contrapuestas (o deberían ser previas) a una disminución en el ritmo de crecimiento de los precios. 
Gráfico 16. Tipo de Cambio Real Bilateral USD (diferencia porcentual respecto al nivel inicial). Desde inflación alta.

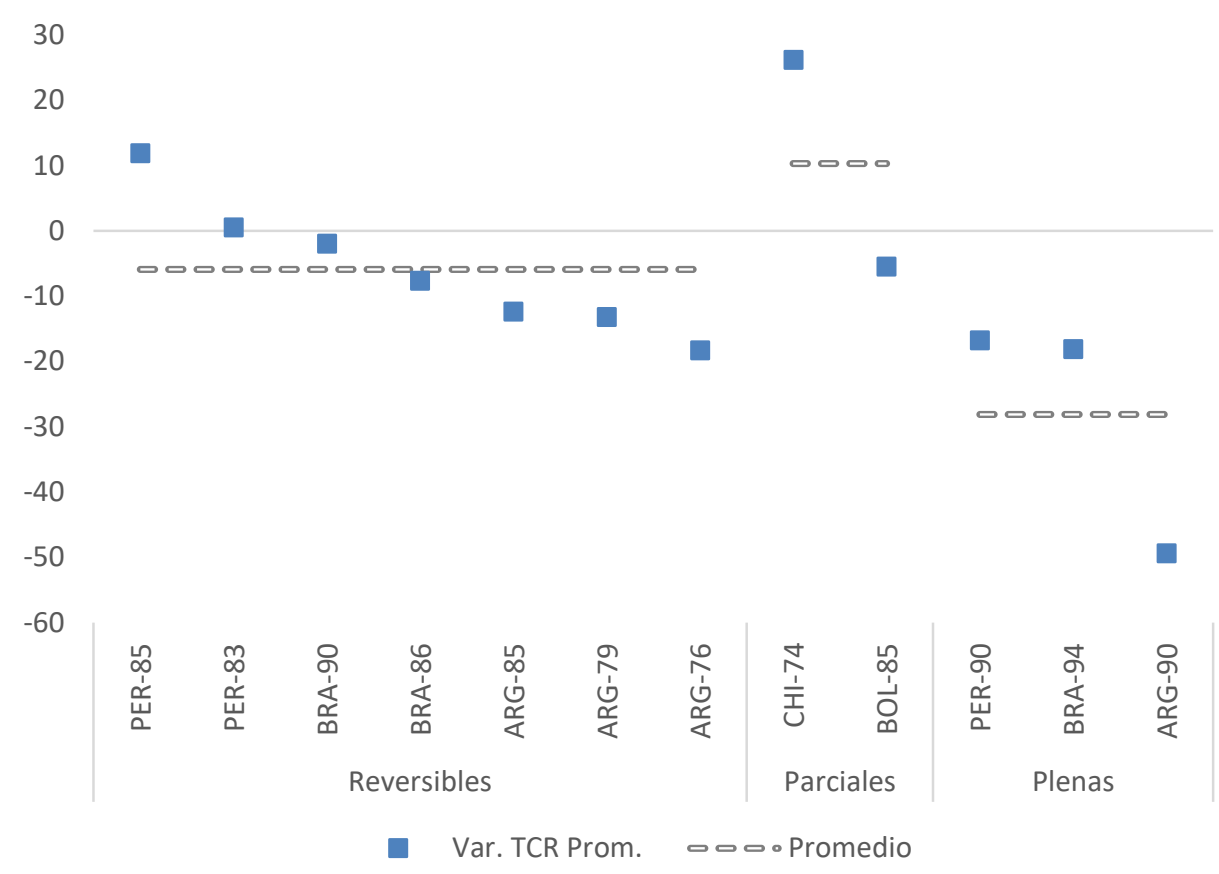

Fuente: Elaboración propia

Gráfico 17. Tipo de Cambio Real Bilateral USD (diferencia porcentual respecto al nivel inicial). Desde inflación moderada-alta.

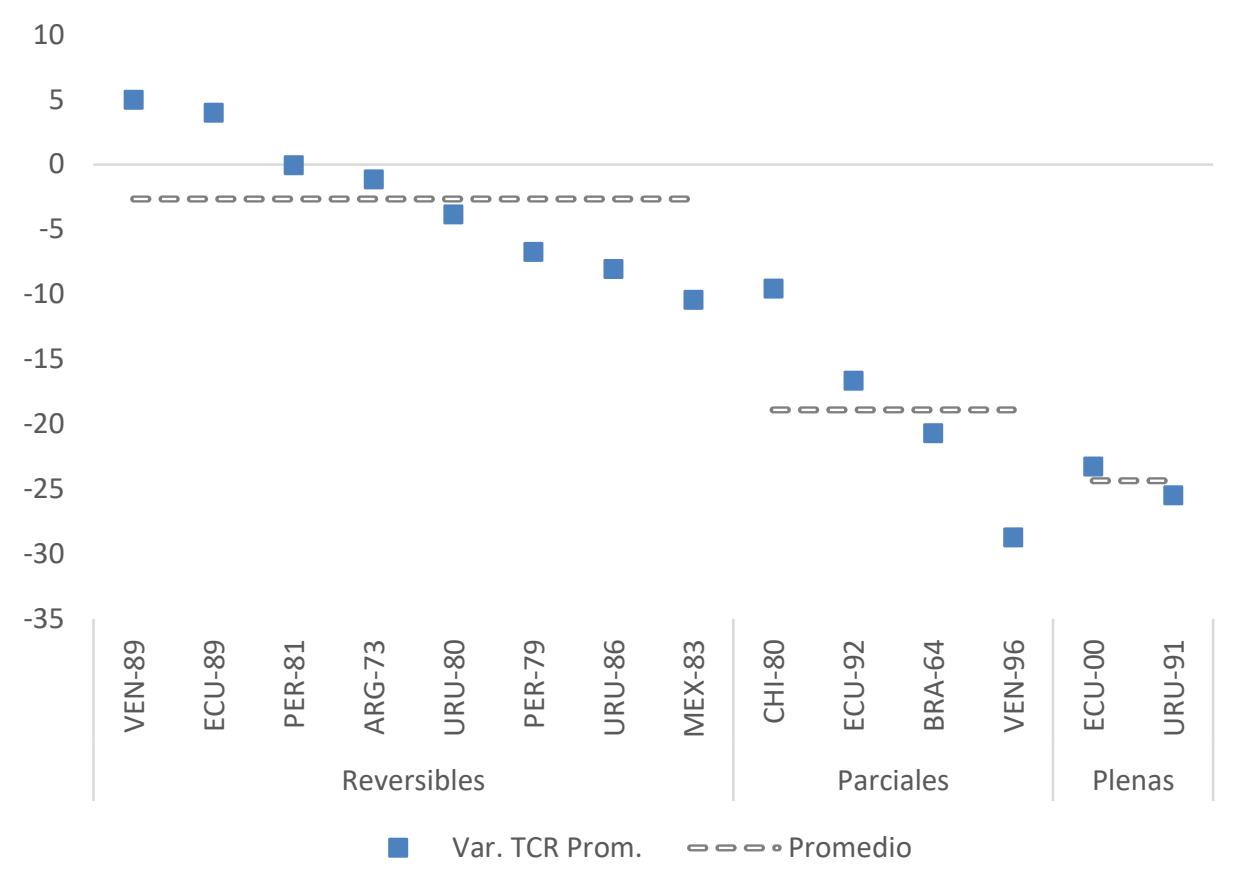

Fuente: Elaboración propia 
Gráfico 18. Tipo de Cambio Real Bilateral USD (diferencia porcentual respecto al nivel inicial). Desde inflación moderada.

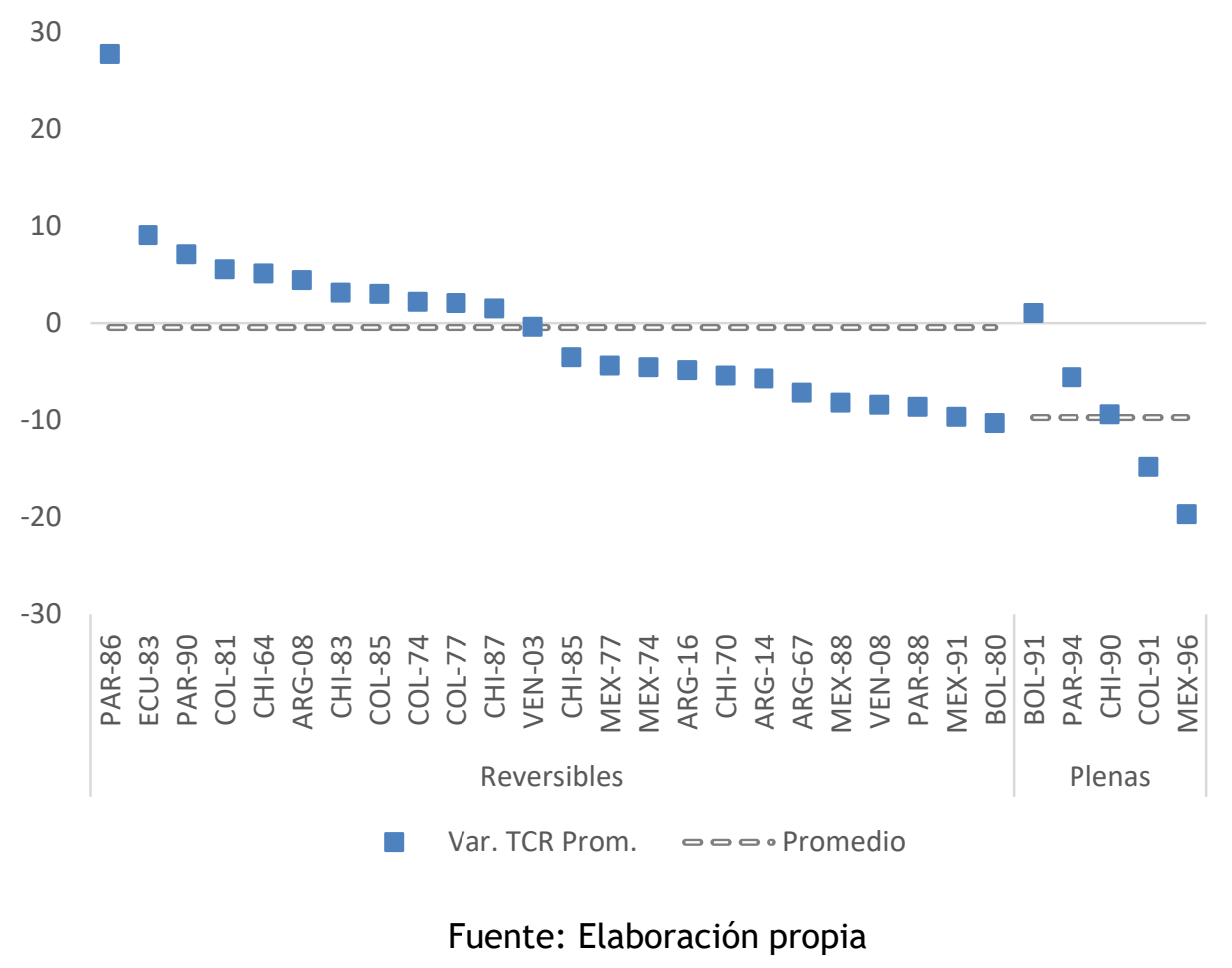

\section{Duración de la desinflación}

La literatura se ha concentrado frecuentemente en analizar los programas de estabilización, pero los mismos han sido, en general, procesos breves, marcados por cambios profundos en la política económica. Por el contrario, podría ocurrir que existan estrategias de desinflación que no necesariamente se comporten de esta manera, sino que se asocien a transiciones prolongadas. En general, se ha asociado a la velocidad de la desinflación con la inercia inflacionaria o, por el contrario, la posibilidad de establecer un cambio de las condiciones en las que la misma opera, fenómeno que se discutirá en el próximo capítulo. En esta sección el interés estará puesto en observar la posible existencia de diferentes velocidades de desinflación y, en caso afirmativo, en considerar si las mismas son condicionales al régimen de origen. La duración de los episodios según régimen de origen se presenta en el Gráfico 19, Gráfico 20 y Gráfico 21.

La primera observación que surge de los resultados es que lo que falla, lo hace rápidamente, particularmente cuanto más intenso es el régimen de inflación. En general, las transiciones reversibles desde alta inflación o moderada-alta inflación tuvieron una duración levemente superior a un año. En el caso de las moderadas, existen algunas excepciones, observando que existieron estrategias de desinflación 
que, aún sin poder establecer un sendero de estabilización completo, tuvieron una duración mayor a un año.

Gráfico 19. Duración de la desinflación. Desde inflación alta.

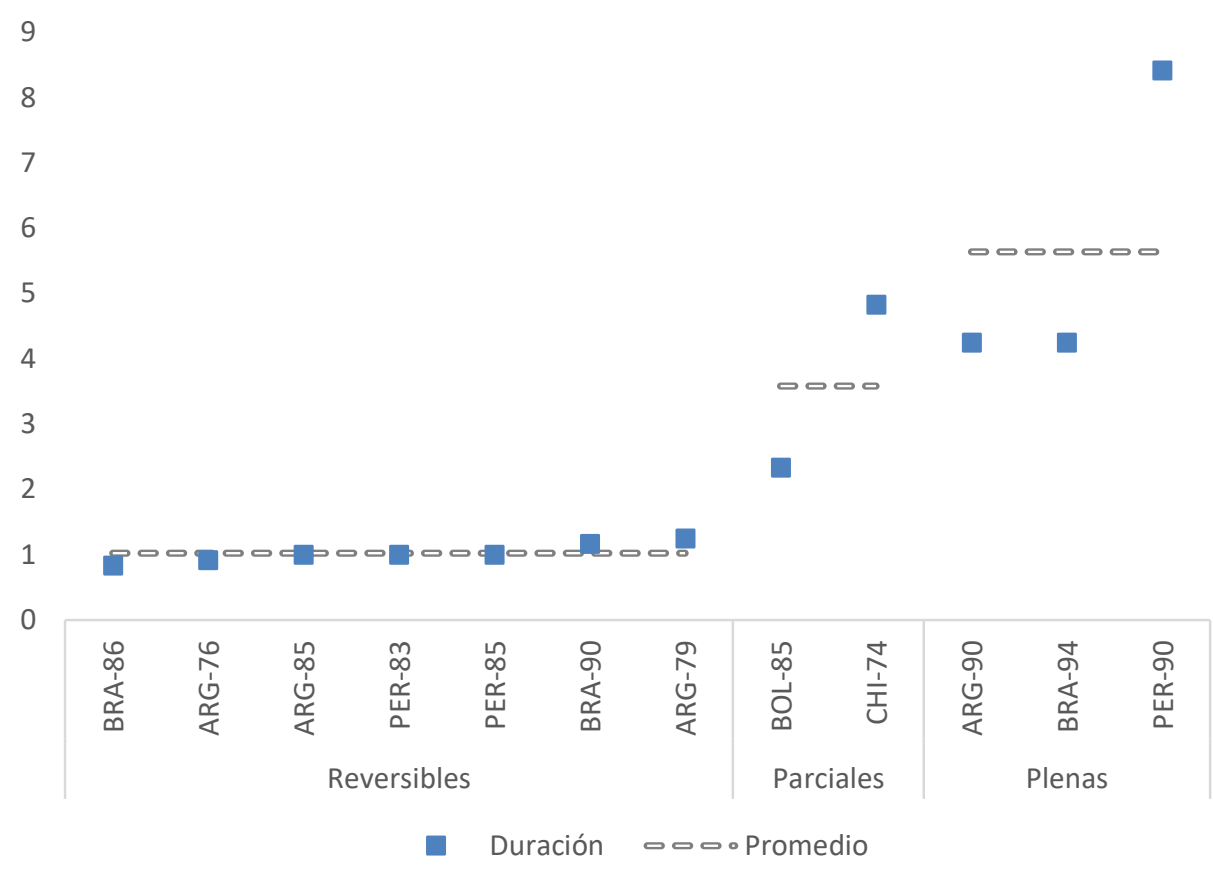

Fuente: Elaboración propia

Gráfico 20. Duración de la desinflación. Desde inflación moderada-alta.
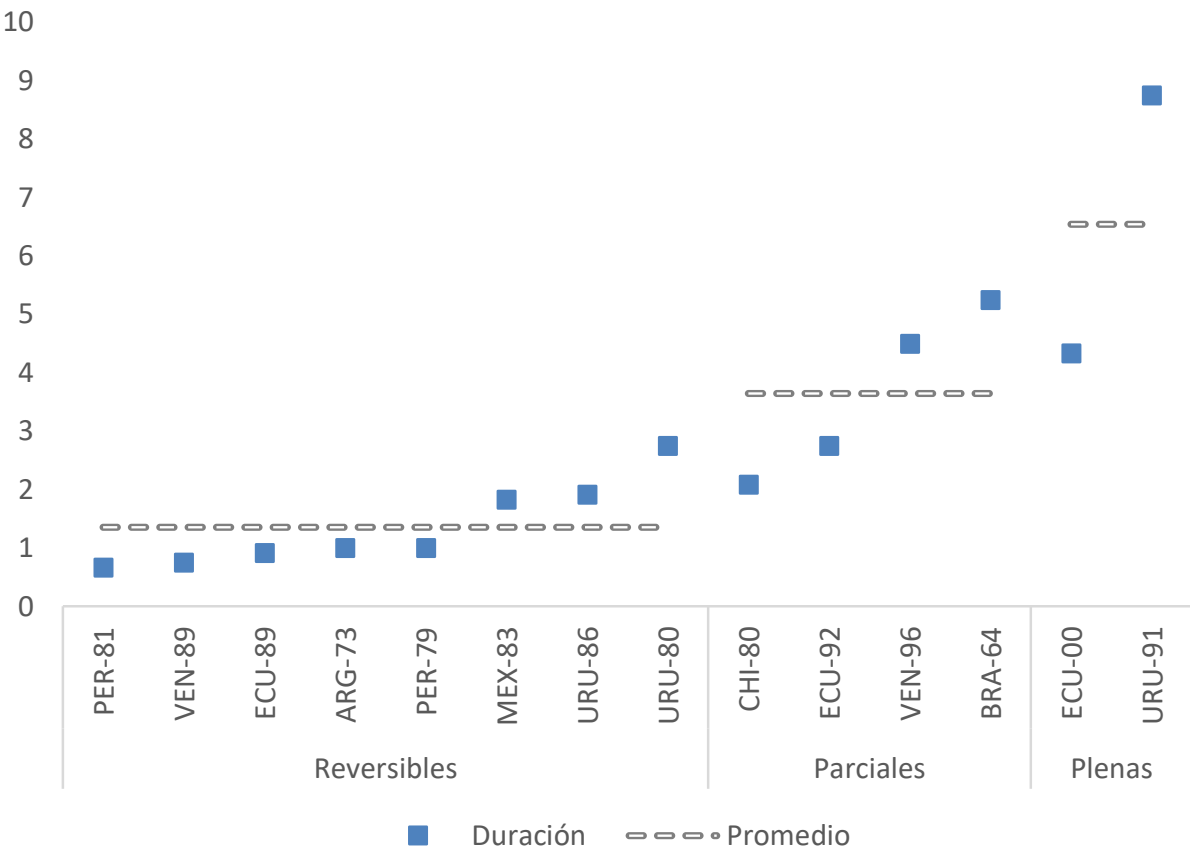

Fuente: Elaboración propia 
En segundo lugar, si bien es posible identificar un elevado número de procesos plenos de alta velocidad, no es menos cierto que existieron otras estrategias, mucho más paulatinas, que permitieron transiciones plenas hacia ambientes de baja inflación, en todos los estados iniciales: Perú en Alta, Uruguay en Moderada-Alta, Colombia y Chile en Moderadas. La velocidad de transición parece ser condicional a la estrategia de desinflación más que al estado original o, en otras palabras, no parece existir una manera única de enfrentar los procesos de desinflación condicional al tipo de régimen de inflación de origen.

Gráfico 21. Duración de la desinflación. Desde inflación moderada.

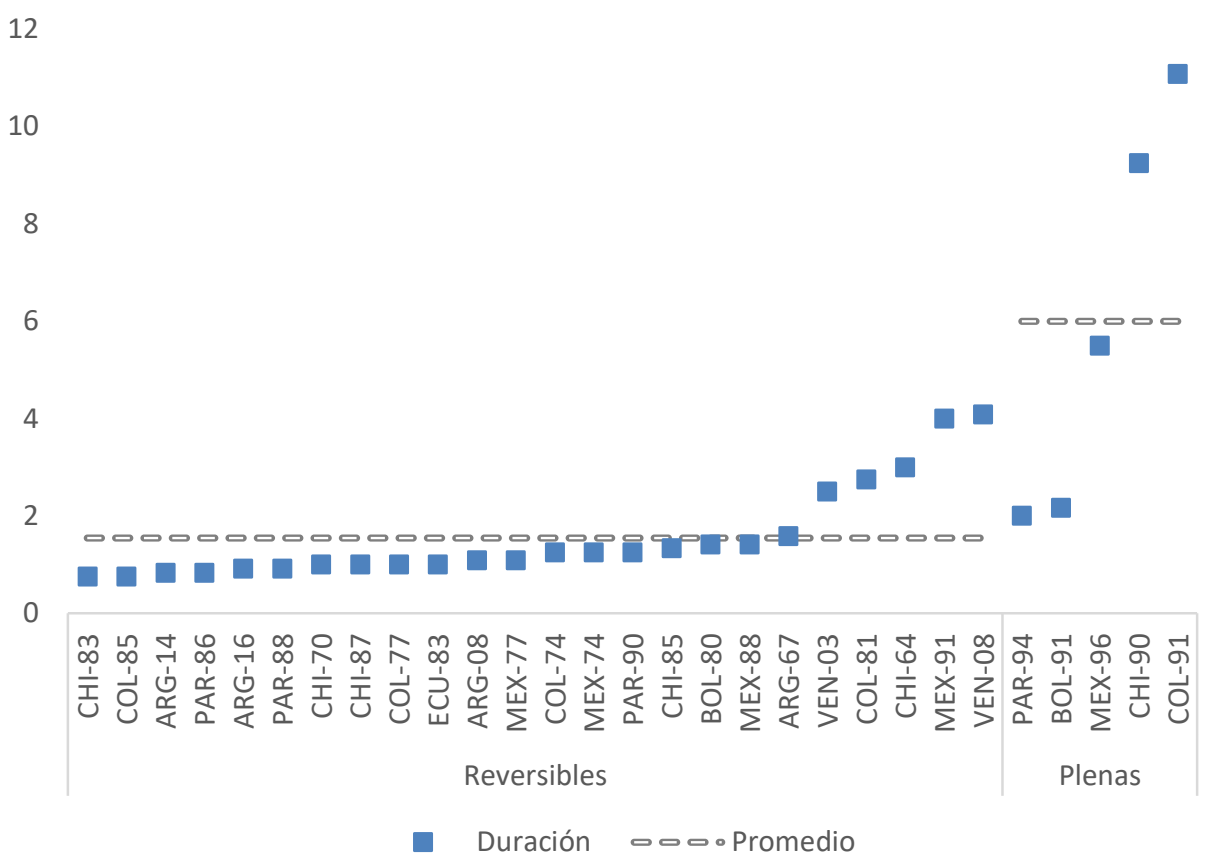

Fuente: Elaboración propia

\section{CONCLUSIONES}

La inflación crónica ha sido, sin duda, un fenómeno particularmente profundo en América Latina: este tipo de regímenes han estado presentes, con diferente intensidad y en distintos momentos, en las once economías consideradas en este capítulo.

Se han analizado en este capítulo un conjunto de patrones asociados a la inflación crónica: la persistencia y estabilidad de estos regímenes, la relación entre las devaluaciones y los precios internos y, por último, las interacciones entre la política fiscal y la política monetaria. En líneas generales, se observa que los regímenes de alta 
inflación se han caracterizado en la región como procesos inestables que no necesariamente revierten hacia una media constante en el tiempo. Estas características se presentan con menor intensidad en los procesos de inflación moderada-alta y moderada, mientras que los regímenes de baja inflación son típicamente procesos de reversión a una media estable en el tiempo. Esta variabilidad se refleja en la persistencia de los shocks, al menos en la forma en la que habitualmente suele medirse la misma, ya que las oscilaciones se transforman en procesos de más larga duración en el caso de las inflaciones crónicas y particularmente en alta inflación. En segundo lugar, los procesos de inflación crónica se caracterizaron por una relación más estrecha entre déficit fiscal y señoreaje, de manera creciente frente a una mayor intensidad de los mismos. En tercer lugar, las oscilaciones del tipo de cambio han tenido una asociación más próxima a mayor régimen de inflación.

Los patrones macroeconómicos descriptos en el párrafo anterior no pueden necesariamente asociarse en una relación causal precisa. Por ejemplo, la relación más estrecha entre señoreaje y déficit fiscal puede ser el resultado de la incapacidad del sector público de acceder a mercados de crédito, lo que a su vez es condicional al régimen de inflación. Como se menciona en el primer capítulo, estos fenómenos están interconectados y no es posible establecer un ordenamiento claro de las causas últimas de todo el proceso. En todo caso, el interés aquí está en el hecho de que, independientemente del sentido de la causalidad, estos fenómenos se refuerzan ante la persistencia de ciertos niveles de inflación, convalidando la tendencia del sistema a mantenerse en un determinado estado. En este sentido las trayectorias de los procesos de desinflación deben mostrar puntos de unión con estos patrones.

Casi todos los países de la región han conseguido elaborar políticas para alcanzar transiciones a ambientes de baja inflación, aunque para ello han recorrido un número no menor de experiencias de prueba y error. En la segunda sección del trabajo se han identificado todos los procesos donde la tasa de inflación ha mostrado una tendencia decreciente en una magnitud relevante. Si los patrones macroeconómicos observados en la primera sección refuerzan los estados de inflación, es natural suponer que los procesos de desinflación han estado vinculados con instrumentos o políticas que permitan enfrentarlos, lo que permitiría establecer ciertos elementos comunes entre dichos procesos. Los procesos exitosos (entendiendo a los mismos como las transiciones plenas a regímenes de baja inflación) mantuvieron al menos dos elementos comunes: cierto grado de balance en las cuentas públicas y alguna forma de apreciación cambiaria. Ambas características responden a patrones macroeconómicos específicos que afectan al proceso de formación de precios. 
El tercer elemento, a saber, la velocidad en la que se dieron estos procesos, no parece ofrecer una distinción concluyente. El ritmo del proceso de desaceleración del incremento de precios parece condicional a la estrategia establecida para enfrentar el proceso inflacionario y no necesariamente al régimen original. Existe evidencia, en este sentido, de transiciones plenas a ambientes de baja inflación mediante dinámicas de desinflación muy graduales tanto desde alta inflación como desde regímenes donde la misma ha sido menos intensa.

\section{REFERENCIAS}

Andrews, D.W.K., Chen H-Y, (1994), “Approximately median-unbiased estimation of autoregressive models”, Journal of Business \& Economic Statistics, Vol.12, No.2, 187204

Ball, Laurence (1994). "What Determines the Sacrifice Ratio?" NBER Chapters, in: Monetary Policy, p. 155-193.

Basco, E.; D'Amato, L. y L. Garegnani (2009). "Understanding the money-prices relationship under low and high inflation regimes: Argentina 1977-2006," Journal of International Money and Finance, Elsevier, vol. 28(7), pages 1182-1203, November.

D’Amato, L. y M. Garegnani (2013) “¿Cuán persistente es la inflación en Argentina?: regímenes inflacionarios y dinámica de precios en los últimos 50 años”, ch. 4, p. 91115 en D'Amato, Laura Inés, Enciso, Enrique López and Giraldo, María Teresa Ramírez eds., "Dinámica inflacionaria, persistencia y formación de precios y salarios”, Centro de Estudios Monetarios Latinoamericanos, CEMLA.

Fischer, S.; Sahay, R. y C. Vegh (2002). “Modern Hyper- and High Inflations” Journal of Economic Literature, 40, issue 3, p. 837-880.

Heymann, Daniel, 1986. "Tres ensayos sobre inflación y políticas de estabilización," Oficina de la CEPAL en Buenos Aires (Estudios e Investigaciones) 28518, Naciones Unidas Comisión Económica para América Latina y el Caribe (CEPAL).

Kehoe, T. J.; J. P. Nicolini y T. J. Sargent (2019) "A Framework for Studying the Monetary and Fiscal History of Latin America, 1960-2017" Federal Reserve Bank of Minneapolis. Research Department Staff Report 
Marques, Robalo C. (2005). “Inflation persistence: facts or artefacts?”. Economic Bulletin and Financial Stability Report Articles and Banco de Portugal Economic Studies

Noriega, A. E.; C. Capistrán y M. Ramos-Francia (2012) “On the dynamics of inflation persistence around the world” Empirical Economics (2013) 44:1243-1265

Sargent, Thomas and Wallace, Neil, (1981), "Some unpleasant monetarist arithmetic", Quarterly Review, issue Fall, number v. 5, no. 3.

ANEXO

Tabla 7. Resultados de regresión entre Señoreaje y Déficit Fiscal.

(1) Señoreaje Señoreaje

\begin{tabular}{lcc} 
VARIABLES & Señoreaje & Señoreaje \\
\hline Déficit Fiscal & $0.326^{* * *}$ & $-0.0613^{*}$ \\
& $(0.0220)$ & $(0.0327)$ \\
Moderada & & $0.236^{* * *}$ \\
& & $(0.0461)$ \\
Moderada-Alta & & $0.356^{* * *}$ \\
& & $(0.0420)$ \\
Alta & & $0.674^{* * *}$ \\
& & $(0.0393)$ \\
Constante & $1.080^{* * *}$ & $1.309^{* * *}$ \\
& $(0.0973)$ & $(0.0805)$ \\
Observations & & 599 \\
R-squared & 599 & 0.518 \\
\hline
\end{tabular}

Errores estándar entre paréntesis ${ }^{* * *} \mathrm{p}<0.01,{ }^{* *} \mathrm{p}<0.05,{ }^{*} \mathrm{p}<0.1$ 
Tabla 8. Caracterización del proceso inflacionario.

\begin{tabular}{|c|c|c|c|c|c|}
\hline \multirow{2}{*}{ País } & \multicolumn{2}{|c|}{ Período } & \multicolumn{2}{|c|}{ Régimen } & \multirow{2}{*}{ Tipo } \\
\hline & Inicio & Final & Inicio & Final & \\
\hline Argentina & jun-76 & may-77 & ALTA & ALTA & Reversibles \\
\hline Argentina & oct-79 & ene-81 & ALTA & ALTA & Reversibles \\
\hline Argentina & jun-85 & jun-86 & ALTA & ALTA & Reversibles \\
\hline Brasil & feb- 86 & dic -86 & ALTA & ALTA & Reversibles \\
\hline Brasil & may-90 & jul-91 & ALTA & ALTA & Reversibles \\
\hline Perú & sep-83 & sep-84 & ALTA & ALTA & Reversibles \\
\hline Perú & ago-85 & ago-86 & ALTA & ALTA & Reversibles \\
\hline Chile & may-74 & mar-79 & ALTA & MOD-ALTA & Parciales \\
\hline Bolivia & sep-85 & ene- 88 & ALTA & MOD & Parciales \\
\hline Argentina & mar-90 & jun-94 & ALTA & BAJA & Plenas \\
\hline Brasil & jun-94 & sep-98 & ALTA & BAJA & Plenas \\
\hline Perú & nov-90 & abr-99 & ALTA & BAJA & Plenas \\
\hline Argentina & may-73 & may-74 & MOD-ALTA & ALTA & Reversibles \\
\hline Perú & ago-81 & $a b r-82$ & MOD-ALTA & ALTA & Reversibles \\
\hline Ecuador & $a b r-89$ & $\operatorname{mar}-90$ & MOD-ALTA & MOD-ALTA & Reversibles \\
\hline México & jun-83 & $a b r-85$ & MOD-ALTA & MOD-ALTA & Reversibles \\
\hline Perú & $a b r-79$ & $a b r-80$ & MOD-ALTA & MOD-ALTA & Reversibles \\
\hline Venezuela & sep-89 & jun-90 & MOD-ALTA & MOD-ALTA & Reversibles \\
\hline Uruguay & feb-80 & nov -82 & MOD-ALTA & MOD-ALTA & Reversibles \\
\hline Uruguay & $a b r-86$ & mar-88 & MOD-ALTA & MOD-ALTA & Reversibles \\
\hline Brasil & sep-64 & dic -69 & MOD-ALTA & MOD & Parciales \\
\hline Chile & mar-80 & $a b r-82$ & MOD-ALTA & MOD & Parciales \\
\hline Ecuador & nov-92 & ago-95 & MOD-ALTA & MOD & Parciales \\
\hline Venezuela & sep-96 & $\operatorname{mar}-01$ & MOD-ALTA & MOD & Parciales \\
\hline Ecuador & sep-00 & ene-05 & MOD-ALTA & BAJA & Plenas \\
\hline Uruguay & ene-91 & oct-99 & MOD-ALTA & BAJA & Plenas \\
\hline Bolivia & ago-80 & ene- 82 & MOD & ALTA & Reversibles \\
\hline Chile & oct-70 & oct-71 & MOD & ALTA & Reversibles \\
\hline Venezuela & sep-08 & oct-12 & MOD & ALTA & Reversibles \\
\hline Argentina & jul-67 & feb-69 & MOD & MOD & Reversibles \\
\hline Argentina & jun-08 & jul-09 & MOD & MOD & Reversibles \\
\hline Argentina & sep-14 & jul-15 & MOD & MOD & Reversibles \\
\hline Argentina & ago-16 & jul-17 & MOD & MOD & Reversibles \\
\hline Chile & mar-64 & mar-67 & MOD & MOD & Reversibles \\
\hline Chile & sep-83 & jun-84 & MOD & MOD & Reversibles \\
\hline Chile & ago-85 & dic- 86 & MOD & MOD & Reversibles \\
\hline Chile & nov-87 & nov- 88 & MOD & MOD & Reversibles \\
\hline Colombia & dic-74 & mar-76 & MOD & MOD & Reversibles \\
\hline Colombia & jul-77 & jul-78 & MOD & MOD & Reversibles \\
\hline Colombia & jul-81 & $a b r-84$ & MOD & MOD & Reversibles \\
\hline Colombia & sep-85 & jun-86 & MOD & MOD & Reversibles \\
\hline Ecuador & oct -83 & oct-84 & MOD & MOD & Reversibles \\
\hline México & ago-74 & nov-75 & MOD & MOD & Reversibles \\
\hline
\end{tabular}




$\begin{array}{lrrrl}\text { México } & \text { ago-77 } & \text { sep-78 MOD } & \text { MOD } & \text { Reversibles } \\ \text { México } & \text { feb-88 } & \text { jul-89 MOD } & \text { MOD } & \text { Reversibles } \\ \text { México } & \text { ene-91 } & \text { ene-95 MOD } & \text { MOD } & \text { Reversibles } \\ \text { Paraguay } & \text { jun-86 } & \text { abr-87 MOD } & \text { MOD } & \text { Reversibles } \\ \text { Paraguay } & \text { mar-88 } & \text { feb-89 MOD } & \text { MOD } & \text { Reversibles } \\ \text { Paraguay } & \text { sep-90 } & \text { dic-91 MOD } & \text { MOD } & \text { Reversibles } \\ \text { Venezuela } & \text { jun-03 } & \text { dic-05 MOD } & \text { MOD } & \text { Reversibles } \\ \text { Bolivia } & \text { may-91 } & \text { jul-93 MOD } & \text { BAJA } & \text { Plenas } \\ \text { Chile } & \text { oct-90 } & \text { ene-00 MOD } & \text { BAJA } & \text { Plenas } \\ \text { Colombia } & \text { abr-91 } & \text { may-02 MOD } & \text { BAJA } & \text { Plenas } \\ \text { México } & \text { feb-96 } & \text { ago-01 MOD } & \text { BAJA } & \text { Plenas } \\ \text { Paraguay } & \text { ago-94 } & \text { ago-96 MOD } & \text { BAJA } & \text { Plenas }\end{array}$




\section{CAPÍtulo III: Ritmos E INSTRUMENTOS EN DESINFlACIONES GRADUALES}

\section{INTRODUCCIÓN}

Si existen razones para pensar que los regímenes de inflación crónica incluyen elementos que refuerzan las dinámicas propias de cada uno de los estados, establecer transiciones que permitan salir de ellos exige la coordinación de instrumentos que permitan quebrar ciertas tendencias inherentes a los mismos. La inercia inflacionaria ha sido relacionada en este sentido con el hecho de que los individuos no alteran el comportamiento de manera inmediata, aun cuando las condiciones sobre las que dicho comportamiento fue establecido han sido modificadas. En este contexto se considera que las decisiones de formación de precios son contingentes al estado del sistema en el pasado, es decir, presenta ciertos grados de inercia. Las fuentes de esa inercia pueden provenir de restricciones contractuales sobre el proceso de formación de precios (por ejemplo, convenios de indexación) o por el simple hecho de que los agentes establecen sus decisiones tomando al pasado como guía del presente. La noción de que la inercia es un elemento que sobreviene de la desconfianza sobre el diseño de la política económica llevó a autores como Sargent (1982) a considerar que establecer anuncios creíbles podría frenar la tasa de inflación de manera repentina sin costos asociados. El postulado de que es posible alcanzar transiciones plenas a través del establecimiento de reglas de comportamiento a futuro del tipo "de ahora y para siempre" en un contexto altamente volátil y en un proceso afectado por impulsos de variado tipo ha sido puesto en duda (Heymann y Leijonfvud, 1991) pero sigue manteniéndose arraigado en la disciplina. Es habitual, en este sentido, considerar a la desinflación como un proceso marcado por anuncios de política económica que repercuten en un cambio abrupto del ritmo de crecimiento de precios. Como contrapunto, existen situaciones donde el proceso de desinflación se da como una transición paulatina y estable hacia niveles de baja inflación, que parecen contradecir este abordaje.

En este capítulo se realizará un estudio de caso de cinco desinflaciones graduales desde estados de inflación crónica a ambientes de baja inflación, tres de ellas desde inflación moderada (Chile, Colombia e Israel) y otras dos desde alta inflación (Perú y Polonia). El objetivo será el de analizar la instrumentación de la política económica en estos contextos y las distintas trayectorias macroeconómicas que presentaron. 
Como se detalla en la Tabla 9 las transiciones de Chile, Colombia e Israel tuvieron una duración aproximada de una década, lo que significó una reducción progresiva del ritmo de crecimiento de los precios de entre $2 \%$ y $3 \%$ por año.

Tabla 9. Caracterización del proceso de desinflación para los casos seleccionados desde Inflación Moderada.

\begin{tabular}{lccc}
\cline { 2 - 4 } & Chile & Colombia & Israel \\
\hline $\begin{array}{l}\text { Duración } \\
\text { Inicio }\end{array}$ & oct-90 & abr-91 & sep-91 \\
Fin & ene-00 & may-02 & feb-01 \\
Años & 9,3 & 11,1 & 9,4 \\
Inflación & & & \\
Inicial & $30,4 \%$ & $31,2 \%$ & $20,9 \%$ \\
Final & $2,8 \%$ & $5,8 \%$ & $0,3 \%$ \\
Velocidad & $3,0 \%$ & $2,3 \%$ & $2,2 \%$ \\
\hline
\end{tabular}

Fuente: Elaboración propia

En el caso de Perú y Polonia la duración total del proceso de desinflación, es decir, del período durante el cual dicha variable mostró una tendencia descendente, es similar a los casos anteriores, aunque el ritmo en el que se dio esa transición es considerablemente distinto. A los fines de mejorar el análisis sobre estos episodios se decidió separar el proceso en dos etapas: una inicial donde la tasa de inflación desciende rápidamente y una segunda donde la misma muestra una tendencia decreciente, pero a un ritmo gradual.

Tabla 10. Caracterización del proceso de desinflación para los casos seleccionados desde Alta Inflación.

\begin{tabular}{lcccc} 
& \multicolumn{2}{c}{ Perú } & \multicolumn{2}{c}{ Polonia } \\
\cline { 2 - 5 } & Rápida & Gradual & Rápida & Gradual \\
\hline Duración & & & & \\
Inicio & abr-90 & ene-94 & mar-90 & ene-93 \\
Fin & dic-93 & abr-99 & dic-92 & mar-03 \\
Años & 3,7 & 5,2 & 2,8 & 10,2 \\
Inflación & & & & \\
$\quad$ Inicial & $1903,1 \%$ & $35,5 \%$ & $1200,0 \%$ & $40,2 \%$ \\
Final & $39,5 \%$ & $3,4 \%$ & $44,7 \%$ & $0,4 \%$ \\
Velocidad & $507,6 \%$ & $6,1 \%$ & $419,2 \%$ & $3,9 \%$ \\
\hline
\end{tabular}

Fuente: Elaboración propia 
La discriminación de cada una de estas etapas se presenta en la Tabla 10. Las estabilizaciones se caracterizaron por ser períodos breves, con una duración de alrededor de tres años y una velocidad elevada de desinflación. Una particularidad en ambos casos es que la tasa de inflación que mantuvieron una vez finalizada la primera etapa era lo suficientemente alta para considerarla de baja inflación, mientras que en ambos países los procesos que llevaron a un ambiente de este tipo tuvieron una duración considerable: 5 años en Perú y más de 10 años en Polonia.

El objetivo del capítulo a continuación es identificar elementos comunes y características particulares en estos procesos de desinflación, con el fin de extraer experiencias útiles para el diseño de política económica. La primera sección analiza la configuración de la política monetaria, tanto desde el punto de vista institucional como de sus objetivos e instrumentos. En la segunda parte se analiza el proceso de desinflación a través de una serie de indicadores, lo que permitirá caracterizar el uso de los instrumentos a lo largo del período considerado.

\section{DISEÑO E INSTRUMENTOS DE POLÍTICA MONETARIA}

\section{Marco institucional}

Como toda política pública, la política monetaria parte de un diseño institucional que la precede $y$, en parte, define los límites precisos sobre los que la misma opera. De esta forma, la carta orgánica de los Bancos Central es el elemento básico que define la misión y las características propias del accionar de la institución, por lo que parece un buen punto de partida para considerar la forma en la que operó la política monetaria en estos países.

Una particularidad de los procesos de desinflación estudiados aquí es que la mayoría de ellos mostraron reformas en la carta orgánica de las instituciones monetarias al inicio del proceso de desinflación (en el caso de Chile, Colombia y Perú) antes de ello (Israel) o durante el mismo (Polonia). Si bien las características propias del diseño incluyen un conjunto amplio de dimensiones, interesa aquí ofrecer una breve reseña sobre cuatro elementos: el rango de autonomía funcional establecido para el organismo, la misión que se le impone a la autoridad monetaria, la estructura y órgano competente para la toma de decisiones y los límites al financiamiento monetario del tesoro. Se considera que estos elementos ofrecen una visión panorámica sobre los límites, capacidades, objetivos y estructura de decisión de los Bancos Centrales, al menos, desde el punto de vista formal. Un resumen de estos elementos se presenta en la Tabla 11. 
Tabla 11. Características principales de la Carta Orgánica de los Bancos Centrales al momento de la desinflación según país y año de reforma.

\begin{tabular}{|c|c|c|c|c|c|c|c|c|}
\hline País & Reforma & Autonomía & Mandato & Tipo & Decisiones & $\begin{array}{c}\text { Financiamiento } \\
\text { tesoro }\end{array}$ & $\begin{array}{c}\text { Casos o } \\
\text { excepciones }\end{array}$ & Limites \\
\hline Chile & 1989 & Constitucional & Único & $\begin{array}{l}\text { Estabilidad de la } \\
\text { moneda y el normal } \\
\text { funcionamiento de } \\
\text { los pagos internos y } \\
\text { externos }\end{array}$ & Comité & Prohibido & Guerra & No \\
\hline Colombia & 1992 & Constitucional & Único & $\begin{array}{l}\text { Mantenimiento de la } \\
\text { capacidad } \\
\text { adquisitiva de la } \\
\text { moneda }\end{array}$ & Comité & Permitido & $\begin{array}{l}\text { Aprobación } \\
\text { unánime } \\
\text { Junta } \\
\text { Directiva }\end{array}$ & No \\
\hline Israel & 1985 & Ley & Único & $\begin{array}{l}\text { Estabilidad de } \\
\text { precios }\end{array}$ & Comité & Prohibido & - & - \\
\hline Perú & 1992 & Constitucional & Único & $\begin{array}{l}\text { Estabilidad } \\
\text { monetaria }\end{array}$ & Comité & Prohibido & $\begin{array}{l}\text { Operaciones } \\
\text { Mercado } \\
\text { Abierto }\end{array}$ & $\begin{array}{c}5 \% \text { Base } \\
\text { Mon. }\end{array}$ \\
\hline \multirow[b]{2}{*}{ Polonia } & 1989 & No & Único & $\begin{array}{l}\text { Mantener el valor de } \\
\text { la moneda }\end{array}$ & $\begin{array}{l}\text { Poder } \\
\text { ejecutivo }\end{array}$ & Permitido & - & - \\
\hline & 1997 & Constitucional & Dual & $\begin{array}{l}\text { Mantener la } \\
\text { estabilidad de } \\
\text { precios en } \\
\text { consonancia con las } \\
\text { políticas del } \\
\text { gobierno }\end{array}$ & Comité & Prohibido & - & - \\
\hline
\end{tabular}

Fuente: Elaboración propia 
Hay en este caso elementos en común en la estructura formal de los Bancos Centrales, entre ellos, la tendencia general a establecer la autonomía (o independencia) de la autoridad monetaria, en muchos casos con rango constitucional. En segundo lugar, se observa una prevalencia del mandato único o, en caso contrario, como más relevante, vinculado a la estabilidad de precios. Por último, prevalece la adopción de decisiones a través de un comité, es decir, a través de un cuerpo colegiado. La única excepción se observa en el caso de Polonia, cuya adopción tanto de la autonomía como de las decisiones por un cuerpo colegiado son posteriores al proceso de desinflación.

Desde el punto de vista operativo se observan diferencias más marcadas en los límites a la capacidad de financiamiento del tesoro. Chile e Israel impusieron límites estrictos, aunque en el primero de estos países se reservó la opción de su uso en caso de fuerza mayor (guerra). Polonia transitó un camino similar recién en la reforma de 1997, aunque no establecía límites con anterioridad a esta reforma. Perú y Colombia mantuvieron algún grado de flexibilidad sobre la posibilidad del financiamiento monetario del déficit, pero con límites precisos. En el caso de Colombia, se requería la aprobación unánime del comité de política monetaria, mientras que en Perú solo se encontraba permitida la adquisición de deuda pública a través de Operaciones de Mercado Abierto, con un límite del 5\% de la Base Monetaria. En todo caso, se observa en todos los países una tendencia a imponer ciertos límites al financiamiento monetario, lo que ayuda a dotar de grados de libertad a la política monetaria.

Así como el mandato solía privilegiar el objetivo de la estabilidad de precios, la forma en la que el mismo se evaluaba fue yendo, de manera progresiva, hacia el establecimiento de una meta de inflación anual. Todos estos países establecieron, con mayor o menor énfasis, anuncios sobre la trayectoria de la tasa de inflación para el año al inicio del proceso de desinflación y de metas explicitas sobre esta variable a medida que el mismo se iba consolidando. En algunos casos, como en Chile e Israel, algunos autores consideran que estos anuncios fueron en sí mismos parte del establecimiento de un régimen de metas de inflación de principios de la década del noventa, pero es discutible desde el punto de vista de la caracterización de los regímenes de metas de inflación puros ${ }^{5}$. En todo caso lo importante aquí es que de

\footnotetext{
${ }^{5}$ La identificación de las fechas de inicio de estos procesos en trabajos que son referencia en la materia (por ejemplo Hammond, 2012) parecen sugerir como condición necesaria la instrumentación de la política monetaria a través de las tasas de interés y la libre flotación de la moneda. Dado que los compromisos sobre la meta de inflación eran contingentes a otros que en parte podían resultar contradictorios (como mantener un determinado valor del tipo de cambio) es posible caracterizar estos regímenes como lo que Carare y Stone (2003) denominaron "inflation targeting lite" o, en una traducción libre, "algo de metas de inflación".
} 
manera progresiva los Bancos Centrales que implementaron transiciones graduales lo hicieron especificando los niveles de inflación proyectadas para cada uno de estos años, agregando una forma de control de desempeño.

De la observación sobre la forma en la que estas proyecciones (o metas) fueron establecidas surge que las mismas tenían en todos los casos un horizonte acotado, en otras palabras, no estaban establecidas como el anuncio de un proceso de desinflación sino más bien como la estimación puntual un paso adelante del proceso de inflación. La forma en la que el mismo se implementó parece sugerir un proceso de prueba y error que incluye tanto desvíos de las proyecciones como posteriores correcciones, cambios entre bandas y anuncios puntuales. En algunos casos, se observa el anuncio de una misma meta para el siguiente año (es decir, el establecimiento de que se detendría el proceso de desinflación) o, en otros, situaciones donde la proyección superaba la inflación del año previo. No parece en este sentido que la meta o proyección se haya establecido como "elemento de coordinación", sino más bien a la necesidad de la autoridad monetaria de mostrar su capacidad de predecir y guiar la forma en la que los precios se comportarían. El punto es relevante por el hecho de que la proposición sobre la que se fundamenta la política monetaria no parece ser la de forzar un sendero de inflación independiente del contexto, sino más bien tener la capacidad de predecirlo, adaptando los anuncios a las posibilidades propias de las circunstancias.

Gráfico 22. Chile. Tasa de inflación interanual y metas.

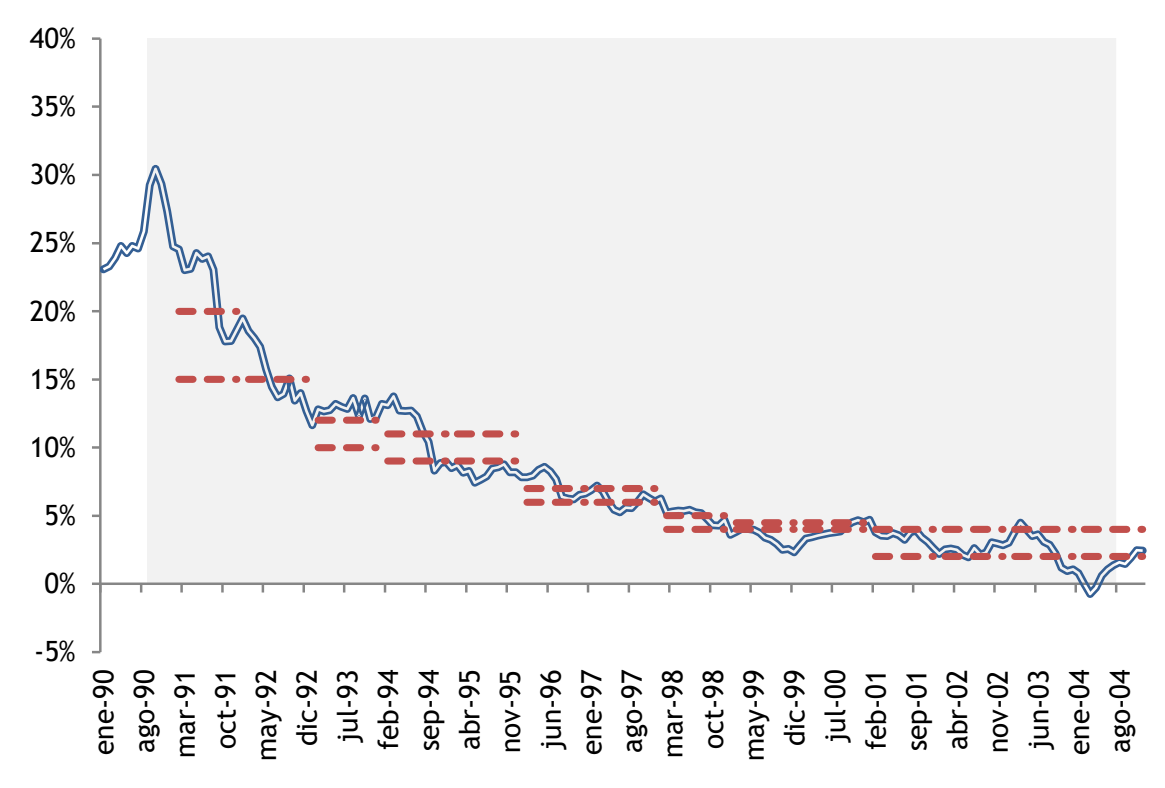

Desinflación $\quad$ Inflación $\quad-\infty$ Meta

Fuente: Elaboración propia 
Gráfico 23. Colombia. Tasa de inflación interanual y metas.

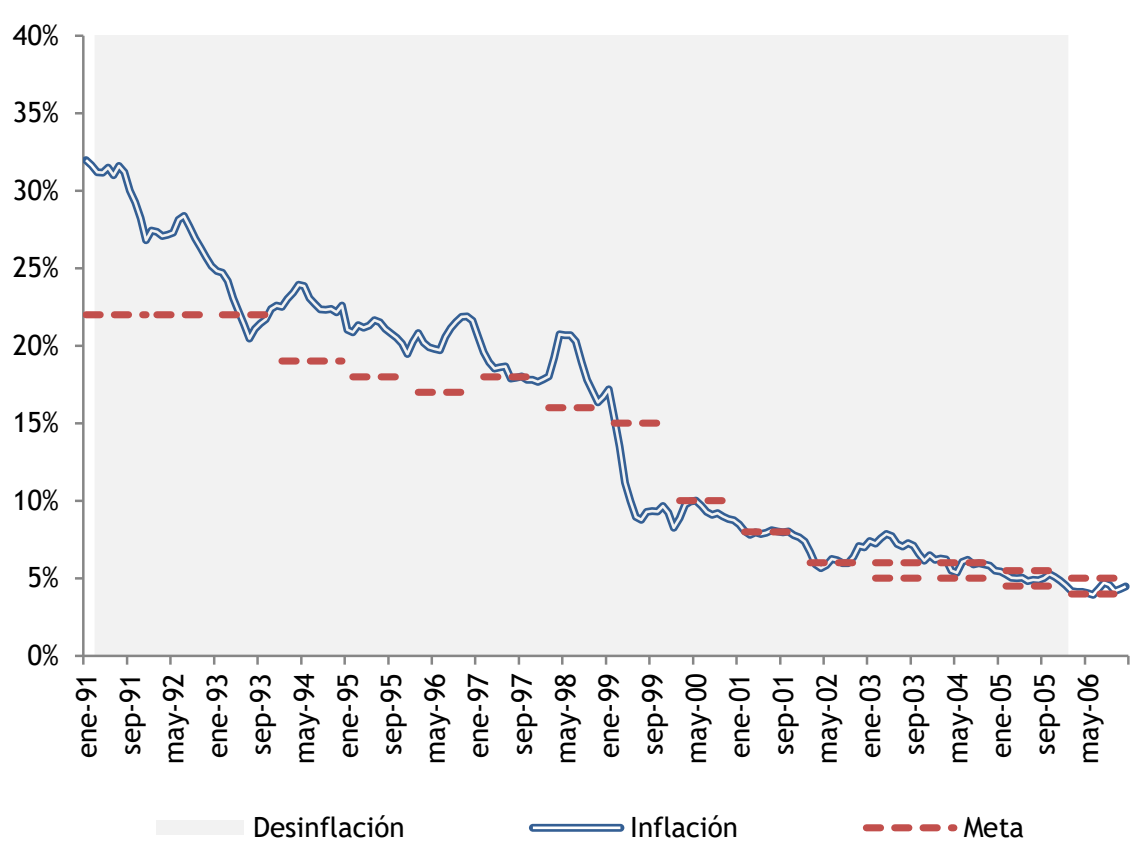

Fuente: Elaboración propia

Gráfico 24. Israel. Tasa de inflación interanual y metas.

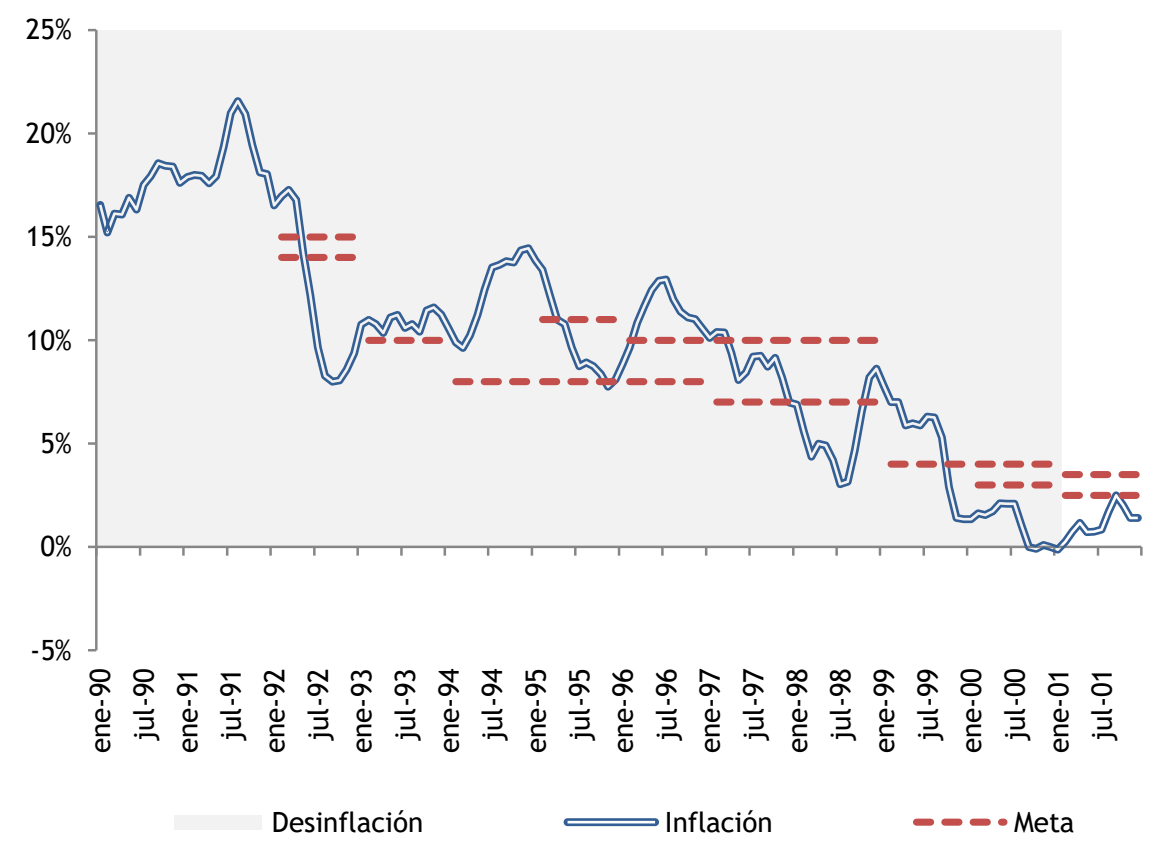

Fuente: Elaboración propia 
Gráfico 25. Perú. Tasa de inflación interanual y metas.

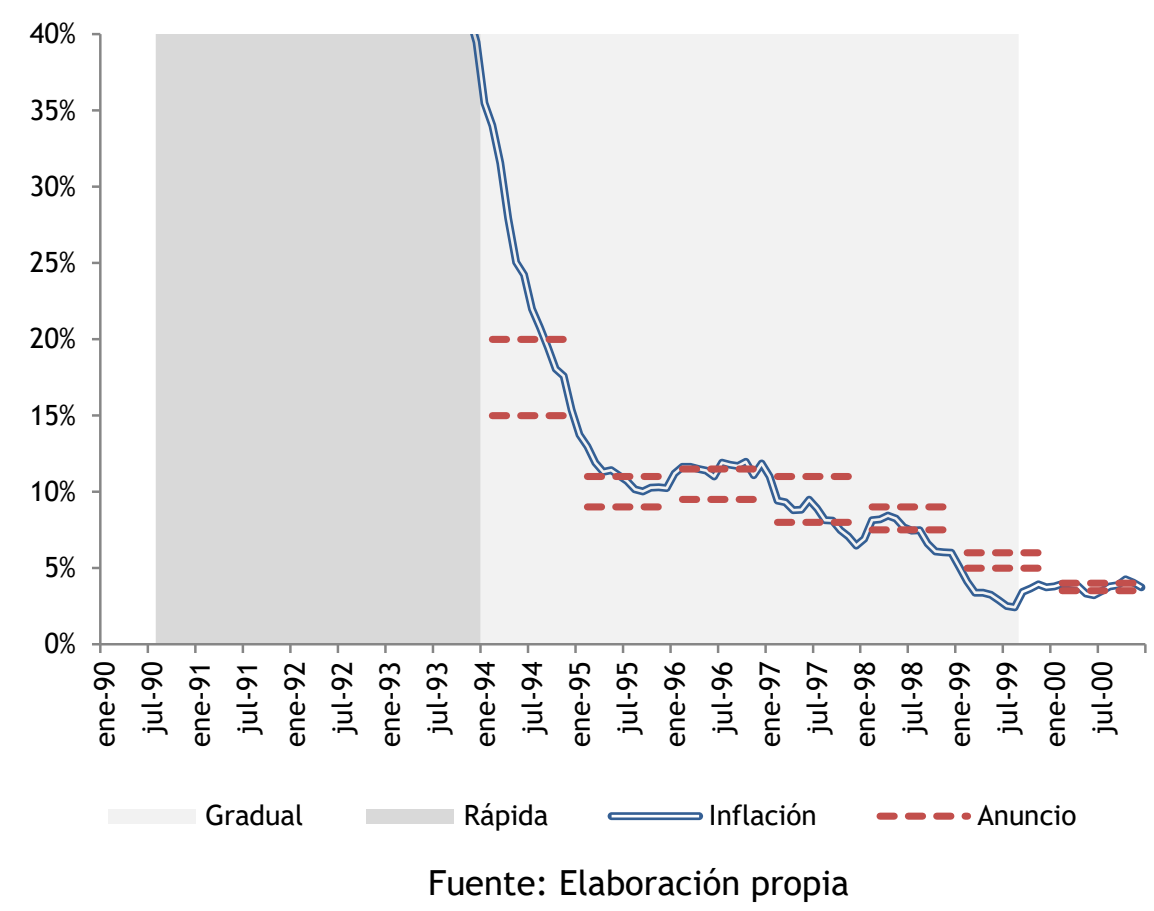

Gráfico 26. Polonia. Tasa de inflación interanual y metas.

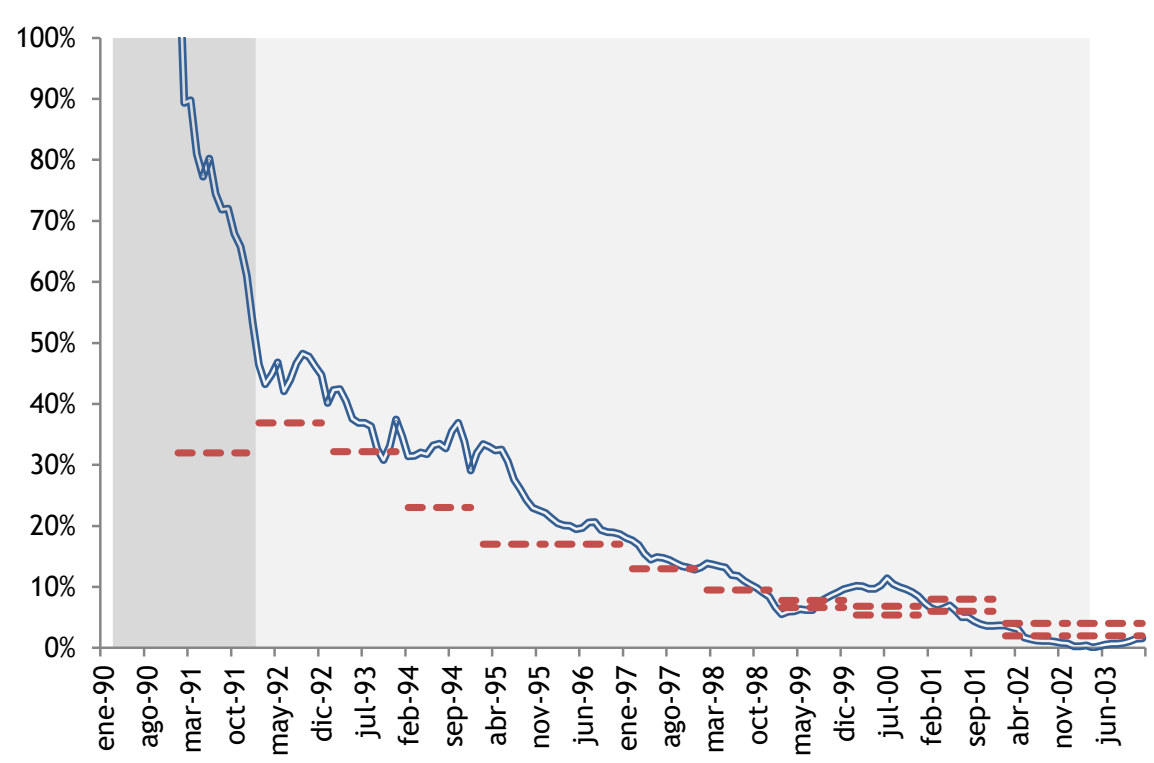

Gradual Rápida Inflación $\rightleftharpoons$ Anuncio

Fuente: Elaboración propia 


\section{Arreglos cambiarios}

En cuanto al esquema cambiario se observa que todos los países estudiados mantuvieron durante la transición formas de intervención en el mercado que dotaban al tipo de cambio de cierto grado de flexibilidad, pero no plena. En el caso de las transiciones desde inflación moderada, las tres economías establecieron bandas cambiarias de distinta variabilidad en el tiempo, en general, tendiendo a ir de menor a mayor flexibilidad. Un resumen de los arreglos y sus modificaciones a lo largo del tiempo se presenta en la Tabla 12.

En el caso de Chile, el país mantenía desde 1984 un régimen de bandas cambiarias con ajuste por inflación rezagada descontando la inflación internacional que fue modificado su amplitud en el tiempo de acuerdo a las circunstancias imperantes con el agregado de una canasta de monedas en 1992 y un ajuste por productividad en algunos momentos puntuales del tiempo. En general, el proceso de ingreso de capitales llevó a que el Banco Central realizara frecuentes ajustes discretos de la paridad, permitiendo una mayor apreciación cambiaria, al menos hasta 1997. A partir de ese año se observa un estrechamiento inicial del canal de flotación, que va progresivamente ampliándose hasta la liberación completa del mercado hacia fines del año 1999.

Gráfico 27. Chile. Tipo de cambio nominal (Moneda Local por USD) durante la desinflación.

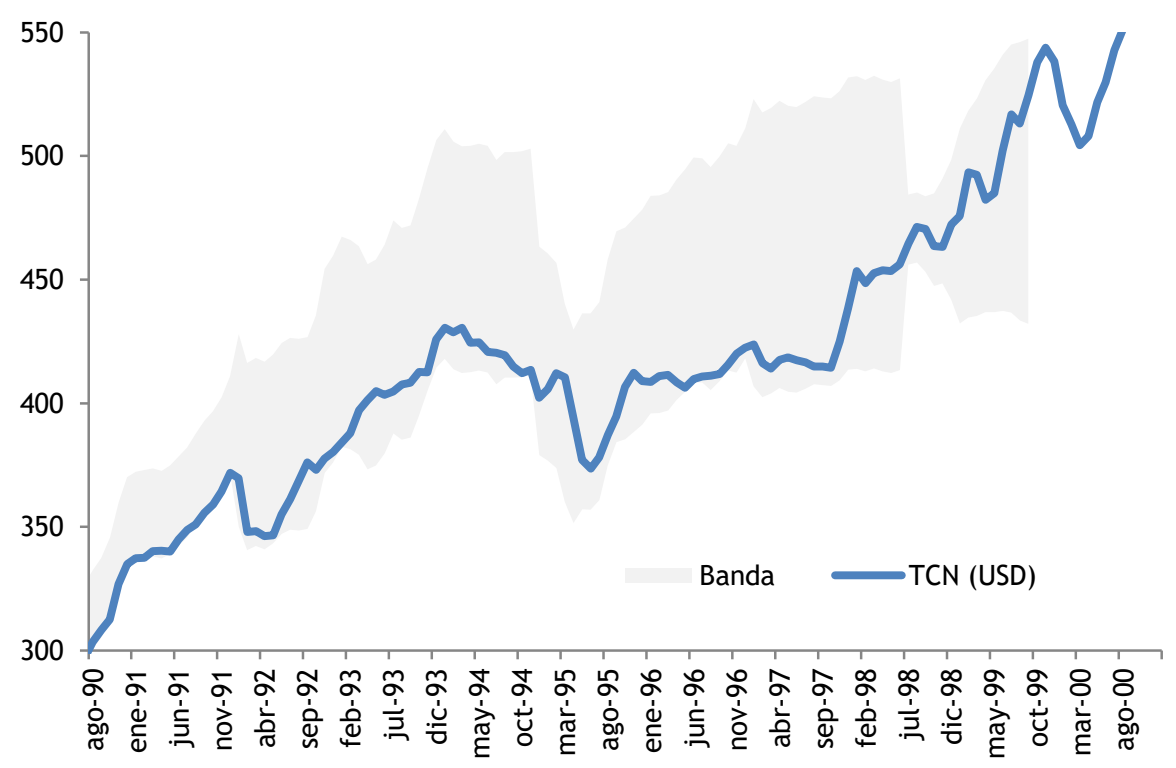

Fuente: Elaboración propia 
Tabla 12. Caracterización de los arreglos cambiarios por país según período.

\begin{tabular}{|c|c|c|c|c|c|c|c|}
\hline País & Años & Régimen & Canasta & $\begin{array}{l}\text { Salto (centro } \\
\text { banda) }\end{array}$ & $\begin{array}{l}\text { Pendiente } \\
\text { anual }\end{array}$ & $\begin{array}{l}\text { Ancho } \\
\text { banda }\end{array}$ & Otro \\
\hline \multirow[t]{2}{*}{ Chile } & $\begin{array}{l}\text { Ene. } 90- \\
\text { Sep.99 }\end{array}$ & Banda Móvil & $\begin{array}{c}\text { Ene. } 90 \text { (100\% USD) Jul.92 } \\
\text { (USD \%50 JPY 20\% DM } \\
\text { 30\%) Dic.94 (USD \%45 JPY } \\
\text { 25\% DM 30\%) Ene.97 (USD } \\
\% 80 \text { JPY 5\% DM 15\%) }\end{array}$ & $\begin{array}{c}\text { Abr. } 91(-1,4 \%) \\
\text { Jun. } 91(-2 \%) \\
\text { Ene.92 (-5\%) } \\
\text { Dic.94 (-9,7\%) } \\
\text { Ene.97 (-4\%) }\end{array}$ & $\begin{array}{l}\text { Inflación } \\
\text { Rezagada + } \\
\text { Inflación } \\
\text { Internacional } \\
\text { MENSUAL }\end{array}$ & $\begin{array}{c}\text { Ene. } 90(5 \%) \\
\text { Ene.92 (10\%) } \\
\text { Ene. } 97 \\
(12,5 \%) \\
\text { Jul. } 98(3 \%) \\
\text { Dic. } 98(8 \%)\end{array}$ & $\begin{array}{c}\text { Ajuste por } \\
\text { productividad } \\
1996 \text { y } 1997 \\
(2 \%)\end{array}$ \\
\hline & Oct.99 & Flotación & & & & & \\
\hline \multirow{3}{*}{ Colombia } & $\begin{array}{l}\text { Ene. } 90- \\
\text { Dic. } 93\end{array}$ & Deslizante & $100 \%$ USD & & $15 \%$ & $6,25 \%$ & $\begin{array}{c}\text { Emisión de } \\
\text { Certificados en } \\
\text { USD a } \\
\text { descuento }\end{array}$ \\
\hline & $\begin{array}{c}\text { Ene.94 - } \\
\text { Dic.99 }\end{array}$ & Banda Móvil & $100 \%$ USD & $\begin{array}{l}\text { Dic. } 94(-7 \%) \\
\text { Sep.98 (14\%) } \\
\text { Jul.99 (7,5\%) }\end{array}$ & $\begin{array}{c}\text { Ene. } 94(11 \%) \\
\text { Dic. } 94(15 \%) \\
\text { ANUAL }\end{array}$ & $\begin{array}{l}\text { Ene. } 94(7 \%) \\
\text { Jul.99 (10\%) }\end{array}$ & \\
\hline & Ene.00 & Flotación & & & & & \\
\hline \multirow{4}{*}{ Israel } & $\begin{array}{l}\text { Mar.90 - } \\
\text { Dic.91 }\end{array}$ & Banda Fija & $\begin{array}{c}\text { Ponderación de Comercio } \\
\text { Exterior }\end{array}$ & & & $5 \%$ & \\
\hline & $\begin{array}{l}\text { Ene.91 - } \\
\text { Jul.97 }\end{array}$ & Banda Móvil & $\begin{array}{c}\text { Ponderación de Comercio } \\
\text { Exterior }\end{array}$ & & $\begin{array}{c}\text { Ene.91 }(9 \%) \\
\text { Nov.92 (8\%) } \\
\text { Jul.93 (6\%) } \\
\text { ANUAL }\end{array}$ & & \\
\hline & $\begin{array}{l}\text { Ago. } 97- \\
\text { Jul.05 }\end{array}$ & $\begin{array}{l}\text { Flotación } \\
\text { Gradual }\end{array}$ & $\begin{array}{c}\text { Ponderación de Comercio } \\
\text { Exterior }\end{array}$ & & & Creciente & \\
\hline & Ago.05 & Flotación & & & & & \\
\hline
\end{tabular}


Tabla 12 (continuación). Caracterización de los arreglos cambiarios por país según período.

\begin{tabular}{|c|c|c|c|c|c|c|}
\hline Perú & Ene.90 - & Flotación & & & & $\begin{array}{l}\text { Intervenciones } \\
\text { cambiarias }\end{array}$ \\
\hline \multirow{5}{*}{ Polonia } & $\begin{array}{l}\text { Ene. } 90 \text { - } \\
\text { Abr.91 }\end{array}$ & Fijo & $100 \%$ USD & $\begin{array}{l}\text { May-91 } \\
(16,8 \%)\end{array}$ & & \\
\hline & $\begin{array}{l}\text { May.91 - } \\
\text { Nov.91 }\end{array}$ & Fijo & $\begin{array}{c}45 \% \text { USD 35\% DM 10\% GBP } \\
5 \% \text { FRF } 5 \% \text { CHF }\end{array}$ & & & \\
\hline & $\begin{array}{l}\text { Oct.91 - } \\
\text { Oct.95 }\end{array}$ & Deslizante & $\begin{array}{c}45 \% \text { USD 35\% DM 10\% GBP } \\
5 \% \text { FRF } 5 \% \text { CHF }\end{array}$ & $\begin{array}{c}\text { Feb. } 92 \\
(10,7 \%) \\
\text { Ago. } 93(7,4 \%)\end{array}$ & $\begin{array}{c}\text { Oct.91 }(1,8 \%) \\
\text { Ago.93 }(1,6 \%) \\
\text { Sep. } 94(1,5 \%) \\
\text { Nov.94 }(1,4 \%) \\
\text { Feb. } 95(1,2 \%) \\
\text { MENSUAL }\end{array}$ & \\
\hline & $\begin{array}{l}\text { May.95- } \\
\text { Mar.00 }\end{array}$ & Banda Móvil & $\begin{array}{c}\text { (45\% USD 35\% DM 10\% } \\
\text { GBP 5\% FRF 5\% CHF) } \\
\text { Ene.99 (55\% EUR 45\% } \\
\text { USD) }\end{array}$ & Dic.95 (-6\%) & $\begin{array}{c}\text { Ene. } 96(1 \%) \\
\text { Jul. } 98(0,65 \%) \\
\text { Sep. } 98(0,5 \%) \\
\text { Mar.99 }(0,3 \%) \\
\text { MENSUAL }\end{array}$ & $\begin{array}{c}\text { May.95 (7\%) } \\
\text { Feb.98 (10\%) } \\
\text { Oct.98 } \\
(12,5 \%) \\
\text { Mar.99 (15\%) }\end{array}$ \\
\hline & Abr.00 & Flotante & & & & \\
\hline
\end{tabular}

Fuente: Elaboración propia 
En el caso de Colombia, el país mantuvo un régimen de tipo de cambio fijo deslizante desde 1967. A partir de 1991, como consecuencia del ingreso de capitales la posibilidad de defender cierto nivel de la paridad cambiaria fue puesta en duda, por lo que el Banco de la Republica decidió flexibilizar el régimen cambiario estableciendo un sistema de certificados de cambio, lo que en la práctica establecía bandas cambiarias de facto (Villar, 1999), que fueron formalmente establecidas en 1994 hasta 1999. A diferencia de Chile, el esquema se basaba en una banda preanunciada que no necesariamente tenía como referencia el desempeño de otras variables, al menos de manera explícita y se utilizó la referencia a una paridad única con el dólar. Una vez más, el caso de Colombia muestra apreciaciones en el nivel medio de la banda durante el proceso de ingreso de capitales, aunque menos frecuentes (lo que llevó a una apreciación inicial menos pronunciada, como se verá en la próxima sección).

Adicionalmente, desde inicios de los noventa se estableció en Chile un esquema de control al ingreso de capitales a través de diferenciales de encajes no remunerados, los cuales ascendían a un 30\% para plazos menores a un año hasta 1998, momento en el que fueron eliminados. En el caso de Colombia, si bien fueron más erráticos, desde 1993 a 1997 se establecieron controles también con un sistema de encajes no remunerados al que se añadió en 1997 un impuesto adicional. En el año 2000 todo el sistema de encajes fue eliminado junto con la liberalización del tipo de cambio. De acuerdo a Magud, Reinhart y Rogoff (2018) los estudios muestran que en ambos casos la presencia de controles dotó de mayores grados de libertad a la política monetaria.

Gráfico 28. Colombia. Tipo de cambio nominal (Moneda Local por USD) durante la desinflación.

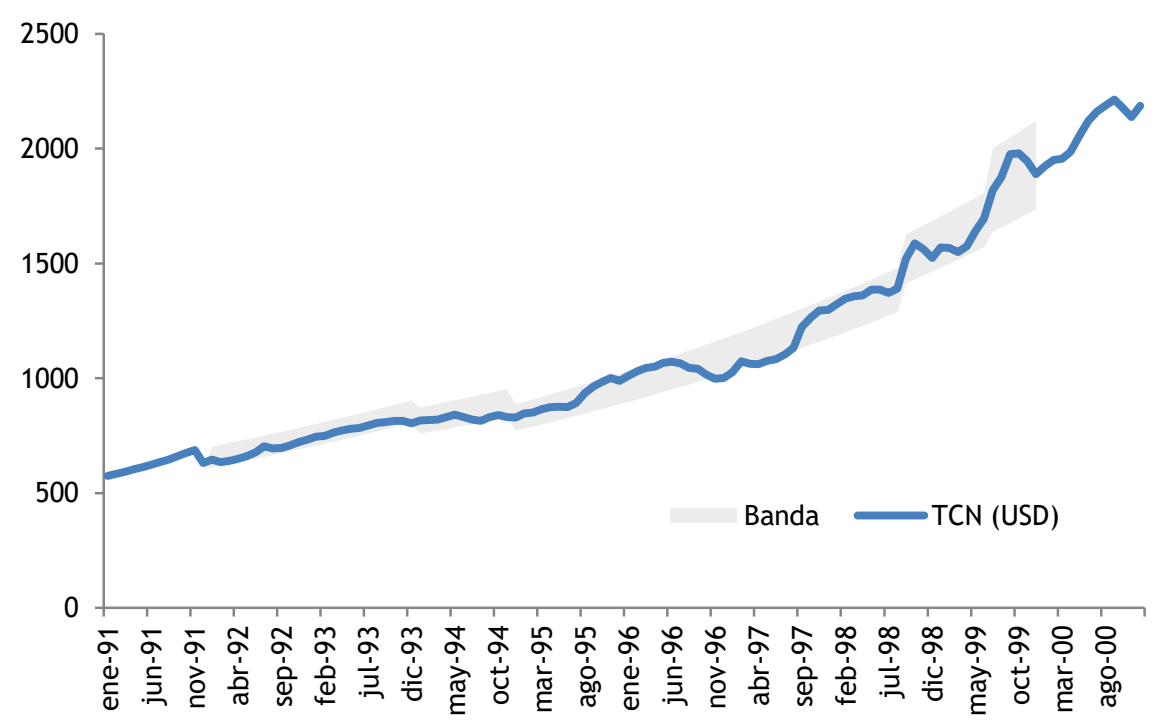

Fuente: Elaboración propia 
Israel implementó una banda cambiaria horizontal en enero de 1989, que se fue modificando para introducir finalmente una banda deslizante en diciembre de 1991. De acuerdo a Djivre y Tsiddon (2002) la pendiente de la banda intentaba capturar el diferencial de inflación interna de Israel respecto de sus socios comerciales (lo que en Chile se descontaba a través de la inflación internacional). A partir de 1997 se fue ampliando progresivamente el ancho de la banda hasta el establecimiento definitivo de un régimen de tipo de cambio flotante en el año 2005.

Gráfico 29. Israel. Tipo de cambio nominal (Canasta por USD) durante la desinflación.

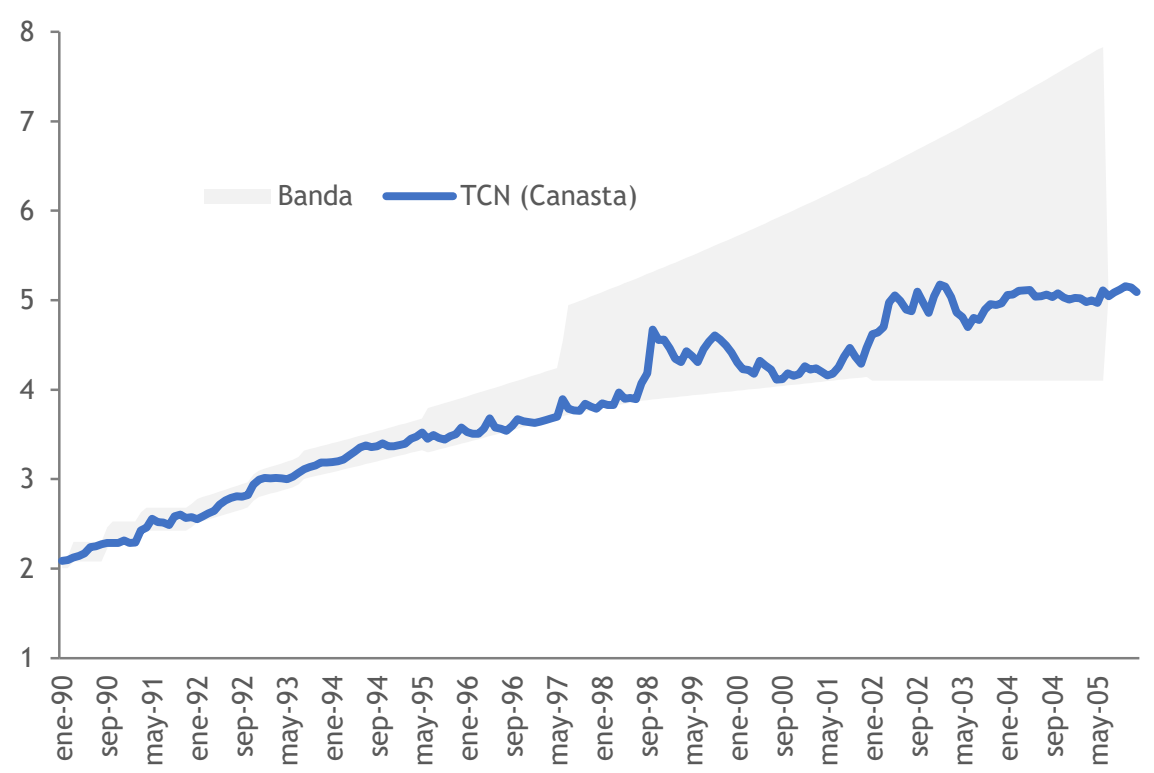

Fuente: Elaboración propia

En las estabilizaciones desde alta inflación se observan diferentes configuraciones: en el caso de Perú, se mantuvo un régimen de flotación sucia, con intervenciones directas del Banco Central. De acuerdo con Armas et al (2001) la instrumentación de la política monetaria se basaba en el control de la liquidez, sin embargo, se hacía efectiva a través del mercado de cambios, lo que en la práctica deja ciertas dudas sobre cuál de ambos era el instrumento de política (más aún cuando, como se verá, el tipo de cambio se apreció considerablemente en las etapas iniciales de la estabilización). 
Gráfico 30. Perú. Tipo de cambio nominal (Moneda Local por USD) durante la desinflación.

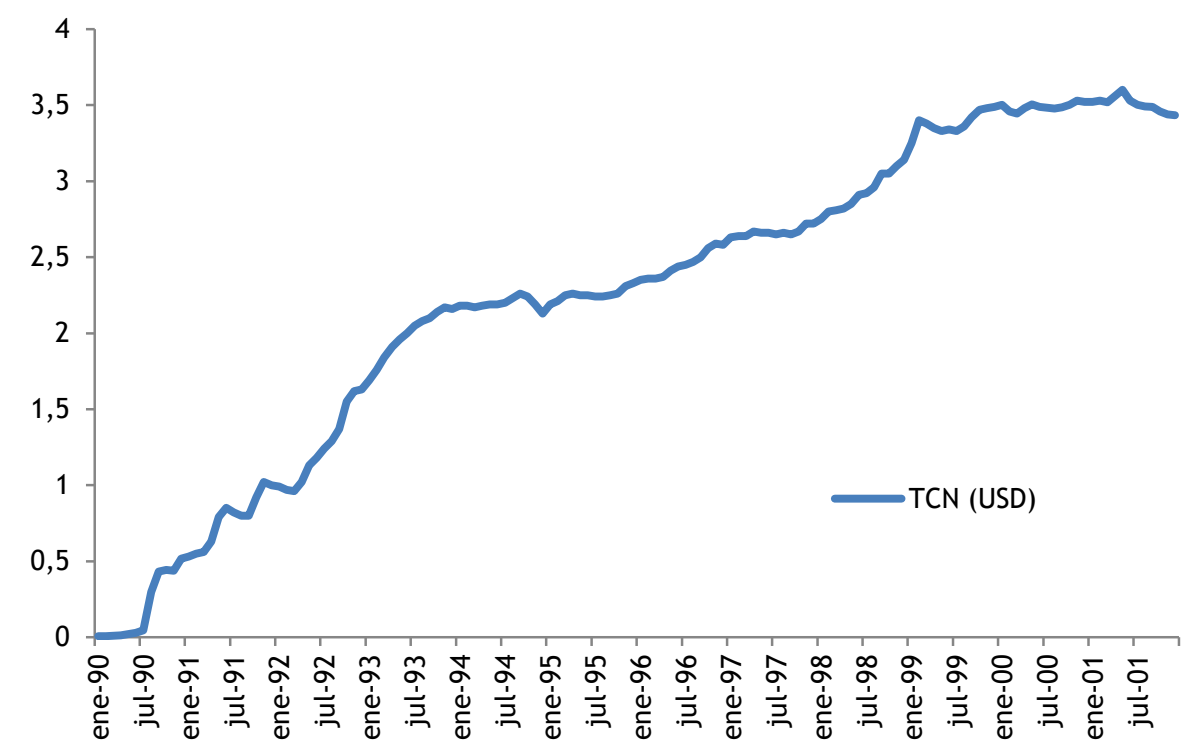

Fuente: Elaboración propia

Gráfico 31. Polonia. Tipo de cambio nominal (Moneda Local por USD) durante la desinflación.

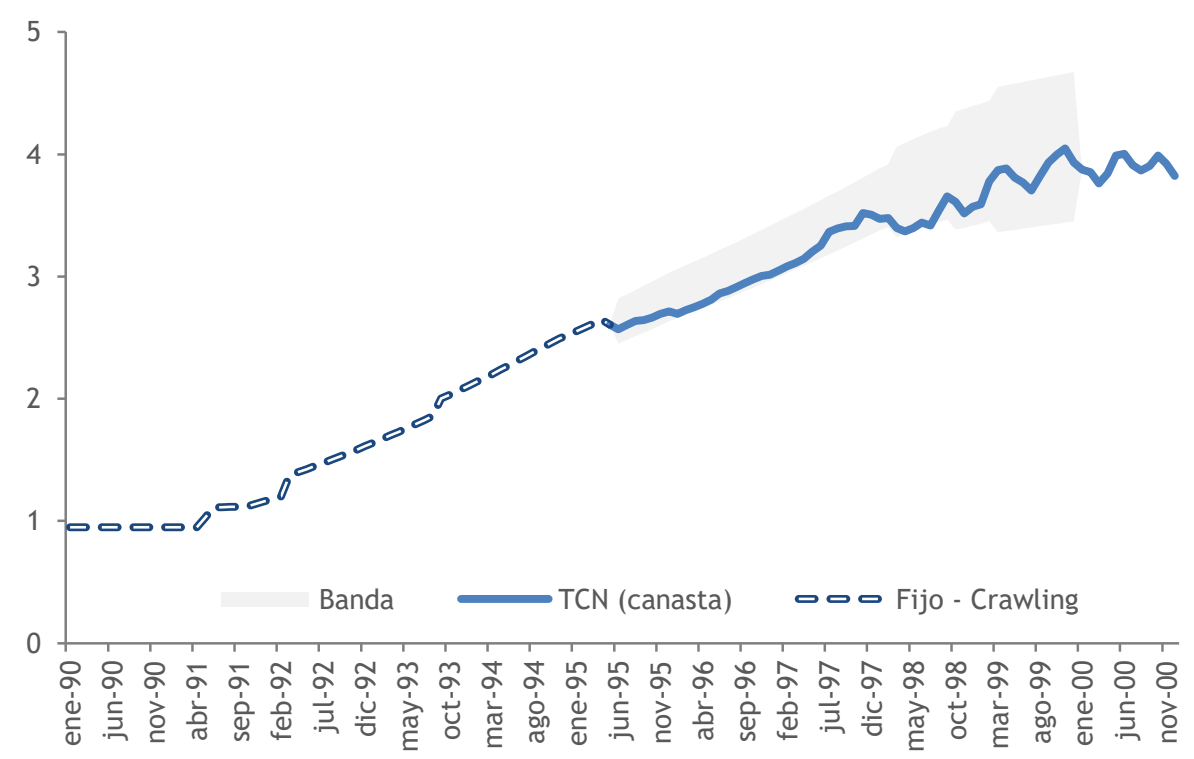

Fuente: Elaboración propia

En Polonia se transitaron varias etapas, desde una fijación inicial en 1990 que dio rápidamente paso a una paridad a través de una canasta de monedas. Entre 1992 
y 1995 se estableció una paridad móvil con ajuste mensual que fue decreciendo en el tiempo. A partir de fines de 1995 se dotó al sistema de mayor movilidad permitiendo que el tipo de cambio fluctuara en una banda móvil que se fue ampliando progresivamente a lo largo del tiempo respecto de una canasta. En general la paridad cambiaria se mantuvo, al igual que en los otros casos, gran parte del período cerca del límite inferior de la banda, lo que generó la necesidad de frecuentes intervenciones cambiarias. En el año 2000 se terminó de liberar el mercado de cambios estableciendo un régimen de tipo de cambio flotante.

Es necesario destacar que, como parte de los precios relativos, en ambos casos los países en alta inflación transitaron procesos de fuertes reformas estructurales que incluyeron elementos relevantes para el proceso de formación de precios, como la desregulación (en muchos casos acompañada por la privatización) y ajuste de tarifas de servicios públicos o bienes en general (particularmente en el caso de Polonia). Estos cambios fueron previos al proceso de desinflación y no se han encontrado referencias respecto de grandes alteraciones de precios relativos durante el mismo.

\section{Manejo de la liquidez y tasas de interés}

Respecto del manejo de la liquidez, los Bancos Centrales mantuvieron estrategias mixtas. En el caso de Colombia, Perú y Polonia los países establecieron metas intermedias de agregados monetarios, si bien su cumplimiento estricto es poco claro, en tanto los mismos fueron contingentes al mantenimiento de los esquemas cambiarios y de alguna forma resultaban redundantes. En el caso de Chile existen menos referencias a este tipo de estructuración de la política monetaria en cuanto a los agregados monetarios, mientras que en Israel era claro que la forma de intervención del mercado se efectuaba a través de las tasas de interés. En general, esta última estrategia fue progresivamente adoptada por los países, hasta la implementación definitiva de un esquema de metas de inflación.

El manejo de tasas de referencia como instrumento de política monetaria en el inicio del proceso de desinflación fue más bien una excepción entre los países estudiados. Hubo, sin embargo, ciertas intervenciones sobre los mercados de crédito que a lo largo del tiempo permitieron a los Bancos Centrales perfeccionar los instrumentos con los que, avanzado el proceso de desinflación, se elaborarían las tasas de referencia de la política monetaria. Un resumen de esta progresión se encuentra en la Tabla 13. 
Tabla 13. Principales tasas de referencia de la política monetaria por país y período.

\begin{tabular}{|c|c|c|c|c|c|}
\hline País & Años & Tasa & Tipo & Unidad de Cuenta & Decisión \\
\hline \multirow{3}{*}{ Chile } & 1990-1996* & $\begin{array}{l}\text { Pagarés reajustables } \\
\text { Banco Central }\end{array}$ & Implícita & Indexada (UF) & $\begin{array}{l}\text { Operaciones } \\
\text { de Mercado } \\
\text { Abierto }\end{array}$ \\
\hline & $1997-2000$ & Referencia & Explicita & Indexada (UF) & Comité \\
\hline & Desde 2001 & Referencia & Explicita & Nominal & Comité \\
\hline Colombia & Desde 1995 & Referencia & Explicita & Nominal & Comité \\
\hline Israel & Desde 1992 & Referencia & Explicita & Nominal & Comité \\
\hline \multirow[t]{2}{*}{ Perú } & $1992-2003^{* *}$ & $\begin{array}{l}\text { Certificado de } \\
\text { depósitos del Banco } \\
\text { Central }\end{array}$ & Implícita & Nominal & $\begin{array}{l}\text { Operaciones } \\
\text { de Mercado } \\
\text { Abierto }\end{array}$ \\
\hline & Desde 2004 & Referencia & Explicita & Nominal & Comité \\
\hline \multirow{2}{*}{ Polonia } & $1993-1997$ & Redescuento & Implícita & Nominal & Interbancaria \\
\hline & Desde 1998 & Referencia & Explicita & Nominal & Comité \\
\hline
\end{tabular}

* De Gregorio, Tokman y Valdez (2005)

** Armas, Grippa, Quispe Misaico y Valdivia (2001)

Fuente: Elaboración propia

En el caso de Chile el volumen de los pasivos remunerados del Banco Central hacia que sus tasas se convirtieran en una referencia central para la estructura de tasas de mercado, al tiempo que las mismas se definían por las operaciones de mercado abierto. La mayor parte de estos pasivos (así como el resto del sistema financiero, como se observa en el Gráfico 32) se encontraban indexados, por lo que las tasas de los mismos se expresaban en términos reales. A partir de 1996 el país instrumentó una tasa explicita de referencia, la cual mantuvo la particularidad de establecerse en términos reales, es decir, se encontraba expresada en unidades de valor constantes (Unidad de Fomento). Recién en el año 2001 Chile instrumenta una tasa de referencia nominal, momento en el cual la economía se encontraba en niveles bajos de inflación.

Colombia comenzó a establecer una tasa de referencia en 1996 principalmente para suavizar la volatilidad del mercado interbancario, lo que permitió mejorar el manejo de este tipo de intervenciones (Urrutia, 2002).

Perú mantuvo durante el período un seguimiento estricto de los agregados monetarios en un contexto de elevada dolarización del sistema financiero (ver Gráfico 33). El manejo de los agregados se realizaba a través de intervenciones en el mercado de cambios, las cuales eran posteriormente esterilizadas mediante certificados de depósitos. De acuerdo a Armas et al (2001) esta tasa de referencia era relevante para 
la coordinación de los activos financieros de corto plazo denominados en moneda doméstica. A partir del año 2004 comenzó a anunciar una tasa de referencia.

Gráfico 32. Chile. Depósitos del sistema financiero denominados en Unidad de Fomento.

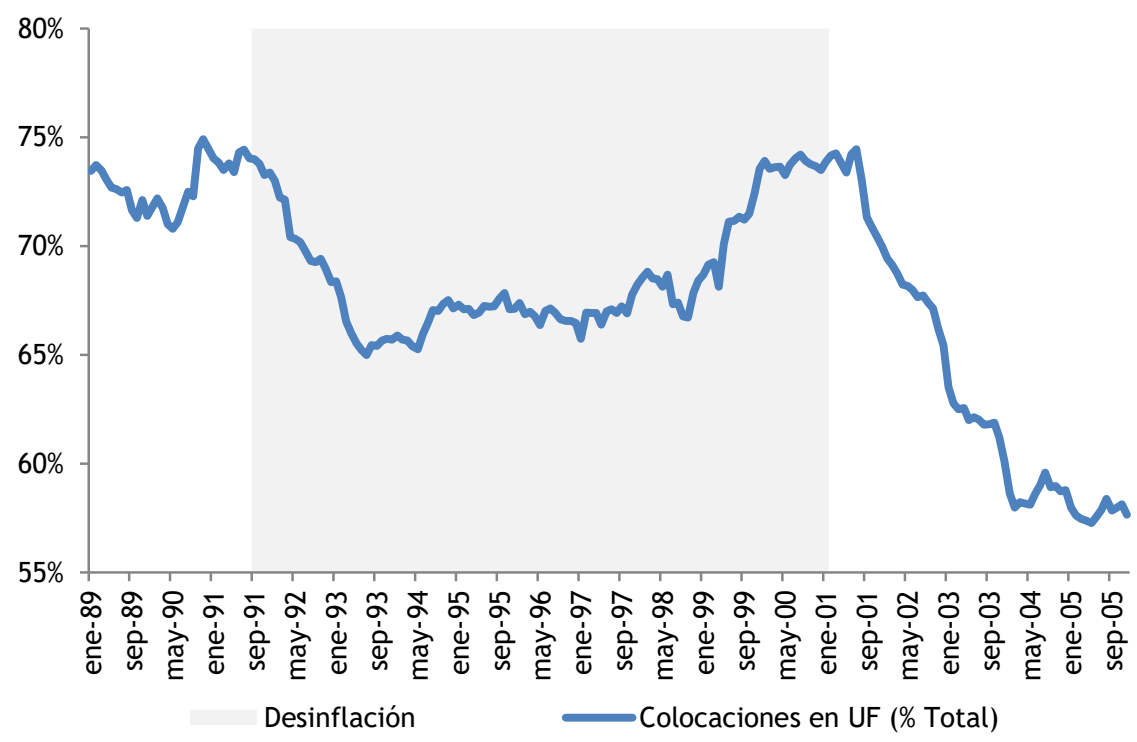

Fuente: Elaboración propia en base a Banco Central de Chile

Gráfico 33. Perú. Dolarización de la liquidez.

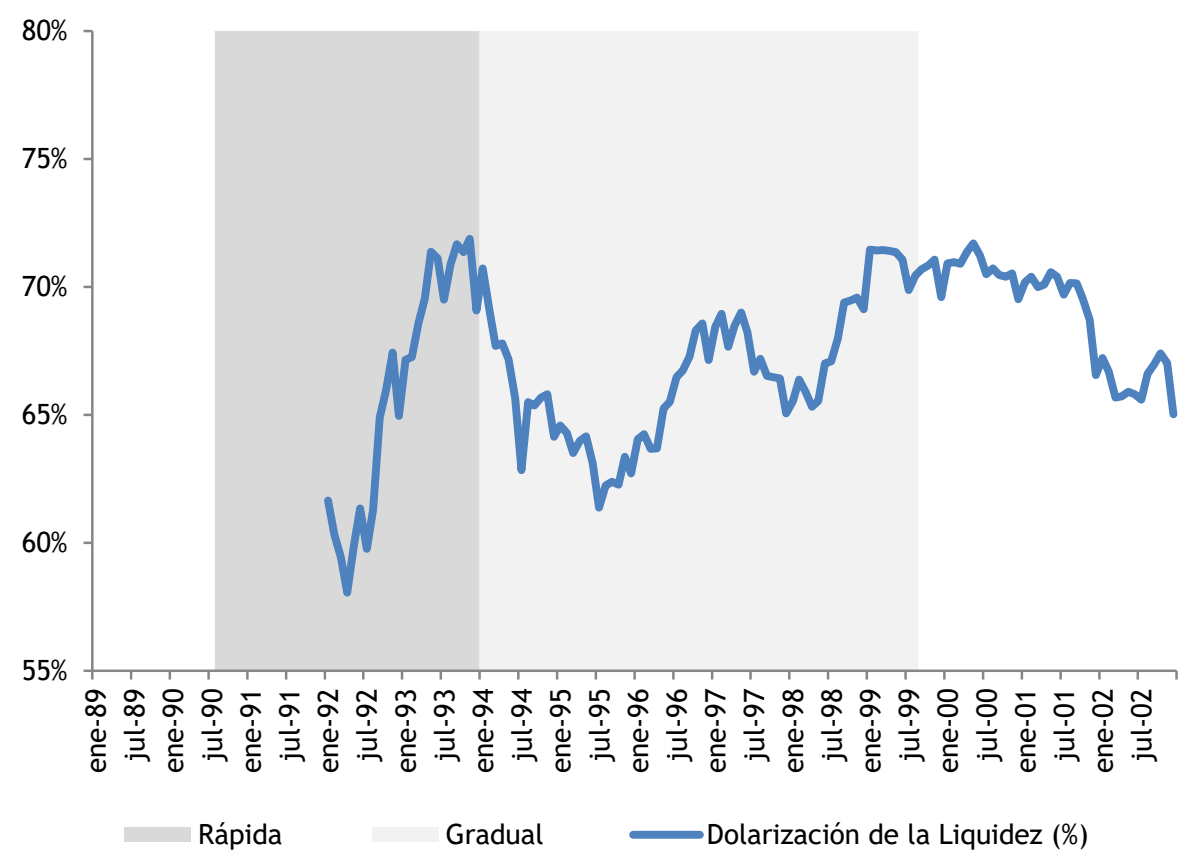

Fuente: Elaboración propia en base a Banco de la Reserva de Perú 
Polonia mantuvo durante toda la transición intervenciones a través de la tasa interbancaria, las cuales derivaron a partir de 1998 y con el establecimiento de modificaciones más generales en la política de la institución (como se dijo anteriormente, por la reforma de la carta orgánica) en la aplicación de una tasa de referencia explícita.

Se observa en general que el uso de tasas de referencia explicitas no fue una característica propia de las desinflaciones sino una excepción, y su instrumentación se dio más bien al tiempo que se avanzaba en el proceso de desinflación. En este camino, el uso de instrumentos de mercado (como los títulos del Banco Central o las tasas interbancarias) sirvieron como herramientas de transición para perfeccionar el manejo de la política monetaria. En todos los casos se avanzó, a diferentes ritmos, hacia la aplicación de una tasa de referencia nominal explicita definida y anunciada por un comité.

\section{TRAYECTORIAS Y DESEMPEÑO MACROECONÓMICO}

La política monetaria mostró a lo largo del período una configuración que ofrecía grados de libertad para operar frente a cambios en el contexto. Las trayectorias de la macroeconomía marcaron, en este sentido, la forma en la que fueron utilizados estos grados de libertad y el uso específico de instrumentos en cada momento del tiempo. Con el fin de caracterizar los procesos subyacentes parece útil señalar dos etapas, caracterizadas por eventos que, en diferente magnitud, afectaron a la economía global. La primera de estas etapas es la que va desde inicios de la década del noventa hasta 1997, período que se caracteriza por un incremento de la movilidad de capitales que fue, como se verá, aprovechado por las cinco economías bajo estudio. La crisis asiática de 1997 y la crisis rusa de 1998 parecen marcar un punto de inflexión que forzó cambios en el diseño del programa macroeconómico, al menos hasta los primeros años de la década del 2000.

Desde el punto de vista de la política fiscal (Gráfico 34), las economías de América Latina mantuvieron durante la primer etapa una balance superavitario, en el caso de Chile y Colombia, o cercano al equilibrio, en el caso de Perú. Israel mantuvo un déficit continuo hasta 1997 y Polonia, a pesar de acercarse al equilibrio fiscal en el proceso de estabilización, mantuvo también déficits recurrentes. Debe remarcarse en este caso que la mayor parte de las economías latinoamericanas habían registrado en la década anterior un proceso de estancamiento (“década perdida”) debido al ajuste posterior a sucesivas crisis de deuda (ver Ocampo, 2014). En este sentido, no resulta 
extraño que el equilibrio fiscal fuese un elemento central en el manejo de las políticas macroeconómicas, al menos en esta primera etapa.

La dinámica de precios relativos parece haber acompañado la disponibilidad de financiamiento externo, en un contexto donde se registraron ingresos significativos de capitales. Los esquemas cambiarios se diseñaron y fueron particularmente efectivos, al menos hasta 1997, para evitar que la apreciación generada por estos flujos fuese abrupta, aunque con el paso del tiempo las monedas de estos países registraron un fortalecimiento significativo (Gráfico 35). Como contrapartida, los Bancos Centrales de las cinco economías registraron en este período una fuerte acumulación de activos externos (Gráfico 36) lo que refuerza el punto anterior respecto del rol de los esquemas cambiarios en la configuración de la política monetaria. En el caso de las transiciones desde alta inflación es claro que la etapa de estabilización se encuentra fundamentalmente marcada por el mantenimiento de paridades relativamente (Perú) o totalmente (Polonia) fijas, dando lugar a un proceso de gran apreciación. Las etapas de transición parecen mantener elementos comunes con las inflaciones moderadas, con arreglos cambiarios que permitieron un proceso de apreciación gradual junto con una acumulación de reservas internacionales.

Es claro en todo caso que la necesidad de defender una paridad cambiaria llevaba a la autoridad monetaria, frente a un abundante ingreso de capitales, a intervenir sobre el mercado aumentando la liquidez (afectando la meta de inflación) o esterilizando (reforzando el ingreso de capitales). La forma de enfrentar este conflicto fue cambiando entre países y en cada uno de ellos a lo largo del tiempo. Morandé (2001) considera que el manejo del límite inferior de la banda en el caso de Chile fue una muestra de que, ante tensiones entre el manejo de la meta de inflación y el objetivo de mantener cierto equilibrio en la cuenta corriente (representado por una paridad real específica), la autoridad monetaria privilegió el objetivo inflacionario. Liviatan y Sussman (2002), en tanto, observan que el hecho de que el Banco Central de Israel no tuviera potestades sobre el límite inferior de la banda cambiaria fue una de las razones por las cuales el proceso de desinflación mostró reversiones frecuentes al inicio. En el caso de Colombia hay apreciaciones al inicio de la implementación de las bandas cambiarias y en un período posterior, pero las mismas fueron menos frecuentes. En el caso de Perú los grados de libertad sobre el nivel deseado del tipo de cambio eran mayores, lo que permitió no tener un conflicto claro. Polonia parece mantenerse en una posición intermedia ya que si bien las apreciaciones discretas no fueron regulares, la pendiente de la banda y la amplitud de la misma permitieron dirigir el ritmo de apreciación. 


\section{Gráfico 34. Resultado Financiero durante la desinflación.}
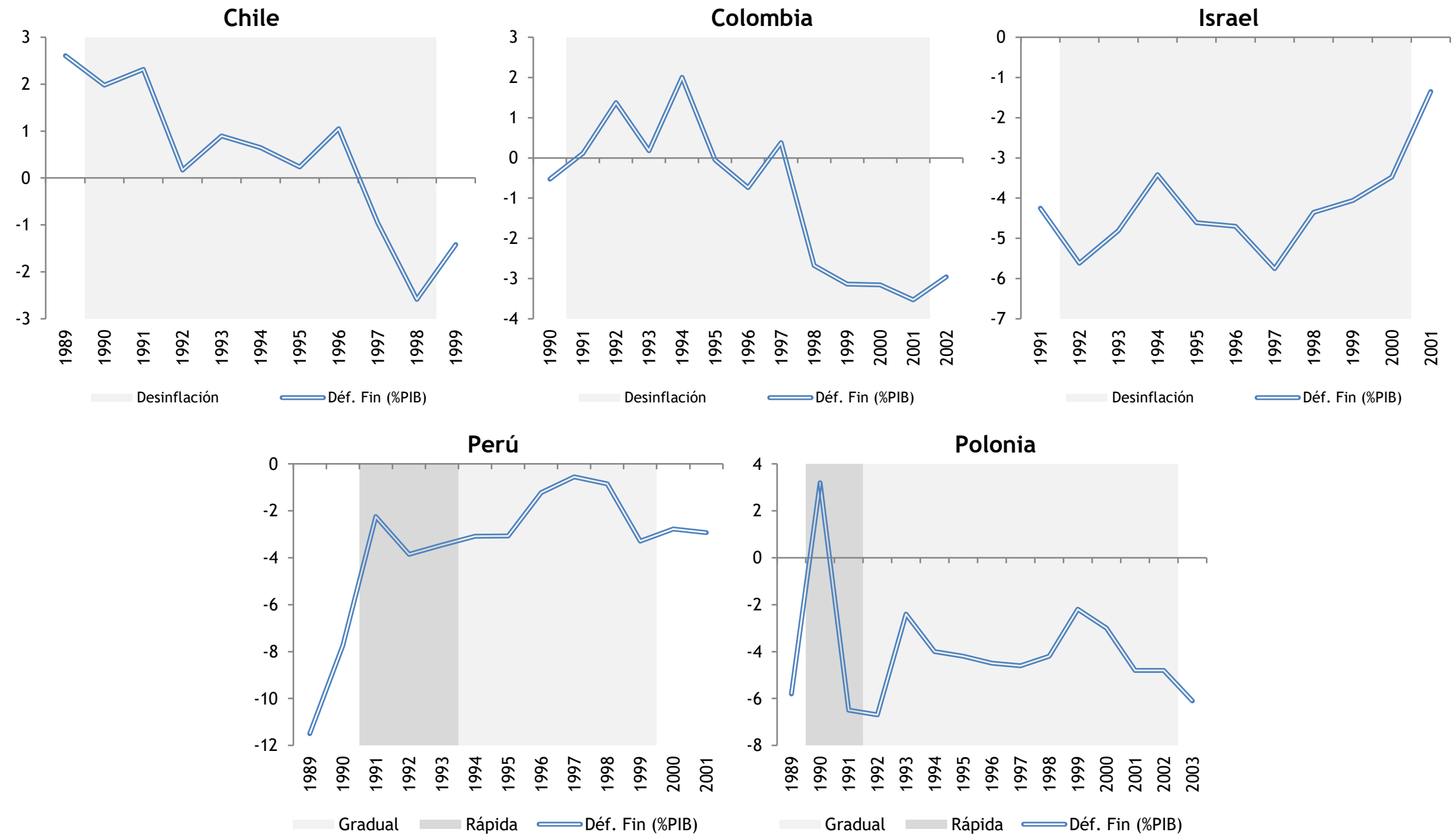

Fuente: Elaboración propia 
Gráfico 35. Tipo de Cambio Real durante la desinflación.
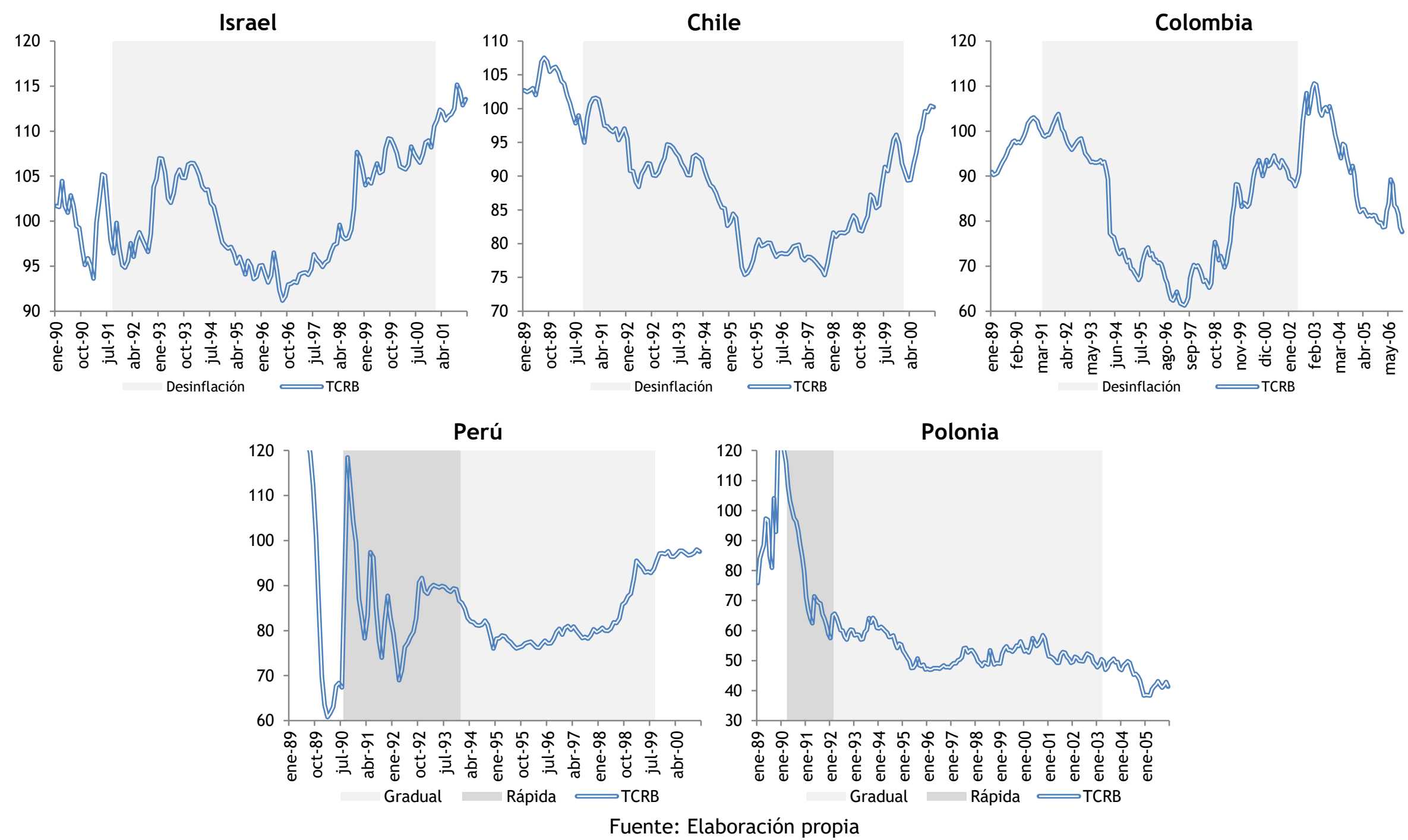

Fuente: Elaboración propia 
Gráfico 36. Reservas internacionales del Banco Central. En millones de USD

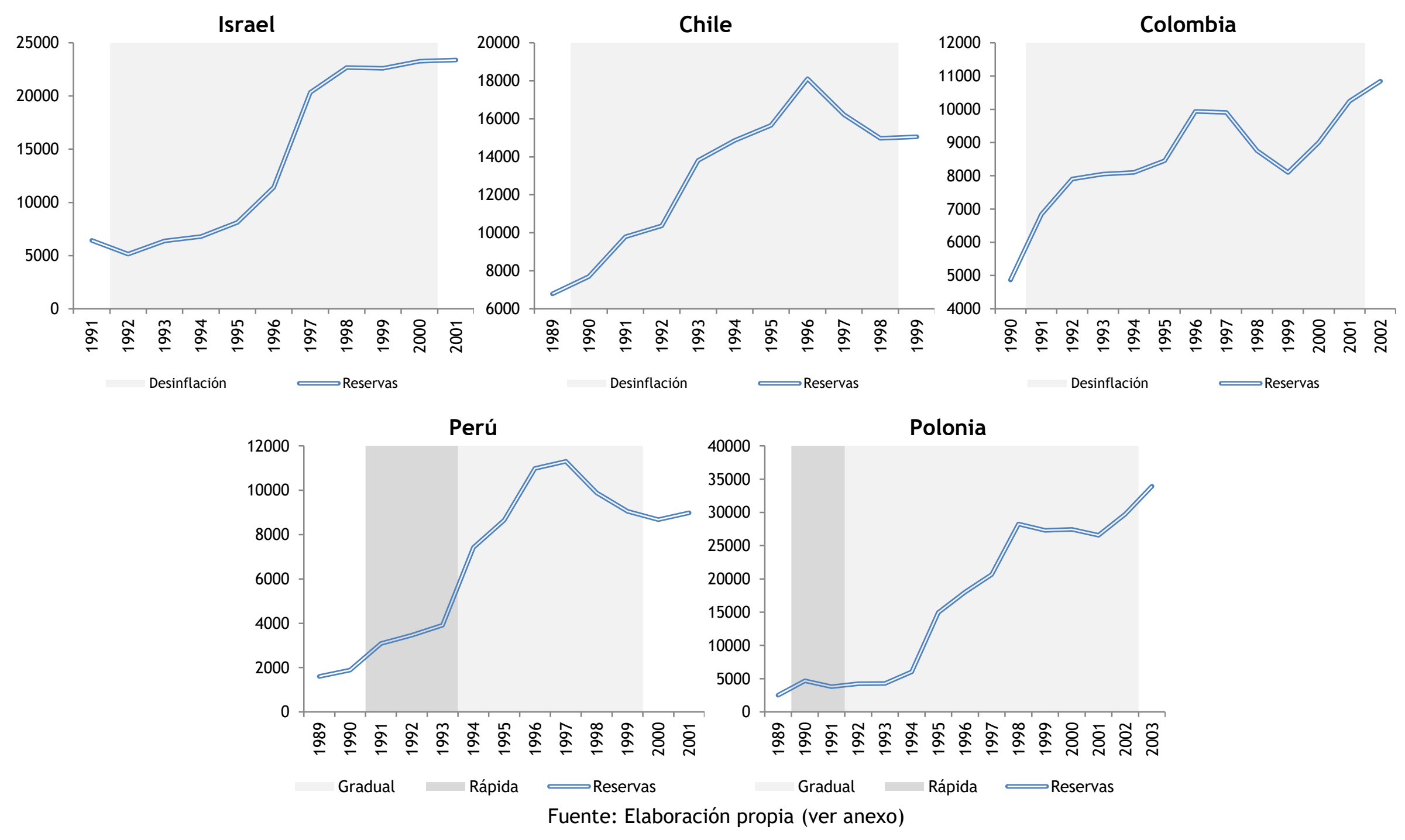


La determinación de las tasas de interés ayuda a comprender de manera más acabada la forma en la que los conflictos entre los esquemas cambiarios y el proceso de desinflación fue modificándose en el tiempo. Chile es sin dudas el caso más particular, ya que mantuvo durante todo el período una tasa de interés de referencia denominada en moneda constante, que se mantuvo en rangos positivos durante todo el período de desinflación. En el caso de Israel las tasas de interés de política no llegaron a compensar la inflación efectiva (y lo hicieron de manera errática respecto de la inflación ex-post) al inicio del proceso de inflación. Algo similar ocurrió en Colombia, donde si bien no existía una tasa de referencia, la tasa del mercado interbancario muestra que en los momentos iniciales del proceso de desinflación las tasas nominales superaban solo en algunas ocasiones la tasa de inflación. De las tres economías, solo Chile consiguió mantener de manera continua los objetivos de inflación sin incurrir en desvíos. A partir de 1995 tanto Israel modificó la tasa de política de manera que la misma fue claramente positiva en términos reales durante el tramo restante de la desinflación. En el caso de Colombia a partir de ese año la Junta de Política Monetaria comienza a establecer intervenciones específicas sobre el mercado interbancario y se anuncia una tasa de referencia, la cual se mantuvo positiva en términos reales. En ambos casos, se observa una disminución de los desvíos respecto de las metas de inflación una vez establecida esta estrategia.

De acuerdo a Morandé (2002) gran parte de los argumentos que se utilizaban para el uso de la tasa de referencia en términos reales se centraban en la mayor estabilidad de la misma frente a modificaciones en la expectativa de inflación. Si bien el autor no encuentra razones sólidas a favor de esta proposición (ya que las alteraciones en la tasa de inflación esperada también deberían repercutir en la definición de la tasa real) el desempeño comparado de los tres países parece favorecer el uso de este instrumento por sobre la tasa nominal. El mismo autor reconoce la posibilidad de que, al inicio del proceso de desinflación y en contextos donde la autoridad monetaria carece de reputación, puede existir resistencia o presiones de carácter político sobre las tasas de interés nominales. Las tasas reales parecen haber sido un instrumento de comunicación efectiva sobre la posición de la política monetaria, al menos al inicio del proceso de desinflación.

En el caso de Perú y Polonia, se observan tasas de interés reales negativas al inicio, pero considerando la fuerte apreciación inicial las mismas fueron elevadas en comparación al rendimiento en moneda extranjera. Los procesos de transición mostraron progresivamente una posición más clara en el establecimiento de tasas reales positivas. 
Gráfico 37. Tasa de interés real y en USD (ex-post).

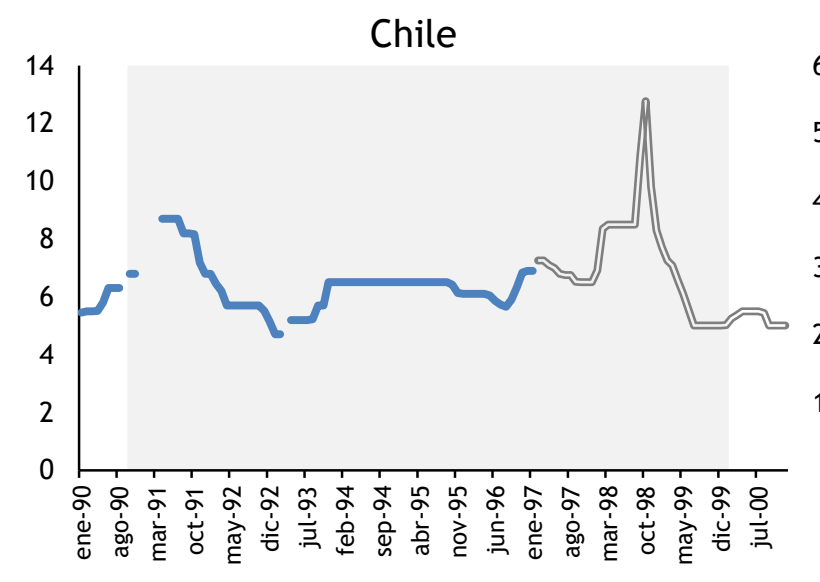

Desinflación Pagarés reajustables

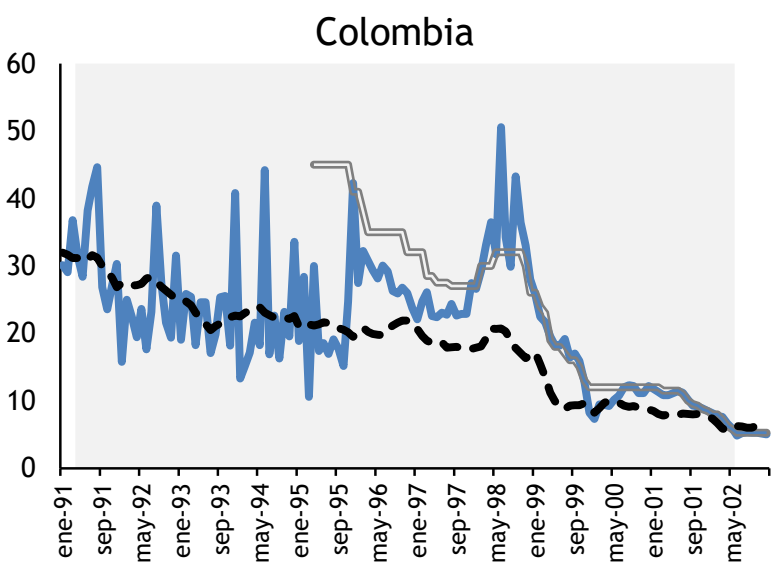

Desinflación Referencia
Interbancaria _ _ Inflación
Israel

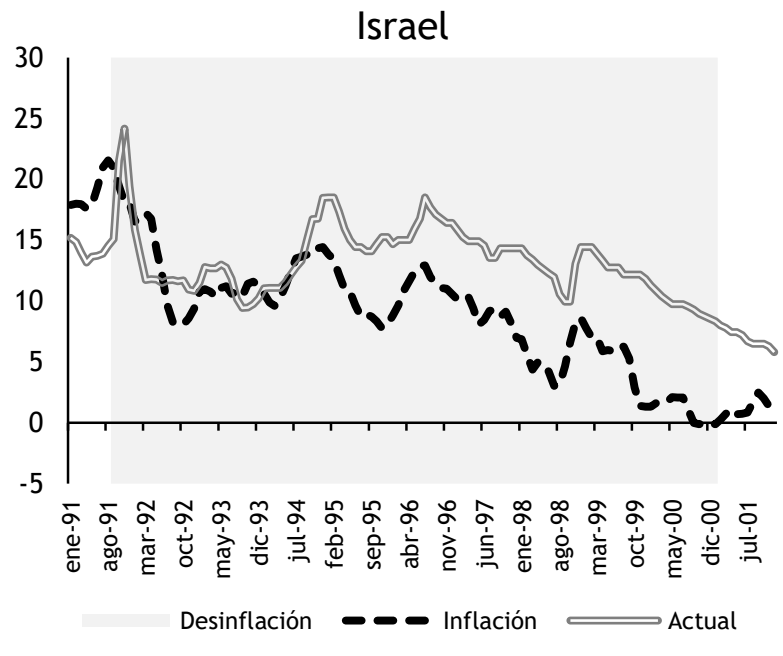

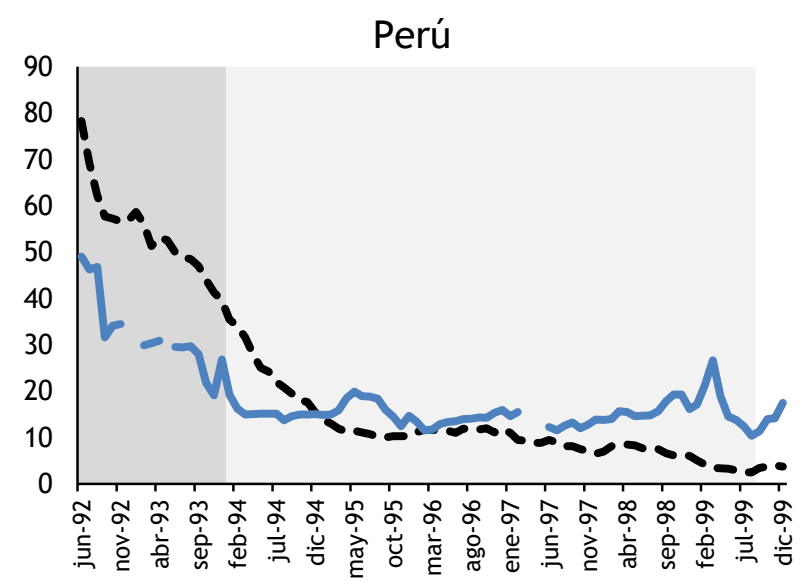

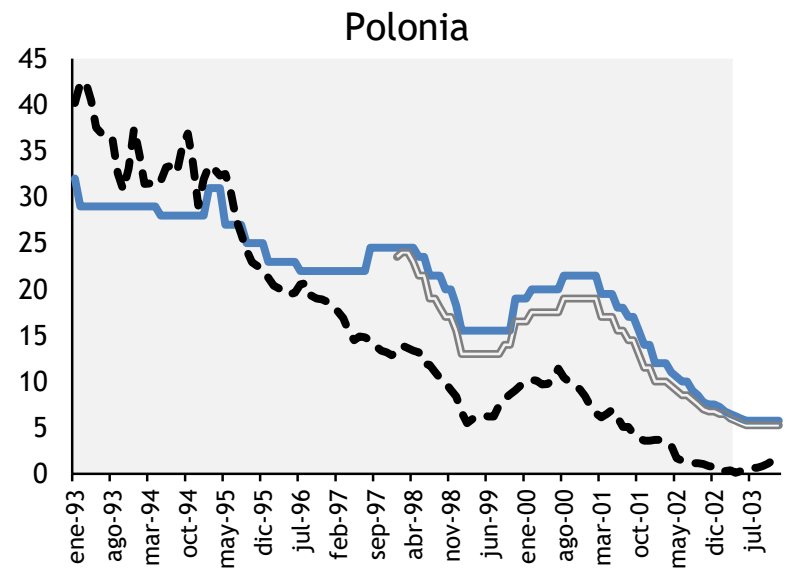

Rápida

Gradual

Gradual

Referencia

Redescuento

- - Inflación

Fuente: Elaboración propia 
Entre 1997 y 1998 la crisis asiática y la crisis rusa alteraron la configuración de la política económica, particularmente en los países de América Latina. Hasta ese momento el proceso estaba marcado por un deterioro del balance de cuenta corriente, que se profundizó de la mano del crecimiento económico y el fortalecimiento de las monedas locales. Las crisis sucesivas endurecieron las condiciones de financiamiento externo, lo que en la práctica se mostró inicialmente bajo la forma de tensiones sobre las paridades cambiarias. En este contexto las autoridades monetarias mantuvieron el compromiso sobre las paridades cambiarias, lo que significó pasar de intervenir en el piso de la banda a defender el techo de la misma. Entre 1997 y principios del 2000 todos los países muestran diferencias claras en el proceso de acumulación de reservas internacionales, pasando de una acumulación neta en el período previo a un mantenimiento, en el caso de Israel, y perdidas en todos los demás países.

Para el momento en el que el impacto externo afecta a los regímenes cambiarios casi todas las economías, con excepción de Colombia, mostraban tasas de inflación menores o iguales al 10\%, resultado de un largo proceso de desinflación. Uno de los resultados más destacables de ese momento fue que el salto en las paridades cambiarias no tuvo correlato con los precios internos. Las economías se comportaron de manera compatible a un régimen de baja inflación, lo que ofreció un grado de libertad adicional a la política monetaria. El incremento en el tipo de cambio real y la desaceleración de la actividad interna se asociaron con un ajuste en el balance de cuenta corriente (Gráfico 38). Para el año 2000 los regímenes cambiarios se habían convertido en una regulación redundante ya que, al disminuir la asociación entre los precios internos y el tipo de cambio, la política monetaria podía permitir un mayor grado de flotación sin preocuparse por que la misma afectase los objetivos de la política monetaria. Por ese entonces, Colombia, Chile y Polonia eliminaron las bandas cambiarias deslizantes y establecieron la libre flotación de la moneda.

El impacto de la crisis internacional afectó con mayor fuerza a los países de América Latina que, en general, usaron el espacio fiscal para realizar políticas expansivas, lo que en la práctica mostró un deterioro del resultado financiero (Gráfico 34). Hasta estos años el crecimiento económico se había mantenido en ritmos elevados para todos los países (Gráfico 39), por lo que no parece posible afirmar que la desinflación haya tenido amplios ratios de sacrificio. En todo caso, hay razones para pensar que esta estrategia gradual de política monetaria favoreció la expansión de la demanda interna en un contexto donde, con cierto grado de indexación o inercia en la determinación de los salarios, la velocidad de desinflación fue proporcional al crecimiento del salario real (Gráfico 40). 
Gráfico 38. Tipo de cambio real y balance de cuenta corriente.
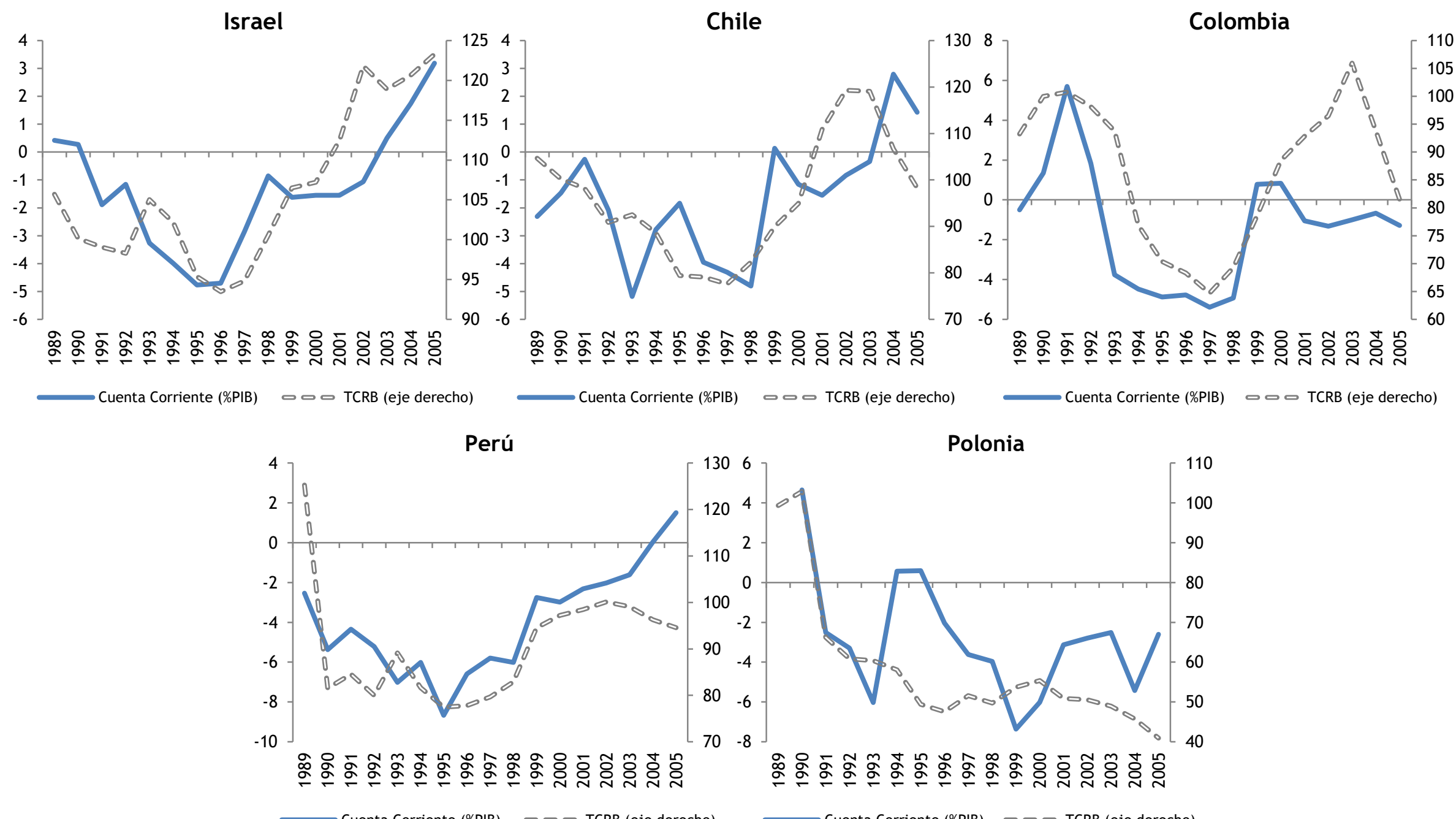

Fuente: Elaboración propia 
Gráfico 39. Tasa de crecimiento del PIB (a precios constantes)
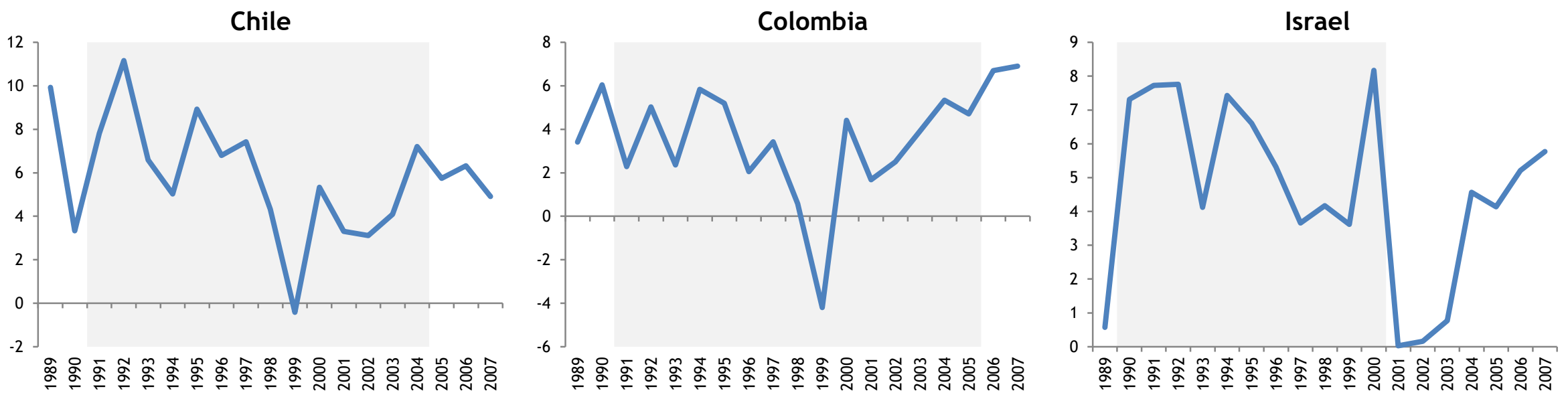

Desinflación

PBI

Desinflación

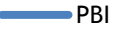

Desinflación

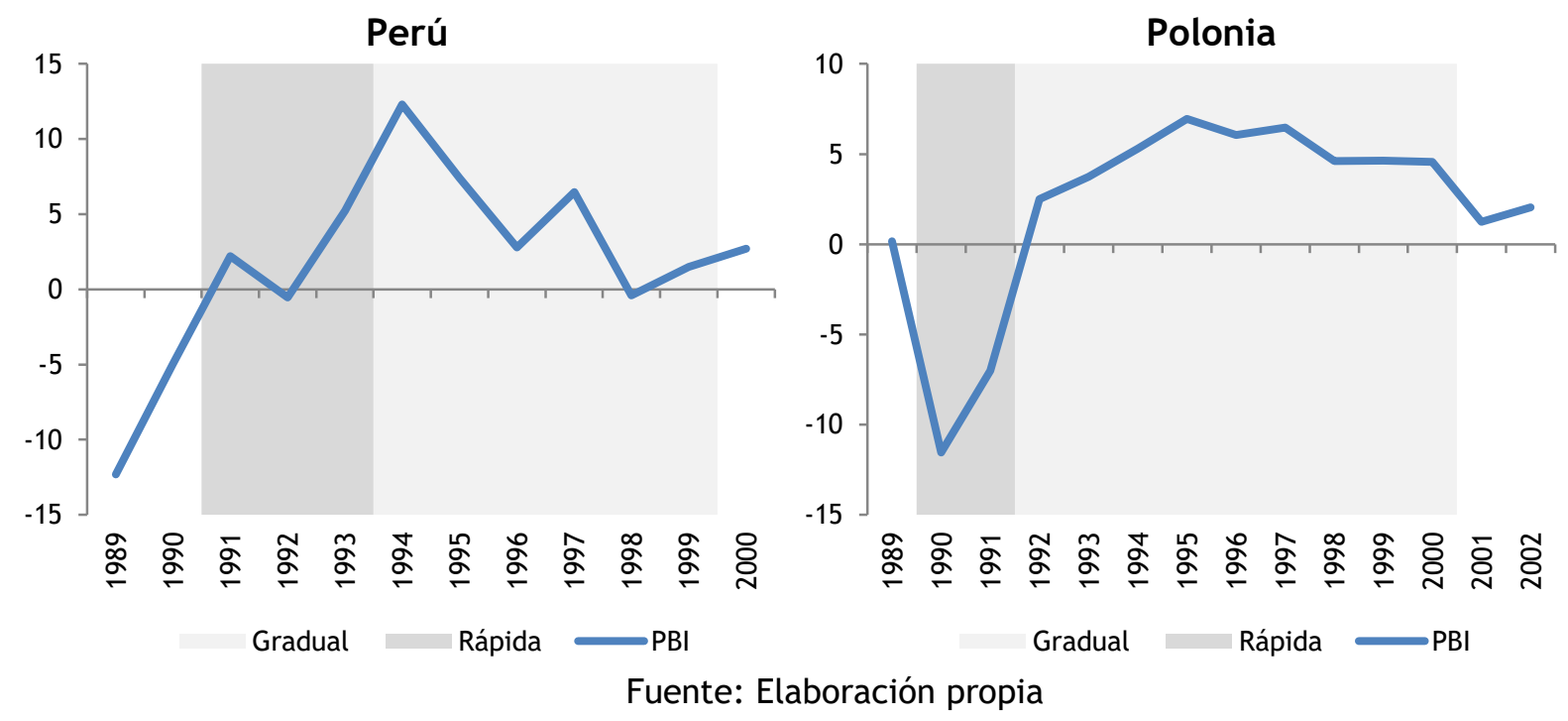


Gráfico 40. Índice de Salario Real (2007=100)
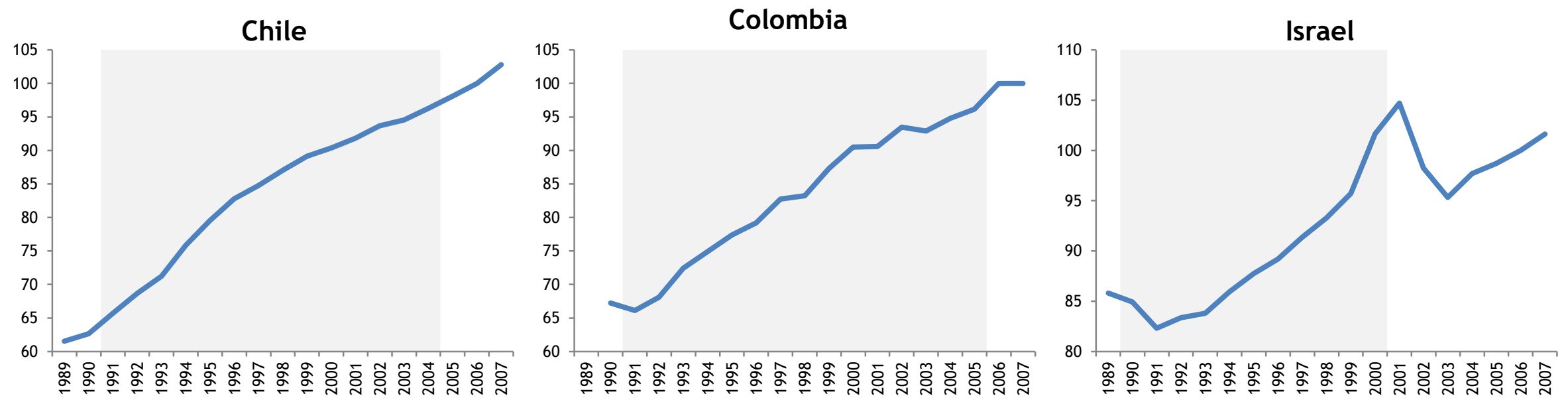

Desinflación Salario Real

Desinflación

Salario Real

Desinflación

Salario Real
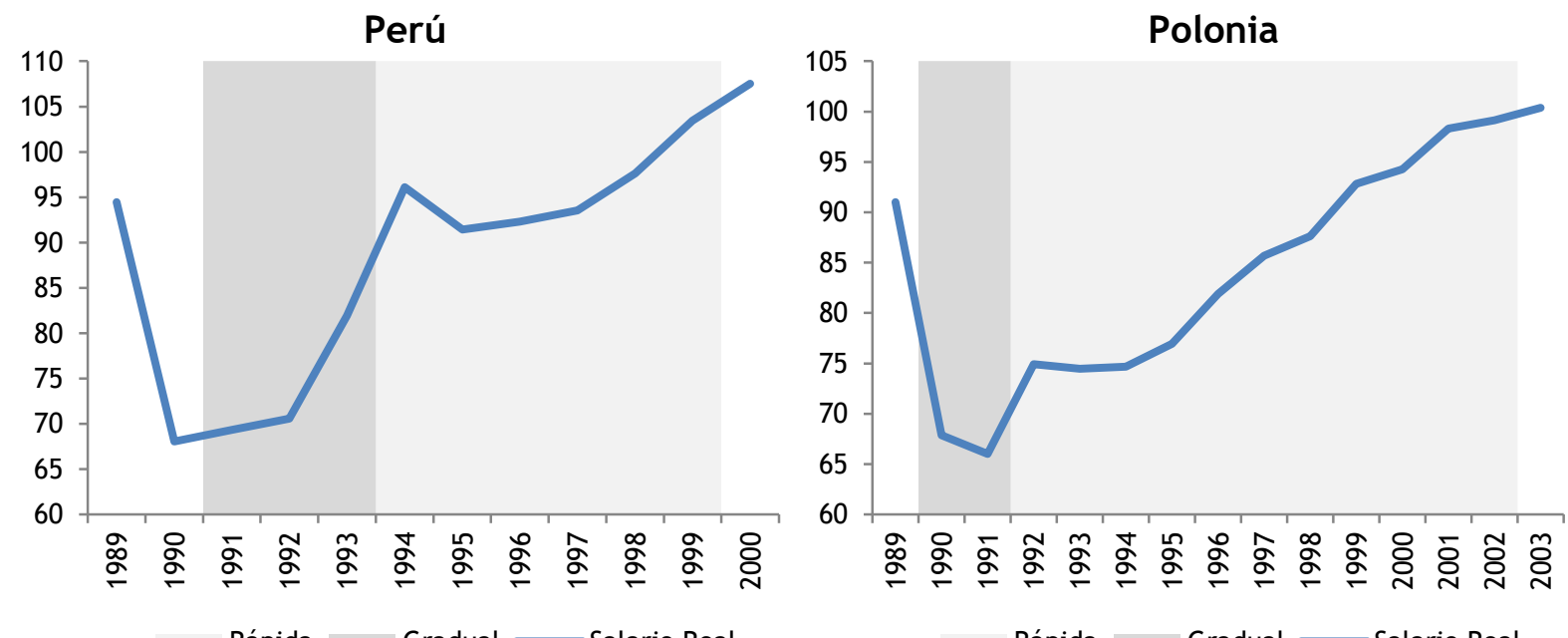

Rápida Gradual $\longrightarrow$ Salario Real

Rápida Gradual $\longrightarrow$ Salario Real

Fuente: Elaboración propia 


\section{CONCLUSIONES}

Los cinco episodios analizados aquí se contraponen con la noción de que solo es posible establecer transiciones a baja inflación de manera abrupta. El hecho de que la inflación se reduzca de manera gradual es el fenómeno más visible de un conjunto de modificaciones que, a diferentes ritmos, se fueron sucediendo en el diseño de la política monetaria.

Las transiciones graduales exigen que ciertas condiciones del pasado permanezcan inalteradas o, al menos, que cambien solo marginalmente. La ausencia de compromisos en la forma de reglas establece ciertos grados de incertidumbre a cambio de dotar al sistema de flexibilidad en el manejo de los instrumentos de política económica. El diseño de estas transiciones en las etapas iniciales parece de esta forma mostrarse contingente al estado de las condiciones imperantes.

El período de transición está marcado por la implementación de anuncios de periodicidad anual sobre la evolución de la inflación futura, en algunos casos, como metas específicas. El ritmo de la desinflación y la forma en la que la el mismo se anunciaba fue modificándose en el tiempo, en un proceso de prueba y error donde el cumplimiento del anuncio cumple un rol relevante. En un contexto donde se carece de reputación, esta estrategia fue el camino para que los Bancos Centrales pudieran acumularla de manera progresiva.

Un problema general en el diseño de la política económica son las tensiones entre el establecimiento de políticas a la manera de reglas fijas ("de ahora y para siempre”), cuyo objetivo principal es enfrentar la falta de credibilidad y los problemas de inconsistencia temporal, y mantener ciertos márgenes de flexibilidad, con el fin de obtener grados de libertad para el manejo diferentes impactos. Desde el punto de vista analítico no existe una respuesta única entre ambas opciones, ya que la elección depende de la variabilidad de los impactos que enfrenta la economía y la magnitud del problema de inconsistencia temporal. De alguna forma, el diseño de la política monetaria en estas desinflaciones muestra una secuencia que convalida esta lógica.

Entre los elementos que en general han precedido al proceso de desinflación, las economías bajo estudio establecieron ciertos grados de libertad y autonomía a la política monetaria, enfocando su misión hacia la preservación del valor de la moneda y estableciendo límites precisos al financiamiento del tesoro. En un régimen de inflación crónica los problemas de credibilidad asociados al financiamiento monetario del déficit se posicionan como elementos de gran magnitud, mientras que las fluctuaciones cambiarias se asocian con oscilaciones amplias en la tasa de inflación capaces de detener el proceso de desinflación. Por otra parte, la posibilidad de 
establecer regímenes cambiarios inflexibles en un contexto de desinflación gradual afecta el valor del tipo de cambio real (ver, por ejemplo, Edwards 1993), amplificando la vulnerabilidad externa y dejando a la economía sujeta a reversiones del flujo de capitales. Parece natural en este sentido que el diseño de la política económica responda de manera diferente a las características distintivas de cada uno de sus componentes: estableciendo reglas más precisas para las relaciones entre la política fiscal y la política monetaria, donde los problemas de credibilidad pueden alterar el proceso de desinflación, y dejando ciertos márgenes de flexibilidad para los esquemas cambiarios, privilegiando el manejo de impactos para asegurar la sostenibilidad externa.

De manera progresiva, los Bancos Centrales fueron perfeccionando instrumentos de intervención sobre el manejo de la liquidez, en un proceso que va desde un mayor peso a las magnitudes cuantitativas hacia la regulación de tasas de interés. Los objetivos sobre un nivel específico de tipo de cambio (es decir, evitar la apreciación abrupta que potencialmente dejaba a la economía vulnerable frente a la reversión del flujo de capitales) y el de mantener cierto ritmo de desinflación no carecieron de conflictos. Mientras la economía registraba ingresos de capitales, la autoridad monetaria acumuló reservas internacionales, interviniendo para evitar un fortalecimiento agudo de la moneda doméstica. Los excedentes de liquidez no esterilizados afectaban las tasas de interés, lo que potencialmente ponía en duda el compromiso de la autoridad monetaria con el objetivo inflacionario. Este tipo de procesos se observa particularmente en las instancias iniciales de la desinflación en Israel y Colombia, período en donde los anuncios de inflación fueron incumplidos en reiteradas oportunidades. En el caso de Chile, la combinación de una tasa de interés indexada y la revisión más frecuente del proceso de apreciación parece haber funcionado de mejor forma para establecer un sendero de desinflación más ordenado. En todos los casos, la implementación de tasas de interés reales positivas (junto con intervenciones para esterilizar la liquidez excedente) sirvió para ordenar las transiciones.

Existen pocos trabajos previos que consideren la posibilidad de establecer políticas graduales para reducir la inflación. Tal vez lo más cercano a una estrategia "gradualista" es lo que Blinder (1994) y Orphanides y Wilcox (2002) llamaron "el enfoque oportunista" de la desinflación. En este caso, los autores consideraban la posibilidad de que, frente a desvíos significativos de la inflación respecto del objetivo deseado, se aprovecharan eventos específicos (como una recesión) para su disminución, evitando cambios abruptos en los instrumentos de política que podían 
resultar en grandes sacrificios en términos de actividad económica. De alguna forma, los casos analizados aquí parecen seguir una lógica similar, en tanto que todas las economías aprovecharon la disponibilidad de financiamiento externo, a la manera de un shock de oferta, como una situación donde el tipo de cambio real podía apreciarse anclando el proceso de formación de precios.

A medida que el proceso de desinflación avanzó, se modificaron ciertas condiciones que afectan el desempeño de la política monetaria. En primer lugar, el cumplimiento de los objetivos genera un proceso de acumulación de reputación por parte de la autoridad monetaria. En segundo lugar, existen elementos de aprendizaje conjunto entre el Banco Central y el resto de la economía en el manejo de ciertos instrumentos, lo que es particularmente visible respecto de la implementación de tasas de interés de referencia. En tercer lugar, ciertos patrones macroeconómicos, como la asociación entre inflación y devaluación, disminuyen en ambientes de menor inflación, lo que otorga mayores grados de libertad a la política monetaria.

Si bien existen elementos para considerar méritos propios en la forma en la que estas economías realizaron una transición hacia ambientes de baja inflación, no es menos cierto que parte de su resultado tenga relación con contingencias azarosas. El hecho de que las economías hayan transitado un sendero previo de casi una década antes de sortear una crisis externa que llevó a una reversión de capitales es sin duda una de ellas. En una estrategia donde el control de la paridad cambiaria se erigió como un elemento central del diseño de política, una reversión de este tipo podría haber detenido el proceso de desinflación antes de que la autoridad monetaria y el mismo proceso alcanzaran el desarrollo suficiente. El éxito o el fracaso, al decir de Kipling, suelen ser dos impostores.

\section{REFERENCIAS}

Barro, R. J. y D. B. Gordon. (1983). Rules, Discretion and Reputation in a Model of Monetary Policy. Journal of Monetary Economics, 12, 1, 101-121.

Carare, A. y M. Stone (2006) “Inflation targeting regimes”, European Economic Review, 50, issue 5, p. 1297-1315.

Carrasquilla, Alberto (1995) "Bandas cambiarias y modificaciones a la política de estabilización: lecciones de la experiencia colombiana” Borradores semanales de Economía N²2. Banco de la República de Colombia. 
Djivre, J. y D. Tsiddon (2002) "A Monetary Labyrinth: Instruments and the Conduct of Monetary Policy in Israel, 1987-1998” en Avi Ben-Bassat (editor) “The Israeli Economy, 1985-1998: from Government Intervention to Market Economics”. Ch 3. The MIT Press

Edwards, Sebastián (1993). “Exchange Rates as Nominal Anchors." Weltwirtschaftliches Archiv129(1): 1-32

Hammond, Gill (2012) "State of the art of inflation targeting”. 4 ed., Centre for Central Banking Studies, Bank of England.

Jurek, M. y P. Marszalek (2008) "Monetary and exchange rate policy in Poland after 1990: relationship and prospects of coordination". Poznan University of economics Review. Volume 8 Number 2

Kydland, F. E. y E. C. Prescott. (1977). Rules Rather Than Discretion: The Inconsistency of Optimal Plans. Journal of Political Economy, 85, 3, 473-491.

Liviatan N. y N. Sussman (2002) "The Disinflation Process in Israel in the Past Decade" en Avi Ben-Bassat (editor) "The Israeli Economy, 1985-1998: from Government Intervention to Market Economics". Ch 4. The MIT Press

Morandé, Felipe L. (2001). "A Decade of Inflation Targeting in Chile: Developments, Lessons, and Challenges," Journal Economía Chilena (The Chilean Economy), Central Bank of Chile, vol. 4(1), pages 35-62, April.

Morandé L., Felipe. (2002). “Nominalización de la tasa de plítica monetaria: debate y consecuencias”. Cuadernos de economía, 39(117), 239-252

Morandé, F. y M. Tapia (2002). "Exchange Rate Policy in Chile: From the Band to Floating and Beyond" Working Papers Central Bank of Chile $N^{\circ} 152$, Central Bank of Chile.

Nuti, Domenico Mario (2000) “The Polish Zloty, 1990-1999: Success and Underperformance" The American Economic Review. Vol. 90, No. 2, Papers and Proceedings of the One Hundred Twelfth Annual Meeting of the American Economic Association (May, 2000), pp. 53-58 
Ocampo, J.A. (2014) “The Latin American Debt Crisis in Historical Perspective”. In: Stiglitz J.E., Heymann D. (eds) “Life After Debt”. International Economic Association Series. Palgrave Macmillan, London

Orphanides, A. y D. Wilcox (2002). "The Opportunistic Approach to Disinflation," International Finance, Wiley Blackwell, vol. 5(1), pages 47-71, Spring.

Urrutia, Miguel (2002). "Una visión alternativa: La Política Monetaria y Cambiaria en la Última Década," Borradores de Economia 207, Banco de la Republica de Colombia.

Villar, L. y H. Rincón (2003). "Flujos de capital y regímenes cambiarios en los noventa" Monetaria, Centro de Estudios Monetarios Latinoamericanos, CEMLA, vol. 0(1), pages 33-88, enero-mar.

Villar, Leonardo (1999) “Política cambiaria en un proceso de ajuste ordenado". Revista del Banco de la República, Vol. LXXII, No. 864. 


\section{COMENTARIOS FINALES}

Los procesos de inflación, cuando se convierten en estados crónicos, alteran el comportamiento de individuos e instituciones. Estos cambios se derivan en parte de que, como todo tributo, el impuesto inflacionario no está exento de efectos asignativos. El hecho de que los individuos eviten los activos denominados en moneda doméstica afecta los mercados financieros, lo que dificulta las condiciones de financiamiento, tanto para el sector privado como para el sector público. El sector privado tiende a cubrirse de la incertidumbre revisando más frecuentemente los precios, pero también asociándolos a cláusulas de reajuste respecto de la inflación pasada, lo que tiene consecuencias sobre la dispersión de precios relativos y la persistencia. El sector público se encuentra con una licuación de las bases imponibles y una dificultad general para presupuestar que incrementa los incentivos a las negociaciones bilaterales, lo que tiende a deteriorar el balance fiscal. Sin acceso a mercados financieros, las interacciones entre la política fiscal y la política monetaria se tornan más frecuentes. La inestabilidad general de este proceso tiende a acortar el horizonte de planeamiento, afectando la planificación sobre actividades de maduración lenta que se asocia a los mercados de crédito, con consecuencias de mediano plazo para el crecimiento económico.

Establecer relaciones causales en condiciones como las planteadas en el párrafo anterior es complejo, por el hecho de que cada una de las características reseñadas surge como consecuencia del proceso inflacionario pero al mismo tiempo tiende a consolidarlo y perpetuarlo. Se ha observado en este sentido que los procesos de inflación crónica han sido un fenómeno regular a lo largo de la historia y tienden a ser situaciones de relativa persistencia. El hecho de que no pueda establecerse una relación precisa entre los fenómenos observados no implica, sin embargo, que no sea posible establecer ciertas regularidades útiles para abordar transiciones a ambientes de menor inflación.

$\mathrm{Si}$ se tuviese que resumir el contenido de este trabajo en una frase, posiblemente sería la siguiente: “aun cuando no es posible establecer elementos causales precisos, hay patrones a nivel agregado en economías donde la inflación es un estado crónico que son relevantes para el diseño de los procesos de desinflación". Se ha prestado especial atención aquí a tres de ellos: la tendencia del proceso inflacionario y su persistencia, las interacciones entre la política fiscal y la política monetaria y la asociación entre el tipo de cambio y los precios internos. La presencia de estos patrones en las economías latinoamericanas marca ciertas regularidades: en primer lugar, regímenes inflacionarios más agudos, lejos de establecer procesos que 
revierten a una media constante, muestran una evolución errática de cambios rápidos en el nivel y velocidad de la tasa de inflación. En este contexto si bien los desvíos respecto de la tendencia se vuelven más persistentes, la noción misma de dicha tendencia es lo que carece de significado. En segundo lugar, existe una asociación más estrecha entre el balance fiscal y el señoreaje a mayor régimen de inflación, lo que señala los problemas de consistencia temporal en el financiamiento del sector público. Por último, existe una asociación creciente entre el tipo de cambio con los precios internos a medida que se incrementan los regímenes de inflación. Estos patrones tienen un correlato con el proceso de desinflación: las transiciones plenas hacia regímenes de baja inflación son aquellas que pudieron establecer cierto grado de balance fiscal y al mismo tiempo mantuvieron una tendencia decreciente del tipo de cambio real, es decir, pudieron establecer condiciones donde la variabilidad del tipo de cambio no supuso un desafío para el proceso de desinflación. En un proceso inestable cuyas fuerzas tienden a mantenerlo en el mismo estado, los procesos de desinflación parecen cumplir el lema según el cual hay varias formas de fallar, pero solo pocas de alcanzar el éxito. Entre estas condiciones, la diferencia entre una estrategia gradual o una de shock no parece ser necesariamente indicativa del éxito o el fracaso, ni tampoco emerge una forma precisa de encarar los procesos de acuerdo a las condiciones iniciales, sino que la misma es condicional al diseño de política económica.

Nadie dudaría que "mantener niveles de inflación bajos y estables" es uno de los principales objetivos de la política económica. Pero a diferencia de otros, como un elevado nivel de actividad, bajo desempleo o una distribución más equitativa del ingreso, la relación entre esta variable y el bienestar suele ser más indirecta. Usando una conocida frase, podría afirmarse que la inflación suele ser el problema más importante entre los problemas menos importantes. En un contexto de inflación crónica, quebrar ciertas dinámicas impone establecer instrumentos precisos para modificar el estado de la economía.

La forma en la que las transiciones graduales se han desarrollado marca ciertos contrastes respecto de algunos de los conceptos generalmente asociados a procesos de desinflación. Entre ellos, que el diseño de la política monetaria no se fundamenta necesariamente en la forma de reglas fijas de comportamiento a futuro sino también por el manejo de ciertos grados de flexibilidad en el uso de algunos instrumentos. Parte de los mismos, como los arreglos cambiarios o el control al ingreso de capitales, fueron esquemas transitorios que buscaban resolver problemas concretos que emergían en el proceso de transición, pero que fueron abandonados una vez finalizado el mismo. 
Otros, como el marco institucional y los grados de libertad frente al financiamiento del tesoro, parecen mantenerse como reglas claras establecidas a lo largo de todo el proceso que se mantienen una vez finalizado el mismo. Al establecerse de manera repetida en el tiempo, el proceso incluye elementos de reputación por parte de la autoridad monetaria pero también un aprendizaje conjunto con el sector privado sobre el diseño y manejo de los instrumentos. Parte de la estrategia en estas economías se aprovechó de manera "oportunista" de un evento particular, como la disponibilidad de financiamiento externo, para establecer ciertas anclas nominales. Cuando este evento finalizó, la política monetaria había acumulado reputación y generado un ambiente de baja inflación, lo que permitió obtener instrumentos adicionales para realizar políticas contracíclicas (tanto monetarias como fiscales). El éxito o el fracaso de la desinflación dependían, en parte, del mantenimiento de estas condiciones, por lo que su duración puede considerarse como el elemento fortuito que, acompañado de una estrategia adecuada, permitió a estos países establecer senderos hacia entornos de baja inflación. 